\title{
Información Importante
}

La Universidad Santo Tomás, informa que el(los) autor(es) ha(n) autorizado a usuarios internos y externos de la institución a consultar el contenido de este documento a través del Catálogo en línea del CRAI-Biblioteca y el Repositorio Institucional en la página Web de la CRAI-Biblioteca, así como en las redes de información del país y del exterior con las cuales tenga convenio la Universidad.

Se permite la consulta a los usuarios interesados en el contenido de este documento, para todos los usos que tengan finalidad académica, nunca para usos comerciales, siempre y cuando mediante la correspondiente cita bibliográfica se le dé crédito al trabajo de grado y a su autor.

De conformidad con lo establecido en el Artículo 30 de la Ley 23 de 1982 y elartículo 11 de la Decisión Andina 351 de 1993, la Universidad Santo Tomás informa que "los derechos morales sobre documento son propiedad de los autores, los cuales son irrenunciables, imprescriptibles, inembargables e inalienables."

\section{Centro de Recursos para el Aprendizaje y la Investigación, CRAI-Biblioteca} Universidad Santo Tomás, Bucaramanga 
Informe final de curso de grado de norma internacional y reportes de información financiera caso comercializadora Allcomputer SAS - propiedades planta y equipo

\author{
Kelly Johana Ayala Robles \\ Silvia Lorena Vargas Criado
}

Trabajo Especial de Grado para obtener grado de Especialista en Gerencia Tributaria

Director:

Sandra Marcela Espitia González

Universidad Santo Tomas, Bucaramanga

División de Ciencias económicas y Administrativas

Especialización en Gerencia Tributaria 


\section{Contenido}

\section{Pág.}

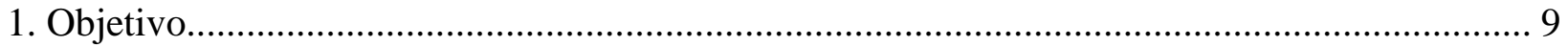

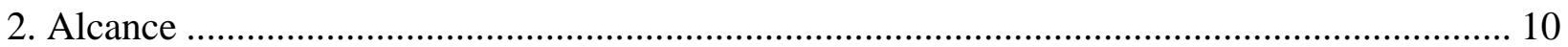

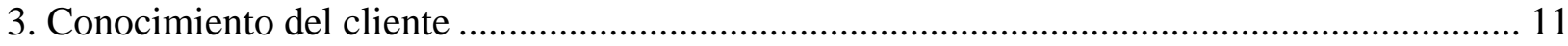

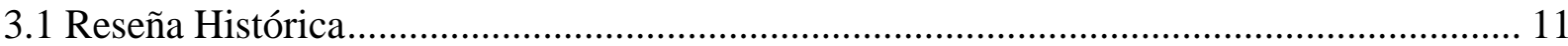

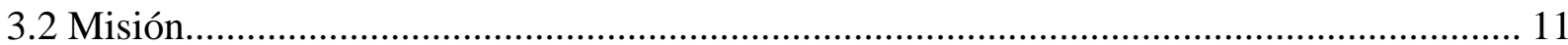

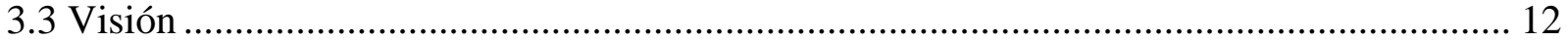

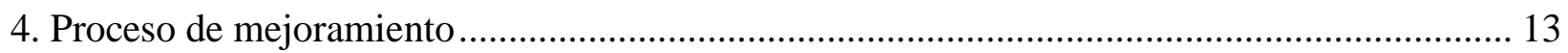

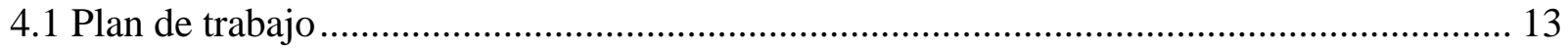

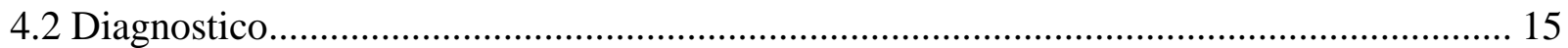

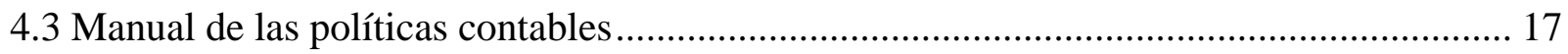

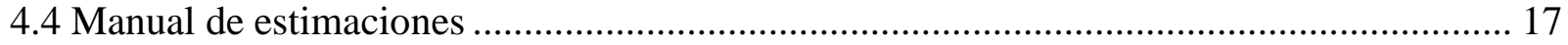

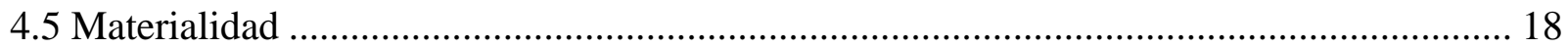

4.6 Estado de la situacion financiera de apertura ............................................................ 19

4.7 Flujograma o ciclo de operación ......................................................................... 21

4.8 Matriz del componente de propiedad planta y equipo ............................................. 22

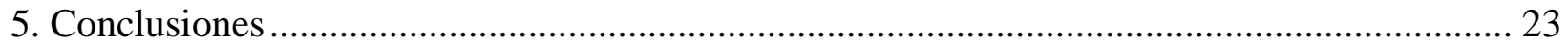

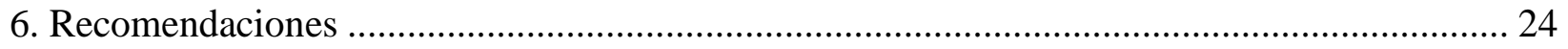

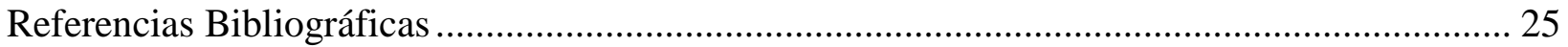


Apéndices... 


\section{Lista de Figuras}

\section{Pág.}

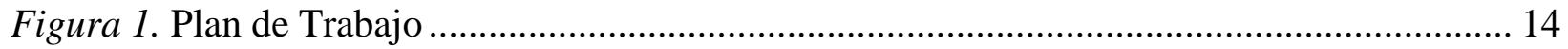

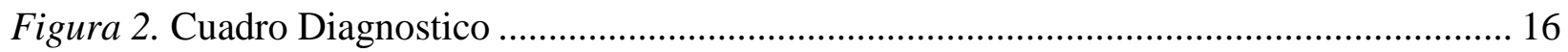

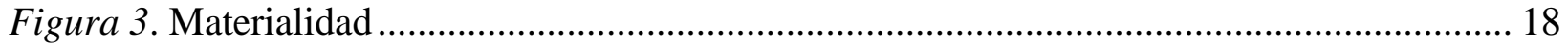

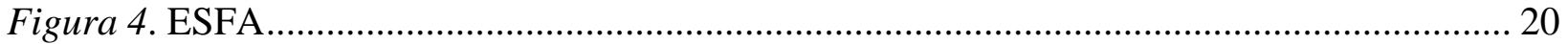

Figura 5. Ciclo de Operación Propiedad Planta y Equipo................................................... 21

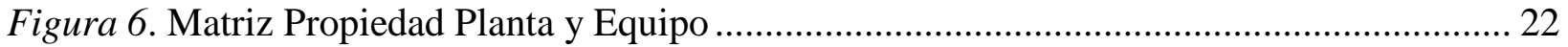




\section{Lisa de Apéndices}

Pág.

Apéndice A. Manual de políticas contables.......................................................................... 28

Apéndice B. Manual de estimaciones contables............................................................... 203 


\section{Resumen}

El presente trabajo es un estudio al marco normativo de la empresa COMERCIALIZADORA ALLCOMPUTER SAS, desde su adopción por primera vez teniendo en cuenta la metodología, el reconocimiento y aplicación de los principios y normas de contabilidad e información financiera y de aseguramiento de información aceptados en Colombia; que corresponde al sistema compuesto por postulados, principios, limitaciones, conceptos, normas técnicas generales, normas técnicas específicas, normas técnicas especiales, normas técnicas sobre revelaciones, normas técnicas sobre registros y libros, interpretaciones y guías, que permiten identificar, medir, clasificar, reconocer, interpretar, analizar, evaluar e informar las operaciones económicas de un ente, de forma clara y completa, relevante, digna de crédito y comparable.

Dicho estudio tenía como objetivo hacer el mantenimiento a la empresa para la sección 17 Propiedad, Planta y equipo, el cual se cumplió satisfactoriamente pues se hicieron los respectivos estudios y cambios cumpliendo con las normas de reconocimiento y revelación de esta.

Con base en el escrito de los autores (Becerra, Rojo, \& Medina, 2012) Las regulaciones fiscales en Colombia siguen vinculadas a la base de medición del costo histórico, mientras que en el Nuevo Marco Técnico Normativo ha evolucionado constantemente, migrando a una base de medición de valor razonable. Es por ello que esta sección requiere un constante seguimiento para cumplir con el principio de fiabilidad.

PALABRAS CLAVES: Propiedad, planta y equipo; marco normativo; normas de contabilidad; aseguramiento de información; sección 17. 


\begin{abstract}
The present work is a study in the regulatory framework of the company COMERCIALIZADORA ALLCOMPUTER SAS, from the next time, the first time, taking into account the correct, recognition and application of accounting principles and standards and financial information and the assurance of the information accepted in Colombia; which corresponds to the system composed of postulates, principles, limitations, concepts, general technical standards, specific technical standards, special technical standards, technical standards on records and books, interpretations and guides, which we can identify, measure, classify, recognize, interpret, analyze, evaluate and report the economic operations of an entity, clear and complete, relevant, worthy of credit and comparable.
\end{abstract}

The purpose of this study was to maintain the company for section 17 Property, plant and equipment, which was satisfactorily fulfilled, as well as the studies and changes that comply with the standards of recognition and disclosure of this.

Based on the writings of the authors (Becerra, Rojo and Medina, 2012) Tax regulations in Colombia are still linked to the base of historical cost measurement, while in the New Normative Technical Framework has evolved constantly, migrating to a base of fair value measurement. That is why this section requires constant monitoring to comply with the principle of reliability.

KEYWORDS: Property, plant and equipment; Regulatory framework; accounting standards; information Assurance; section 17. 


\section{Objetivo}

Realizar el mantenimiento a la empresa ALLCOMPUTER SAS en el nuevo marco técnico normativo contable, sección 17 propiedades planta y equipo. 


\section{Alcance}

Profundizar en materia financiera, contable y tributaria. 


\section{Conocimiento del cliente}

COMERCIALIZADORA ALLCOMPUTER SAS es una entidad jurídica constituida por documento privado No 1250 de asamblea de accionistas del 05 de noviembre de 2002, inscrita el 10 de noviembre de 2002, bajo el número 52781 del libro IX.

La empresa es de carácter comercial bajo la forma de Sociedad por acciones simplificada (SAS), del orden nacional, vigilada por la superintendencia de sociedades.

\subsection{Reseña Histórica}

En sus 12 AÑOS de existencia, COMERCIALIZADORA ALLCOMPUTER S.A.S, ha en causado sus esfuerzos al mejoramiento de la vida de los santandereanos y otras regiones del país, ofreciendo productos de tecnología e informática que brinden las herramientas necesarias para el crecimiento de las empresas. Optimizando y automatizando procesos de atención al usuario.

\subsection{Misión}

Incrementar la productividad y eficiencia de nuestros clientes a través de tecnología e innovación constantes de nuestros productos y servicios. 


\subsection{Visión}

Ser una empresa líder en el 2021 a nivel nacional como proveedora de servicios de tecnología. Con productos de calidad que satisfagan las necesidades de nuestros clientes. 


\section{Proceso de mejoramiento}

La importancia del proceso de mejoramiento radica en el método de estudio y aplicación del objetivo general del trabajo, con el fin de determinar la adecuada implementación de las secciones de las NIIF para PYMES.

Para ello se determinan los siguientes pasos:

\subsection{Plan de trabajo}

\begin{tabular}{|c|c|c|c|}
\hline \multicolumn{4}{|c|}{$\begin{array}{l}\text { PLAN DE IM PLEMENTACION } \\
\text { NORMAS INTERNACIONALES DE INFORMACIÓN FINANCIERA } \\
\text { IPO } 2 \text { (Decreto } 3022 \text { de didembre de12013) }\end{array}$} \\
\hline \\
\hline \multicolumn{4}{|c|}{ 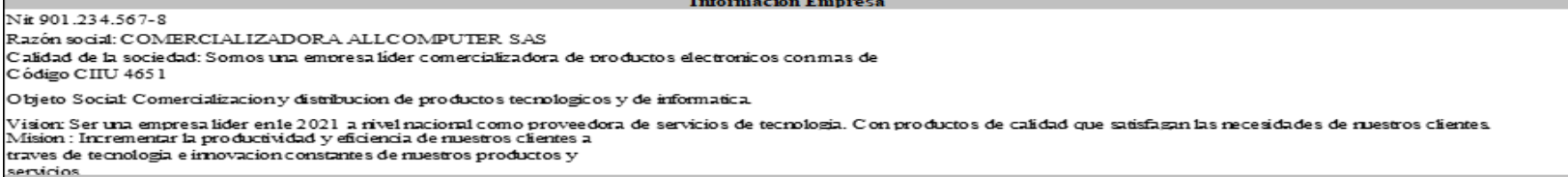 } \\
\hline \multicolumn{4}{|c|}{ Información del Líder } \\
\hline Actividades & $\begin{array}{l}\text { Fecha } \\
\text { Inicio }\end{array}$ & $\begin{array}{c}\text { Fecha } \\
\text { Finaliza ción }\end{array}$ & Comentarios \\
\hline 1. Designa ción del responsable o responsables del Proceso. & $\begin{array}{l}\text { Octubre } \\
22 \text { del } \\
2018\end{array}$ & $\underset{2018}{\text { Octubre } 22 \text { de1 }}$ & $\begin{array}{l}\text { E1 responsable de los Estados Finzancieros, tanto bajo norma local como IFRS es } \\
\text { la gerencia Esta delegará sus funciones (más no su resporsabbilidad) en un equipo } \\
\text { de trabajo }\end{array}$ \\
\hline 2. Confo rmación de l equipo de traba jo. & $\begin{array}{l}\text { Octubre } \\
27 \text { de1 } \\
2018\end{array}$ & $\begin{array}{c}\text { Octubre } 27 \text { de1 } \\
2018\end{array}$ & 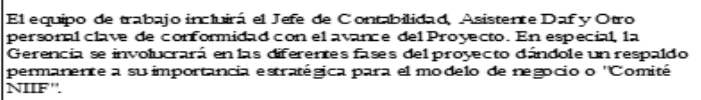 \\
\hline 3. E stablecer un crono grama de acciones $y$ activid ades. & $\begin{array}{l}\text { Octubre } \\
27 \text { de1 } \\
2018\end{array}$ & $\begin{array}{c}\text { Octubre } 27 \text { de1 } \\
2018\end{array}$ & 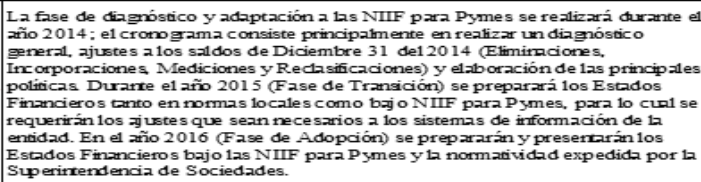 \\
\hline $\begin{array}{l}\text { 4. Fxponer opo itunamente, ante el máximo órgano socinl de la } \\
\text { emplesa, un resumen ejecutivo del Decreto } 3022 \text { del } 2013 \text {, sus } \\
\text { mod ifica ciones o adiciones. }\end{array}$ & $\begin{array}{l}\text { Octubre } \\
27 \text { del } \\
2018\end{array}$ & $\begin{array}{c}\text { Noviembre } 01 \\
\text { de1 } 2018\end{array}$ & 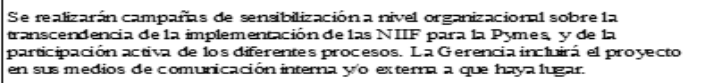 \\
\hline 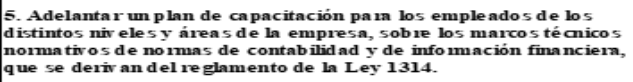 & $\begin{array}{l}\text { Noviembr } \\
\text { e o1 del } \\
2018\end{array}$ & $\begin{array}{c}\text { Noviembre } 06 \\
\text { de12018 }\end{array}$ & $\begin{array}{l}\text { Se proyectan aproxima damerre } 80 \text { horas de capaciración al personal corrable y } \\
\text { de las difererres áreas en el de sarrollo de todo el proyecto. }\end{array}$ \\
\hline
\end{tabular}




\begin{tabular}{|c|c|c|c|}
\hline $\begin{array}{l}\text { 6. Analizar el marco técnico normativo del Decreto } 3022 \text { del 2013, sus } \\
\text { modificaciones o adiciones, y establecer las secciones de la norma } \\
\text { que le son aplicables. }\end{array}$ & $\begin{array}{l}\text { Octubre } \\
22 \text { del } \\
2018\end{array}$ & $\begin{array}{c}\text { Noviembre } 15 \\
\text { del } 2018\end{array}$ & $\begin{array}{l}\text { Se realizará un inventario de las NIIF para Pymes aplicables a la entidad de } \\
\text { acuerdo con sus características (de acuerdo con la naturaleza del negocio y las } \\
\text { características especiales de la organización). Los impactos se medirán mediante } \\
\text { la elaboración de un diagnóstico financiero que mostrará los hallazgos y } \\
\text { recomendaciones que requiere la implementación y aplicación de este modelo. }\end{array}$ \\
\hline $\begin{array}{l}\text { 7. Evaluar los impactos de aplicación, sobre la estructura financiera, } \\
\text { operativa, administrativa y tecnológica de la empresa. }\end{array}$ & $\begin{array}{l}\text { Octubre } \\
22 \text { del } \\
2018\end{array}$ & $\begin{array}{c}\text { Noviembre } 16 \\
\text { del } 2018\end{array}$ & $\begin{array}{l}\text { La entidad elaborará un inventario físico de los activos y determinará su Valor } \\
\text { razonable para la adopción por primera vez de las NIIF para Pymes; realizará } \\
\text { pruebas de existencia y de integridad en relación con los activos, pasivos, } \\
\text { patrimonio, ingresos y gastos, depurará la información a que haya lugar, según se } \\
\text { indique en el diagnóstico y procurará el reconocimiento y revelación de } \\
\text { información contable confiable y relevante. Esta depuración puede incluir } \\
\text { aspectos como la revisión de cuentas por cobrar, revisión del estado de los } \\
\text { procesos jurídicos en contra (y en favor) de manera que se determine la } \\
\text { pertinencia de reconocer provisiones, revisar el código de buen gobierno } \\
\text { corporativo, si a ello hubiere lugar, diseñar formatos para el reporte de } \\
\text { información contable y financiera de conformidad con las NIIF para Pymes, y } \\
\text { determinar políticas contables que procuren la transparencia de la información } \\
\text { ante los distintos grupos de interés. }\end{array}$ \\
\hline $\begin{array}{l}\text { 8. Establecer las políticas contables aplicables a la empresa, en el } \\
\text { nuevo marco normativo. }\end{array}$ & $\begin{array}{l}\text { Octubre } \\
22 \text { del } \\
2018\end{array}$ & $\begin{array}{c}\text { Noviembre } 16 \\
\text { del } 2018\end{array}$ & $\begin{array}{l}\text { Las Políticas Contables serán aprobadas por la Gerencia General, quien } \\
\text { promoverá su uso interno y buscará que Revisoría Fiscal verifique su } \\
\text { cumplimiento. }\end{array}$ \\
\hline $\begin{array}{l}\text { 9. Adecuar los recursos tecnológicos y robustecer las competencias } \\
\text { del talento humano acorde con las nuevas exigencias del marco } \\
\text { normativo. }\end{array}$ & $\begin{array}{l}\text { Octubre } \\
22 \text { del } \\
2018\end{array}$ & $\begin{array}{c}\text { Noviembre } 16 \\
\text { del } 2018\end{array}$ & $\begin{array}{l}\text { La empresa solicitará por escrito al proveedor de software actual, si el sistema de } \\
\text { información contable cumple con los requisitos exigidos por las NIIF para Pymes } \\
\text {. De acuerdo con lo anterior determinará la pertinencia de establecer cambios en } \\
\text { dichos sistemas de información, con el objeto de lograr sistemas de información } \\
\text { integrados. }\end{array}$ \\
\hline $\begin{array}{l}\text { 10. Implementación de mecanismos de monitoreo y control sobre el } \\
\text { Plan de Implementación. }\end{array}$ & $\begin{array}{c}\text { Noviembr } \\
\text { e } 16 \text { del } \\
2018\end{array}$ & $\begin{array}{c}\text { Noviembre } 20 \\
\text { del } 2018\end{array}$ & $\begin{array}{l}\text { El Equipo o Comité NIIF con el apoyo de la Gerencia, velará que se cumpla } \\
\text { cada uno de las actividades que conforma este Plan de Implementación. }\end{array}$ \\
\hline 11. Preparación del Estado de Situación Financiera de Apertura. & $\begin{array}{l}\text { Octubre } \\
22 \text { del } \\
2018\end{array}$ & $\begin{array}{c}\text { Noviembre } 20 \\
\text { del } 2018\end{array}$ & $\begin{array}{l}\text { El Estado de Situación Financiera de Apertura (Balance) se elaborará en } \\
\text { Microsoft Excel. Estos saldos se incluirán en el sistema de información contable } \\
\text { (seguimiento) separando los datos de la información tributaria y se realizará las } \\
\text { conciliaciones requeridas por la NIIF para las Pymes. }\end{array}$ \\
\hline \multicolumn{4}{|c|}{ Información de la Controlante (Campos para diligenciar por la subordinada) } \\
\hline \multicolumn{3}{|l|}{ Razón Social: COMERCIALIZADORA ALLCOMPUTER SAS } & \\
\hline \multicolumn{4}{|l|}{ Vigilada o Supervisada por Supersociedades } \\
\hline \multicolumn{4}{|l|}{ Nit $901.234 .567-8$} \\
\hline & & & $\begin{array}{r}\text { Fuente: } \\
\text { Actualicese.com }\end{array}$ \\
\hline
\end{tabular}

\section{Figura 1. Plan de Trabajo}

Nota: Plan de trabajo de la empresa All Computer S.A.S. Adaptado de: (Actualicese, 2018) 


\subsection{Diagnostico}

COMERCIALIZADORA ALLCOMPUTER SAS NIT 901.234.567-8

\begin{tabular}{|c|c|c|c|c|}
\hline \multirow[t]{2}{*}{ Sec. } & \multirow{2}{*}{$\begin{array}{c}\text { Normas Internacionales de Información } \\
\text { Financiera NIIF }\end{array}$} & \multicolumn{2}{|c|}{$\begin{array}{l}\text { Aplicables a } \\
\text { la entidad? }\end{array}$} & \multirow[t]{2}{*}{ Justificación } \\
\hline & & SI & NO & \\
\hline 1 & Pequeñas y medianas entidades & SI & & $\begin{array}{l}\text { Según eIDecreto } 3019 \text { de } 2013 \text { y el Decreto } 3022 \text { de } 2013 \text { una entidad no debe } \\
\text { aplicar NIIF sino contabilidad simplificada (la que siempre realiza la entidad) si cumple } \\
\text { estos tres requisitos: menos de } 11 \text { trabajadores, menos de } 500 \text { SMMLV y menos de } \\
6.000 \text { SMMLV, promedio a diciembre } 31 \text { de } 2013 \text {. Si deja de cumplir alquno de } \\
\text { estos requisitos es del grupo } 2 \text { y debe aplicar las NIIF PYMES. La entidad realizó } \\
\text { además en el "Acta de clasificación" para establecer formalmente a qué grupo }\end{array}$ \\
\hline 3 & Presentación de Estados Financieros & SI & & $\begin{array}{l}\text { La entidad debe presentar información regularmente, especificamente los estados } \\
\text { financieros determinados en la Seccion } 4 \text { con los efectos de las transacciones, otros } \\
\text { sucesos y condiciones, de acuerdo con las definiciones y criterios de reconocimiento } \\
\text { de activos, pasivos, ingresos y gastos, adptados a sus propias políticas contables. }\end{array}$ \\
\hline 4 & Estado de Situación Financiera & SI & & $\begin{array}{l}\text { La entidad debe presentar este estado financiero discriminando los activos, pasivos y } \\
\text { patrimonio de la entidad a una fecha de corte. }\end{array}$ \\
\hline 5 & $\begin{array}{l}\text { Estado de Resultados Integrales y Estado } \\
\text { de Resultados }\end{array}$ & SI & & $\begin{array}{l}\text { La entidad debe preparar esta información de acuerdo a los requermientos de los } \\
\text { estandares que para tal fin se apliquen y a sus políticas contables, es por esto que es } \\
\text { necesario mediante esta sección dar cumplimiento a la presentación del estado de } \\
\text { resultado integral y estado de resultado. }\end{array}$ \\
\hline 6 & $\begin{array}{l}\text { Estado de cambios en el patrimonio y } \\
\text { estado de resultados y ganancias } \\
\text { acumuladas }\end{array}$ & SI & & $\begin{array}{l}\text { La entidad debe elaborar el estado de cambios en el patrimonio con la finalidad de } \\
\text { mostrar las variaciones de los diferentes elementos que componen el patrimonio, en un } \\
\text { periodo. }\end{array}$ \\
\hline 7 & Estado de flujos de efectivo & SI & & $\begin{array}{l}\text { La entidad debe suministrar información sobre los cambios históricos en el efectivo y } \\
\text { equivalentes al efectivo de la entidad mediante un estado de flujos de efectivo en el que } \\
\text { los flujos de fondos del período se clasifican según procedan de actividades de } \\
\text { operación, de inversión y de financiación. }\end{array}$ \\
\hline 8 & Notas a los estados financieros & SI & & $\begin{array}{l}\text { La entidad está obligada a presentar información adicional para explicar, aclarar y } \\
\text { ampliar las cifras presentadas en los estados financieros. Las notas son las que indica } \\
\text { cada estándar y es sobre saldos, no de cada transacción. }\end{array}$ \\
\hline 9 & $\begin{array}{l}\text { Estados financieros consolidados y } \\
\text { separados }\end{array}$ & & NO & $\begin{array}{l}\text { Estos estados financieros se presentan como primer paso para consolidar estados } \\
\text { financieros y consisten en eliminar el Método De Participación Patrimonial y dejar las } \\
\text { inversiones al costo. Esta sección NO le aplica a la entidad. }\end{array}$ \\
\hline 10 & Políticas contables, estimaciones y errores & SI & & $\begin{array}{l}\text { La entidad debe elaborar políticas contables para transacciones, sucesos (eventos de } \\
\text { riego) y condiciones (contratos comerciales ejecutados). }\end{array}$ \\
\hline 11 & Instrumentos financieros básicos & SI & & $\begin{array}{l}\text { La entidad posee contratos que dan lugar a un activo financiero para ella y a su vez un } \\
\text { pasivo financiero para otra. } \\
\text { Esta sección es de uso obligatorio (Activos Financiero y Pasivos Financieros), Se hará } \\
\text { uso de las clasificaciones a que se refiere la NIC } 39 \text { segun el párrafo } 11.2 \text { de la NIIF } \\
\text { para PYMES. }\end{array}$ \\
\hline 13 & Inventarios & SI & & $\begin{array}{l}\text { La entidad debe aplicar esta Sección porque dispone de inventarios de mercancías en } \\
\text { forma de materiales o suministros, para ser consumidos en el proceso de prestación de } \\
\text { servicios. }\end{array}$ \\
\hline 14 & Inversiones en asociadas & & NO & $\begin{array}{l}\text { Su aplicación es obligatoria teniendo en cuenta que la entidad posee inversiones } \\
\text { equivalente al } 20 \% \text { o más del patrimonio de la asociadas (o posee influencia } \\
\text { significativa). }\end{array}$ \\
\hline 15 & Inversiones en negocios conjuntos & & $\mathrm{NO}$ & El desarrollo de la actividad económica no contempla negocios conjuntos. \\
\hline
\end{tabular}




\begin{tabular}{|c|c|c|c|c|}
\hline 16 & Propiedades de inversión & SI & & $\begin{array}{l}\text { La entidad no posee propiedades (terrenos o edificios) sin usar, que se tengan para } \\
\text { arrendarlos o para uso indeterminado. }\end{array}$ \\
\hline 17 & Propiedades, planta y equipo & SI & & $\begin{array}{l}\text { La entidad requiere conocer la información acerca de la inversión que posee en sus } \\
\text { propiedades, planta y equipo, así como los cambios que se hayan producido en dicha } \\
\text { inversión durante el periodo. }\end{array}$ \\
\hline 18 & Activos intangibles distintos de la plusvalía & SI & & $\begin{array}{l}\text { Aplica para el reconocimiento de los activos intangibles que sean identificables, de } \\
\text { carácter no monetario y sin apariencia física. }\end{array}$ \\
\hline 19 & Combinaciones de negocio y plusvalía & & NO & $\begin{array}{l}\text { En la entidad no existe la figura de combinaciones de negocios (unión de entidades en } \\
\text { una única entidad que informa) y de plusvalía, por tanto no se requiere este estándar } \\
\text { para su aplicación. }\end{array}$ \\
\hline 20 & Arrendamientos & SI & & La entidad realiza operaciones de leasing financiero y leaseback \\
\hline 21 & Provisiones y contingencias & SI & & La entidad reconoce provisiones, pasivos contingentes y activos contingentes. \\
\hline 22 & Pasivos y patrimonio & SI & & La entidad realiza transacciones relacionadas con estos instrumentos. \\
\hline 23 & Ingresos de actividades ordinarias & SI & & La entidad percibe ingresos por \\
\hline 24 & Subvenciones del gobierno & & NO & $\begin{array}{l}\text { Esta Sección especitica la contabilidad de todas las subvenciones del gobierno. } \\
\text { Una subvención del gobierno es una transferencia de recursos a una entidad, } \\
\text { condicionada al cumplimiento futuro o pasado, de ciertas obligaciones relacionadas con } \\
\text { sus actividades de operación. En esta entidad sólo se presentan subvenciones } \\
\text { relacionadas con ingresos por subisidio a la tarifa, en cumplimiento de un hecho pasado } \\
\text { y como tal se reconoce como ingreso. }\end{array}$ \\
\hline 25 & Costos por préstamos & SI & & $\begin{array}{l}\text { La entidad tiene obligación bancarias que generan intereses y estos deben ser causados } \\
\text { bajo el estándar propuesto. }\end{array}$ \\
\hline 26 & Pagos basados en acciones & & NO & $\begin{array}{l}\text { La entidad no realiza pagos en acciones por honorarios, servicios, salarios, } \\
\text { proveedores ni por ningún otro concepto. }\end{array}$ \\
\hline 27 & Deterioro del valor de los activos & SI & & $\begin{array}{l}\text { La entidad aplicará esta norma para asegurarse de que sus activos (o Unidades } \\
\text { Generadoras de Efectivo) están contabilizados por un importe que no sea superior a su } \\
\text { importe recuperable. }\end{array}$ \\
\hline 28 & Beneficios a los empleados & SI & & $\begin{array}{l}\text { La entidad solo tiene compromisos y gastos laborales con sus empleados, en la } \\
\text { prestación del servicio en el corto plazo, especificamente en salarios y prestaciones } \\
\text { sociales. }\end{array}$ \\
\hline 29 & Impuesto a las ganancias & SI & & Aplica a las diferencias temporarias entre las normas locales (fiscales) y las NIIF \\
\hline 30 & Conversión de la moneda extranjera & & NO & La entidad no realiza transacciones en moneda extranjera. \\
\hline 31 & Hiperinflación & & NO & $\begin{array}{l}\text { La economía colombiana no se encuentra en estado hiperinflacionario (la tasa } \\
\text { acumulada de inflación a lo largo de } 3 \text { años no se aproxima o sobrepasa el 100\%) }\end{array}$ \\
\hline 32 & $\begin{array}{l}\text { Hechos ocurridos después del periodo } \\
\text { sobre el que se informa }\end{array}$ & SI & & $\begin{array}{l}\text { La entidad debe contabilizar los hechos ocurridos después del periodo cierre y antes } \\
\text { de que los estados financieros sean aprobados. }\end{array}$ \\
\hline 33 & $\begin{array}{l}\text { Informaciones a revelar sobre partes } \\
\text { relacionadas }\end{array}$ & SI & & $\begin{array}{l}\text { Existe la posibilidad de que la situación financiera y resultados del periodo de la } \\
\text { entidad, puedan verse afectados por la existencia de partes relacionadas, así como por } \\
\text { transacciones y saldos pendientes, incluyendo compromisos, con dichas partes. }\end{array}$ \\
\hline 34 & Actividades especiales & & NO & $\begin{array}{l}\text { La entidad no se ejecuta las actividades especiales a las que menciona esta Sección } \\
\text { tales como exploración de petróleo y gas o Activos Biológicos. }\end{array}$ \\
\hline 35 & Transición a la NIIF para las pymes & SI & & $\begin{array}{l}\text { La entidad debera aplicar esta Sección para depurar las cifras del Estado de Situación } \\
\text { Financiera (Balance) de Apertura. }\end{array}$ \\
\hline & $\begin{array}{l}\text { Silvia Lorena Vargas Líder general del } \\
\text { proyecto NIIF }\end{array}$ & & & Kelly Johana Ayala. - Líder proyecto implementación NIIF \\
\hline
\end{tabular}

\section{Figura 2. Cuadro Diagnostico}

Nota: Diagnostico de la empresa All Computer S.A.S. de acuerdo al nuevo marco técnico normativo en NIIF. Adaptado de (Consejo Tecnico de la Contaduria, , s.f.) 


\subsection{Manual de las políticas contables}

El manual de políticas tiene un propósito fundamental en la organización COMERCIALIZADORA ALLCOMPUTER SAS, con el fin de realizar el reconocimiento, medición, presentación y revelación de la información financiera de la organización y por ello se ajusta en debida forma según lo establecido por el Nuevo Marco Técnico Contable de aplicación, orientadas a la fiabilidad de la información.

Ver anexo No 1 Manual de políticas contables.

\subsection{Manual de estimaciones}

El manual estimaciones es una herramienta que marca los lineamientos requeridos por la organización para realizar el análisis y evaluación específico de ciertas partidas para ello se crea aproximaciones al valor de la partida en ausencia de un medio preciso de medición.

Ver anexo No 2 Manual de estimaciones contables. 


\subsection{Materialidad}

DOCUMENTO DE MATERIALIDAD

(Cifras expresadas en pesos)

\begin{tabular}{|c|c|c|}
\hline COMERCIALIZADORA ALLCOMPUTER SAS & $\begin{array}{l}\text { Período } \\
\text { terminado el: }\end{array}$ & Referencia \\
\hline & $31 / 12 / 2014$ & \\
\hline & & \\
\hline \multicolumn{3}{|c|}{ 1.1 Para determinar la materialidad debemos seleccionar una de las tres bases que se muestran a continuación: } \\
\hline & MARQUE CON X & \\
\hline \multicolumn{3}{|l|}{ Utilidad antes de impuestos } \\
\hline Activos totales & $\mathrm{X}$ & \\
\hline \multicolumn{3}{|l|}{ Ingresos totales } \\
\hline \multicolumn{3}{|c|}{$\begin{array}{l}\text { Base: La base utilizada debe ser la proyectada a la fecha del ejercicio objeto de la auditoría (en este caso, diciembre } 31 \text { ); solo complete } \\
\text { aquella que se escoja en el numeral } 1.1 \text { de éste documento. }\end{array}$} \\
\hline \multicolumn{3}{|l|}{1.2 Incluir el valor base a utilizar para el cálculo de la materialidad } \\
\hline Nota: Incluir solo un valor el seleccionado en el numeral 1.1 & & Miles de pesos \\
\hline Utilidad antes de impuestos & & 0 \\
\hline Activos totales & & 1.833 .566 .909 \\
\hline Ingresos totales & & 0 \\
\hline \multicolumn{3}{|l|}{$\begin{array}{l}\text { 1.3 Error máximo tolerable en los estados financieros: La base del numeral } 1.2 \text { se multiplica por } \\
\text { el porcentaje indicado en este numeral. (está formulado - calculado de forma automática) }\end{array}$} \\
\hline Utilidad antes de impuestos & $60 \%$ & 0 \\
\hline Activos totales & $60 \%$ & 5.500 .701 \\
\hline Ingresos totales & $60 \%$ & 0 \\
\hline \multicolumn{3}{|l|}{$\begin{array}{l}\text { Monto mínimo para acumular diferencias de auditoría: La base del numeral } 1.3 \text { se multiplica por } \\
\text { el porcentaje indicado en este numeral. (está formulado - calculado de forma automática) }\end{array}$} \\
\hline Utilidad antes de impuestos & $5 \%$ & 0 \\
\hline Activos totales & $2 \%$ & 110.014 \\
\hline Ingresos totales & $2 \%$ & 0 \\
\hline & & \\
\hline
\end{tabular}

\section{Figura 3. Materialidad}

Nota: Informe de materialidad de la empresa All Computer S.A.S. con referencia a los activos

totales por la operación comercial de la entidad. Adaptado de (Auditool, s.f.) 


\subsection{Estado de la situacion financiera de apertura}

\begin{tabular}{|c|c|c|c|c|}
\hline $\begin{array}{r}\text { COME } \\
\text { ESTADO D }\end{array}$ & $\begin{array}{l}\mathbf{L C} \\
\mathrm{NC} \\
201\end{array}$ & $\begin{array}{l}\text { UTER S.A.S } \\
\text { DE APERTURA }\end{array}$ & & \\
\hline ACTIVO & & & & \\
\hline Efectivo y equivalente de efectivo & & & $\$$ & $185.600 .000,00$ \\
\hline Efectivo & & & & \\
\hline Caja & $\$$ & $500.000,00$ & & \\
\hline Caja Menor & $\$$ & $100.000,00$ & & \\
\hline Banco de Bogota & $\$$ & $100.000 .000,00$ & & \\
\hline Bancolombia & $\$$ & $80.000 .000,00$ & & \\
\hline Equivalentes de efectivo & & & & \\
\hline CDT 90 dias & $\$$ & $5.000 .000,00$ & & \\
\hline$\underline{\text { Instrumentos Financieros }}$ & & & $\$$ & $192.636 .274,87$ \\
\hline Bono & $\$$ & $10.658 .344,79$ & & \\
\hline CDT 48 meses Bancolombia & $\$$ & $12.113 .865,00$ & & \\
\hline Acciones ecopetrol & $\$$ & $130.000 .000,00$ & & \\
\hline Acciones grupo Aval & $\$$ & $9.600 .000,00$ & & \\
\hline Acciones mayatex & $\$$ & $800.000,00$ & & \\
\hline Cuentas por cobrar & $\$$ & $29.464 .065,08$ & & \\
\hline$\underline{\text { Inventarios }}$ & & & $\$$ & $288.000 .000,00$ \\
\hline Mercancias no fabricadas por la empresa & $\$$ & $288.000 .000,00$ & & \\
\hline Propiedad planta y equipo & & & $\$$ & $632.000 .000,00$ \\
\hline Edificio donde labora & $\$$ & $250.000 .000,00$ & & \\
\hline Maquina y equipo & $\$$ & $40.000 .000,00$ & & \\
\hline Vehiculo & $\$$ & $30.000 .000,00$ & & \\
\hline Computadores & $\$$ & $12.000 .000,00$ & & \\
\hline Camión (Leasing) & $\$$ & $300.000 .000,00$ & & \\
\hline Propiedades de inversión & & & $\$$ & 770.000.000,00 \\
\hline Terreno & $\$$ & $540.000 .000,00$ & & \\
\hline Edificio arrendado & $\$$ & $230.000 .000,00$ & & \\
\hline Depreciación & & & $\$$ & $(291.822 .222,22)$ \\
\hline Edificio donde labora & $\$$ & $-131.944 .444,44$ & & \\
\hline Maquina y equipo & $\$$ & $(17.777 .777,78)$ & & \\
\hline Vehiculo & $\$$ & $(12.500 .000,00)$ & & \\
\hline Computadores & $\$$ & $(9.600 .000,00)$ & & \\
\hline Camión (Leasing) & $\$$ & $(120.000 .000,00)$ & & \\
\hline$\underline{\text { Intangible }}$ & & & $\$$ & $100.000 .000,00$ \\
\hline Licencia & $\$$ & $100.000 .000,00$ & & \\
\hline Amortizacion Int. & & & $\$$ & $(42.857 .142,86)$ \\
\hline Licencia & $\$$ & $(42.857 .142,86)$ & & \\
\hline & & ACTIVO & $\$$ & $1.833 .556 .909,80$ \\
\hline
\end{tabular}




\section{PASIVO}

Obligaciones financieras

$\$$

$(233.185 .101,63)$

Leasing Camion

Obligación Bancolombia

\$ $\quad(228.637 .415,02)$

$\$ \quad(4.547 .686,61)$

Proveedores

$(350.000 .000,00)$

Beneficios aempleados

$\$$

$(121.666 .666,67)$

Provisiones

$\$$

$(36.000 .000,00)$

Impuesto Diferido

$\$$

$(67.860 .988,37)$

TOTAL PASIVO

$\$$

$(808.712 .756,67)$

\section{PATRIMONIO}

Capital Social

Reservas

Utilidades del ejercicio

Utilidades retenidas

Utilidades retenidas

Ajuste a bono xxx

Ajuste a CDT 48 meses Bancolombia

Ajuste al valor de acciones Ecopetrol

Ajuste por baja en cxc Comercializadora ABC

Eliminación Provisión de cartera

Ajuste por deterioro de cartera

Calculo VNR Inventario

Baja de inventarios

Eliminación Provisión de inventario

Eliminación Depreciación en local

Eliminación activos medidos modelo revaluación

Reconocimiento activos modelo revaluacion

Reconocimiento depreciación

Depreciacion camión leasing

Ajuste amortizacion intangible - Licencia

Ajuste a costo amortizacion Pas. Fro Oblig. Bancol

Ajuste a costo amortizacion Pas. Beneficios a empleados

Ajuste a Impuesto Diferido

$\$$

$\$$

$\$$

$\$$

$(1.658 .344,79)$

$(113.865,00)$

$(10.000 .000,00)$

$15.000 .000,00$

$(4.964 .065,08)$

2.000.000,00

$2.250 .000,00$

$(29.225 .000,00)$

$(38.472 .222,22)$

420.000.000,00

$(1.020 .000 .000,00)$

$(18.788 .888,89)$

120.000.000,00

$(17.142 .857,14)$

$(8.370,17)$

1.666.666,67

67860988,37

TOTAL PATRIMONIO \$

TOTAL PASIVO + PATRIMONIO \$
(1.024.844.153,13)

$(500.000 .000,00)$

$(3.000 .000,00)$

$(7.118 .194,87)$

$(3.130 .000,00)$

$(511.595 .958,26)$

$(1.833 .556 .909,80)$

\section{Figura 4. ESFA}

Nota: Estado de situación financiera de apertura de la empresa All Computer S.A.S. 


\subsection{Flujograma o ciclo de operación}

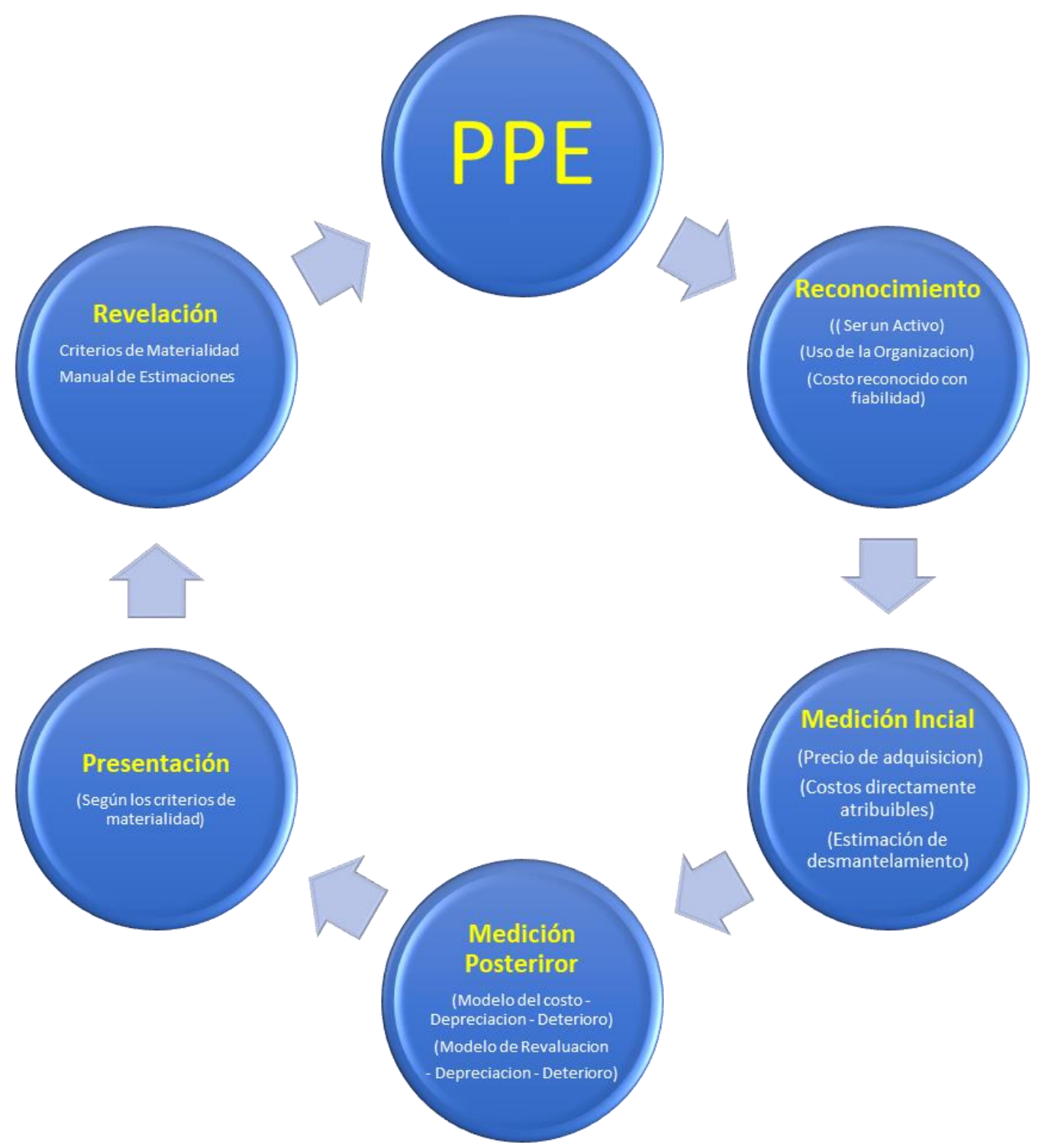

Figura 5. Ciclo de Operación Propiedad Planta y Equipo

Nota. Corresponde al flujograma de proceso del manejo de Propiedad Planta y Equipo. 


\subsection{Matriz del componente de propiedad planta y equipo}

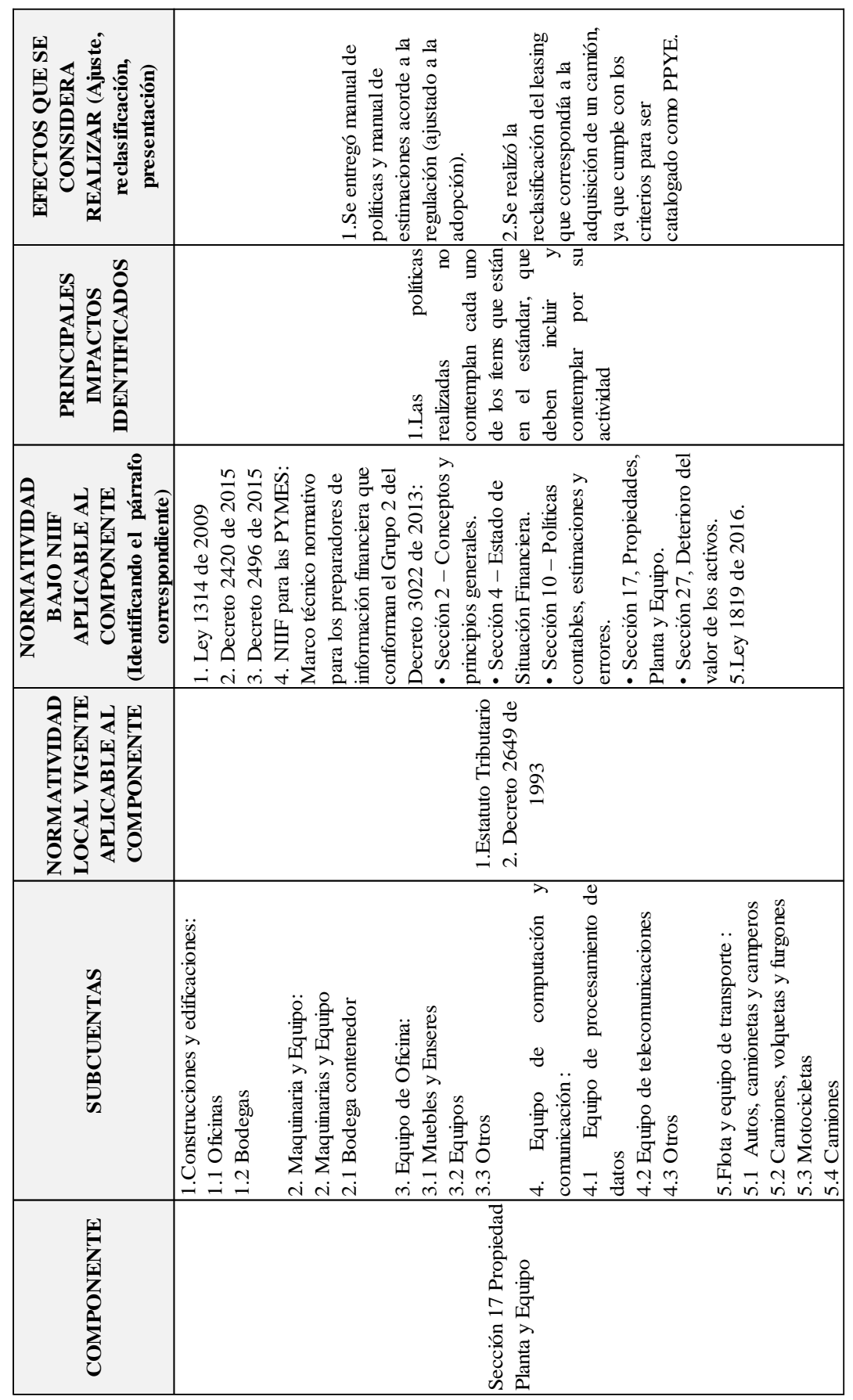

Figura 6. Matriz Propiedad Planta y Equipo

Nota. Resultado de mantenimiento según la sección 17 - Propiedad Planta y Equipo de la empresa All Computer S.A.S. 


\section{Conclusiones}

El éxito del adecuado proceso de implementación, parte de la elaboración de un apropiado manual de Políticas Contables, que permita a la COMERCIALIZADORA ALLCOMPUTER SAS, fijar las bases sobre las cuales usará los criterios normativos establecidos en el estándar de las NIIF para las PYMES, las cuales se basan en el Reconocimiento, Medición, Presentación y Revelación de la información financiera.

El Manual es eminentemente dinámico y deberá monitorearse y actualizarse en la medida que se produzcan cambios en los marcos técnicos normativos contables colombianos. 


\section{Recomendaciones}

El estado de situación financiera de apertura fue elaborado con base en el nuevo marco técnico normativo compilado en el decreto 2420 de 2015 el cual contiene las secciones de las NIIF para las PYMES (versión aprobada por el IFRS 2009), es importante destacar que en esta versión no se les permitía a las organizaciones catalogadas como PYMES la opción de medición por el método de revaluación, este cambio se observa a partir de la versión de las secciones NIIF para las PYMES (versión aprobada por el IFRS 2015), la organización puede examinar y evaluar, si sigue midiendo la propiedad planta y equipo por el modelo del costo, o por el contrario por el modelo de revaluación, deberá determinar cuál de las dos opciones refleja de manera fiable la información financiera de la organización.

Dentro del proceso de convergencia a normas internacionales, se ha podido evidenciar la importancia que tiene el proceso de formación, capacitación, autoevaluación y constante actualización a la profesión de la contaduría pública, ya que la normatividad está en cambio continuamente adaptándose a los diferentes estándares internacionales, con el propósito de brindar información financiera a los diferentes participantes. 


\section{Referencias Bibliográficas}

Actualicese. (2018). Obtenido de https://actualicese.com

Actualicese.com. (25 de 02 de 2015). https://actualicese.com. Obtenido de https://actualicese.com: https://actualicese.com/modelos-y-formatos/plan-de-implementacion-niif-para-empresasdel-grupo-2/

Actualicese.com. (2018). actualicese.com. Obtenido de actualicese.com: https://actualicese.com/actualidad/2016/02/17/propiedades-planta-y-equipo-de-laspymes-podran-medirse-a-valor-razonable/

Actualicese.com. (s.f.). https://actualicese.com/. Obtenido de https://actualicese.com/: https://actualicese.com/

Auditool. (s.f.). https://www.auditool.org. Obtenido de https://www.auditool.org: https://www.auditool.org/blog/auditoria-externa/5331-la-materialidad-en-la-auditoria-deestados-financieros-principios-basicos

Auditool. (s.f.). Materialidad. Obtenido de www.auditool.org

Becerra, O. A., Rojo, L. A., \& Medina, A. V. (2012). Análisis de las diferencias entre el tratamiento contable y el fiscal para los elementos de propiedades, planta y equipo: el caso peruano. Contabilidad y Negocios: Revista del Departamento Académico, 5-22.

Consejo Tecnico de la Contaduria, . (s.f.). Diagnostico . Obtenido de www.ctcp.com

Forvm. (s.f.). forvm.com.co. Obtenido de forvm.com.co: https://forvm.com.co/wpcontent/uploads/2015/06/Forvm-Plantilla-liquidador-impuestodiferido. $x l s x+\& c d=1 \&$ hl=es $-419 \& c t=c \operatorname{lnk} \& g l=c o$ 
Publica, C. T. (2018). http://www.ctcp.gov.co. Obtenido de http://www.ctcp.gov.co: http://www.ctcp.gov.co/puerta/athena/_files/docs/1472852039-4458.pdf 


\section{Apéndices}




\section{Apéndice A. Manual de políticas}

\section{contables}




\title{
MANUAL DE POLITICAS CONTABLES
}

\author{
NORMAS \\ INTERNACIONALES DE \\ INFORMACIÓN FINANCIERA \\ PARA PYMES \\ 1 DE ENERO 2015
}




\section{Autorizaciones}

ELABORÓ REVISÓ APROBÓ
Equipo NIIF asignado por la Revisor Fiscal
Gerente General

Compañía para el proceso de convergencia

Origen de cambios de versiones

\begin{tabular}{cc}
\hline VERSIÓN & ORIGEN DE LOS CAMBIOS \\
01 & Versión Inicial
\end{tabular}

Este Manual no puede ser copiado ni dado a conocer a terceros, sin autorización expresa de COMERCILIZADORA ALLCOMPUTER SAS

Si este documento es impreso, es considerado COPIA NO CONTROLADA. 


\section{Contenido}

\section{Pág.}

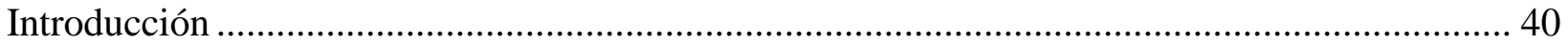

1. Reseña histórica de comercializadora Allcomputer S.A.S ............................................... 42

2. Marco legal de comercializadora Allcomputer S.A.S ................................................... 43

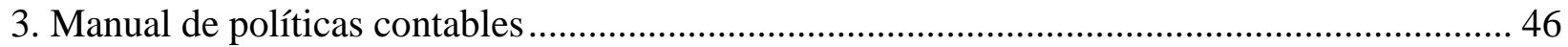

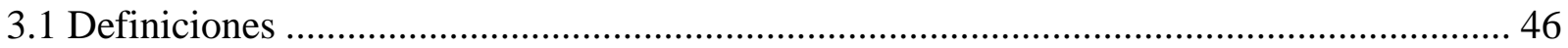

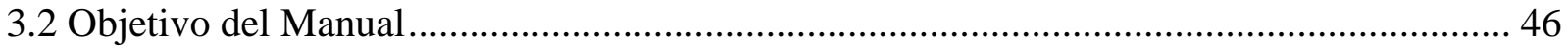

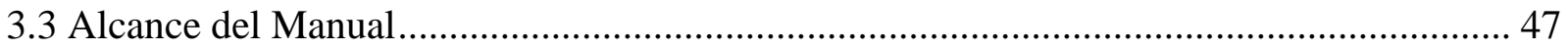

3.4 Conceptos y Principios Fundamentales para la Información Financiera ......................... 48

3.5 Bases Generales de Medición bajo NIIF ....................................................................... 48

3.6 Responsabilidad del Manual de Políticas Contables ...................................................... 50

3.7 Secciones NIIF para las PYMES Aplicables y Políticas Contables................................. 50

4. Política contable para la preparación y presentación de estados financieros.......................... 53

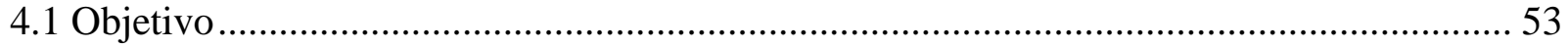

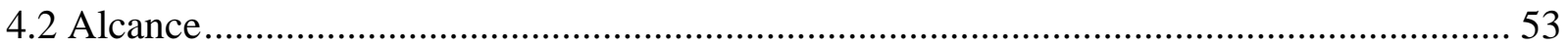

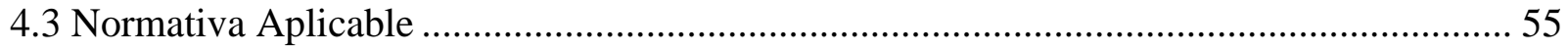

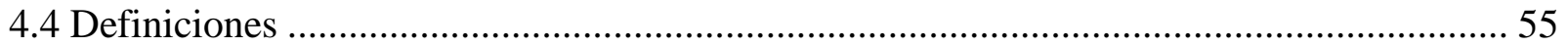

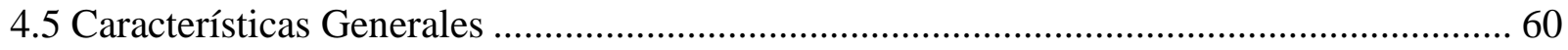

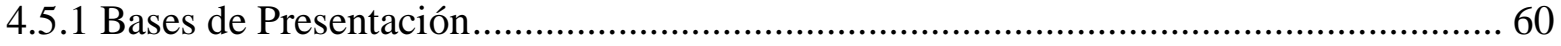




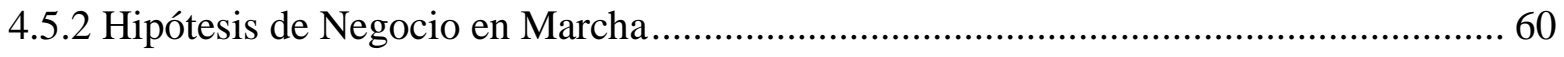

4.5.3 Base Contable de Causación...................................................................................... 61

4.5.4 Materialidad (Importancia Relativa) y Agrupación de Datos ................................... 61

4.5.5 Compensación de Activos y Pasivos e Ingresos y Gastos ........................................ 62

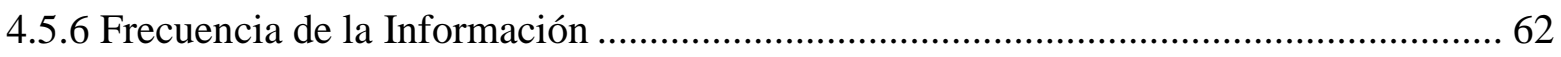

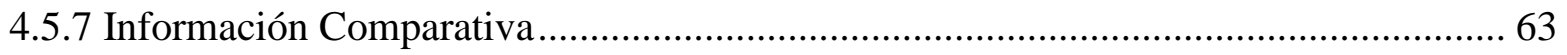

4.5.8 Uniformidad en la Presentación ........................................................................ 63

4.5.9 Moneda Funcional (Legal) y de Presentación ..................................................... 64

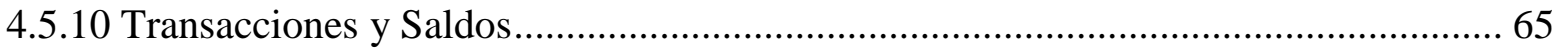

4.6 Presentación e Identificación de los Estados Financieros .............................................6 65

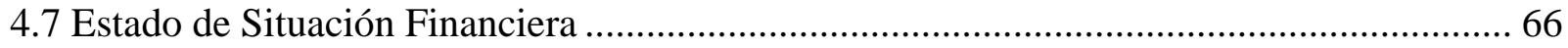

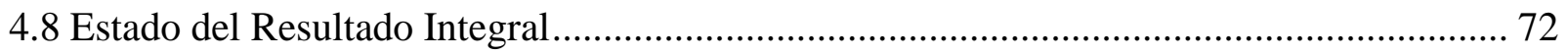

4.9 Estado de Cambios en el Patrimonio ................................................................... 74

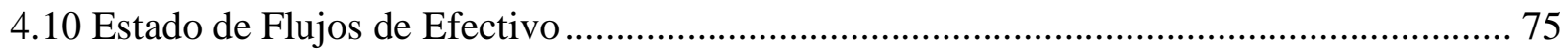

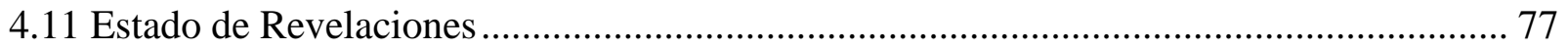

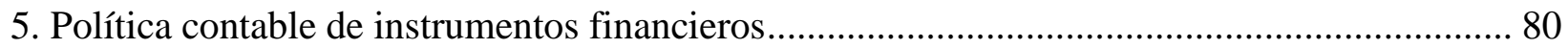

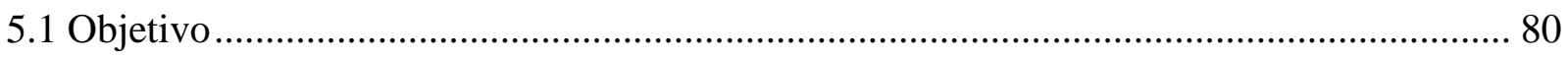

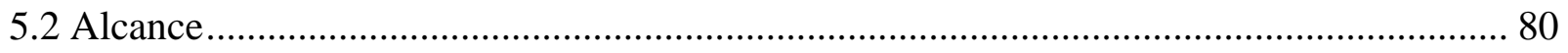

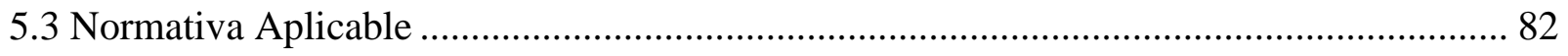

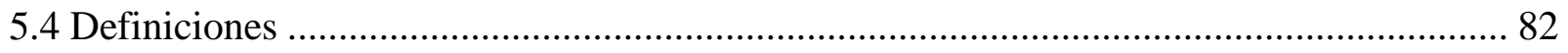

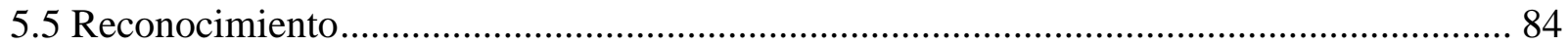

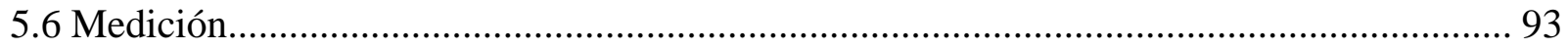

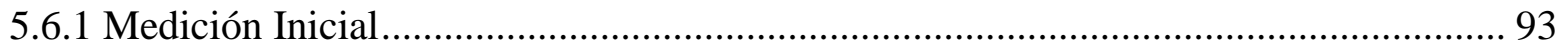




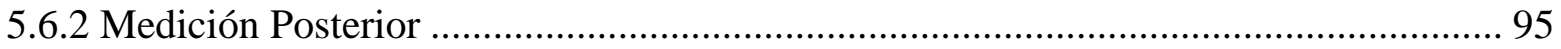

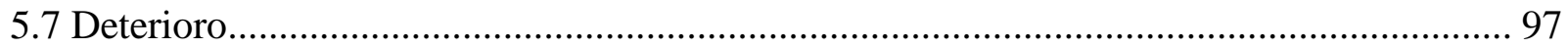

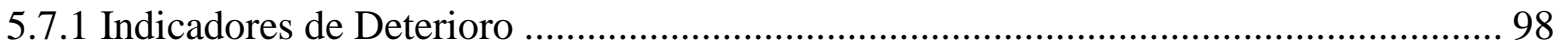

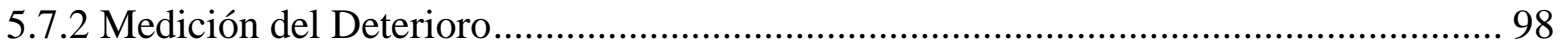

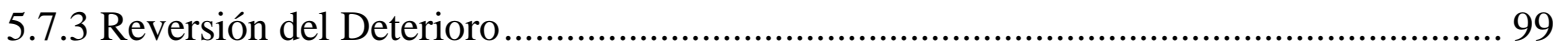

5.8 Baja en Cuentas de los Instrumentos Financieros ............................................................ 99

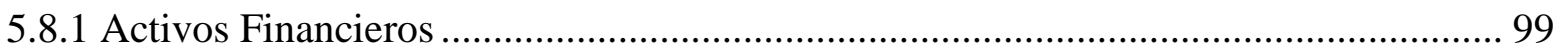

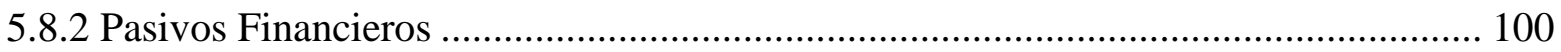

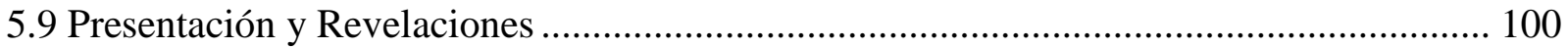

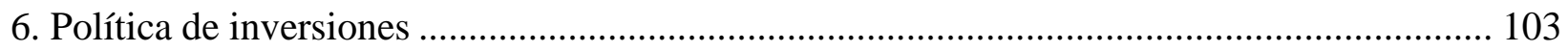

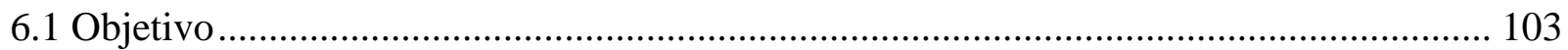

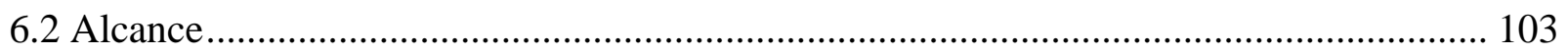

6.3 Política Contable General................................................................................................ 104

6.4 Reconocimiento y Medición .................................................................................... 104

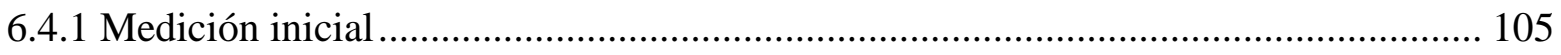

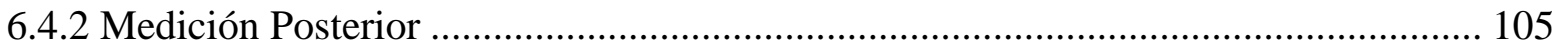

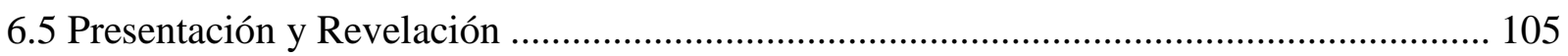

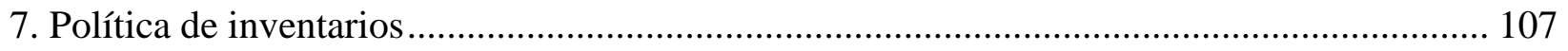

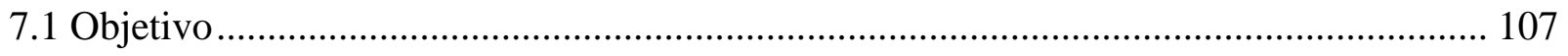

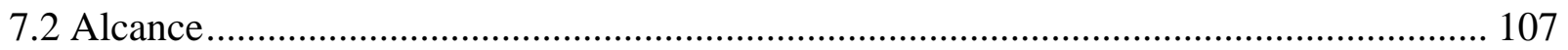

7.2.1 Inventario de materiales y suministros ……….......................................................... 107

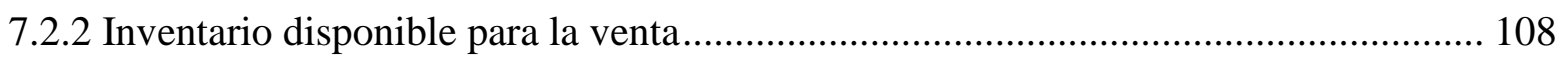

7.2.3 Inventario de producto en proceso........................................................................... 108 


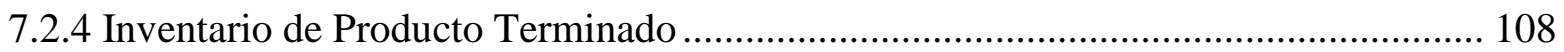

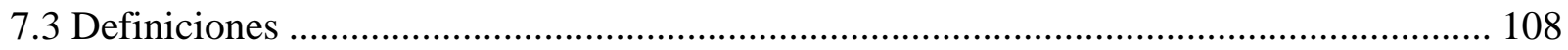

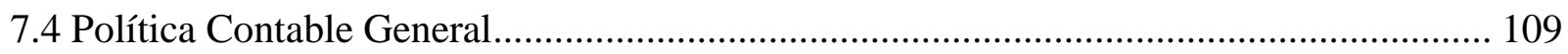

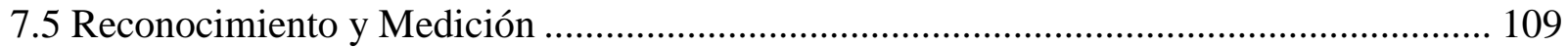

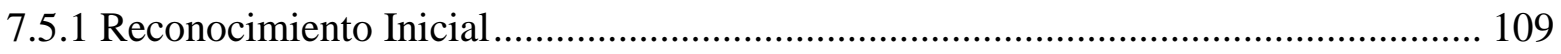

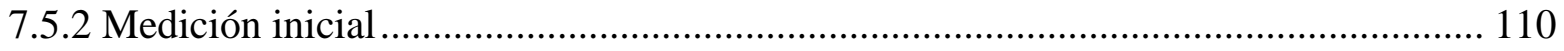

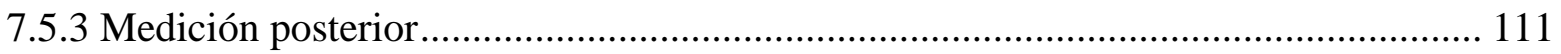

7.6 Presentación y Revelación ............................................................................................... 114

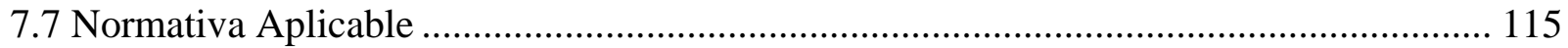

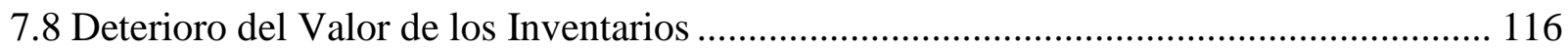

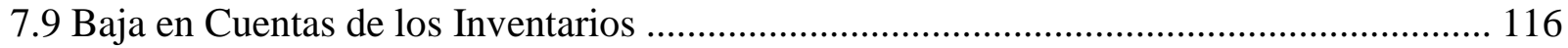

7.10 Presentación y Revelaciones ........................................................................................ 117

8. Política contable de propiedades, planta y equipo …….......................................................... 118

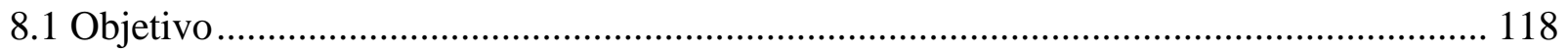

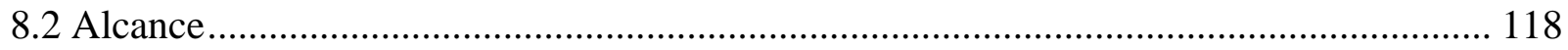

8.3 Normativa Aplicable ……………………………….............................................. 120

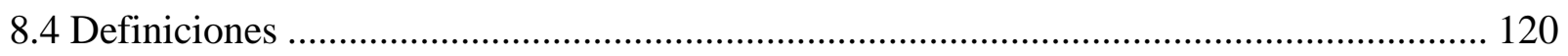

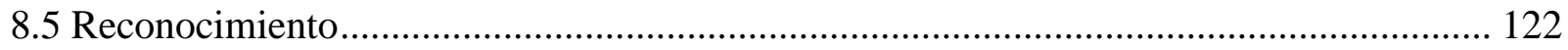

8.5.1 Costo Atribuido para el Balance de Apertura............................................................... 124

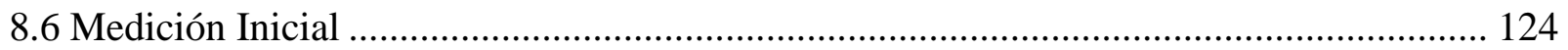

8.6.1 Materialidad para el Reconocimiento ………….................................................. 125

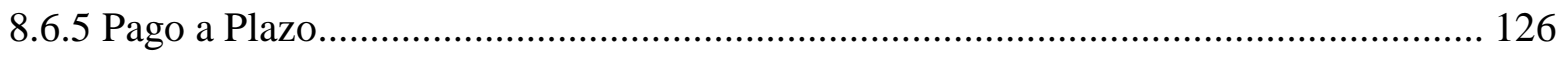

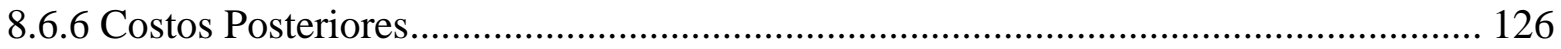


8.7 Medición Posterior …………………………………................................................. 127

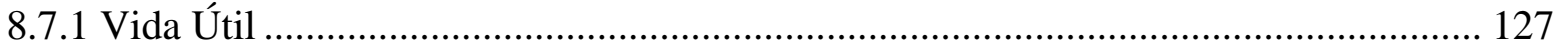

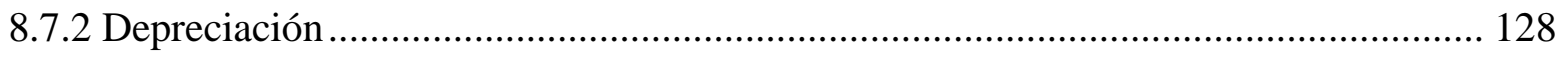

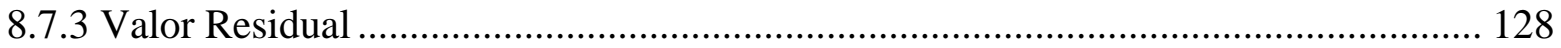

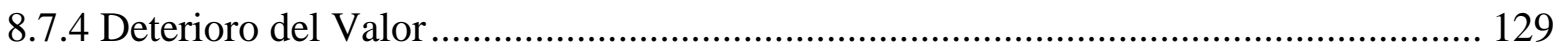

8.8 Activos No Corrientes Mantenidos para la Venta.......................................................... 129

8.9 Baja en Cuentas de PP\&E ....................................................................................... 130

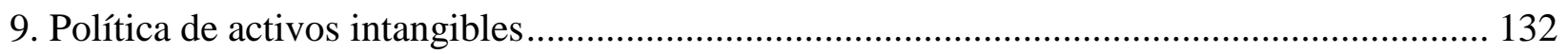

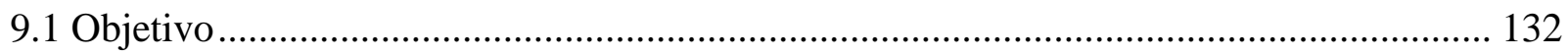

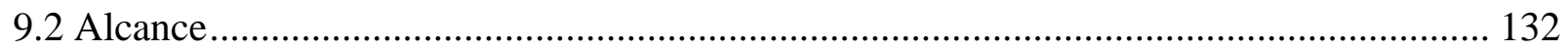

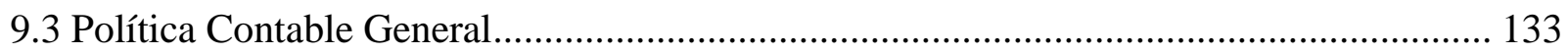

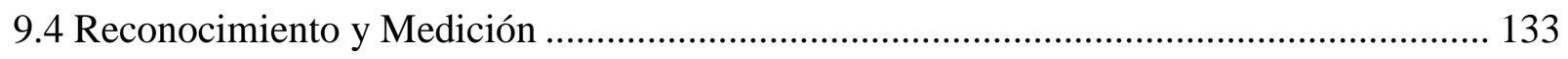

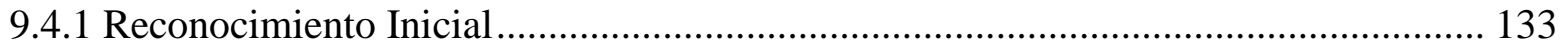

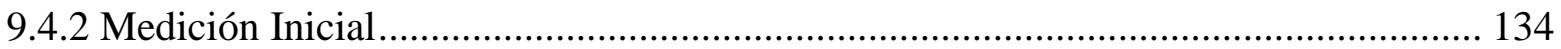

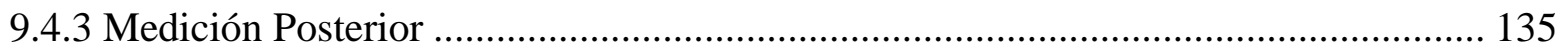

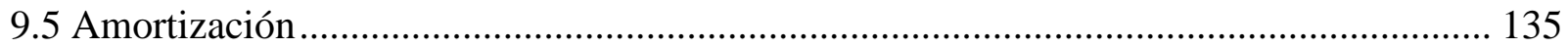

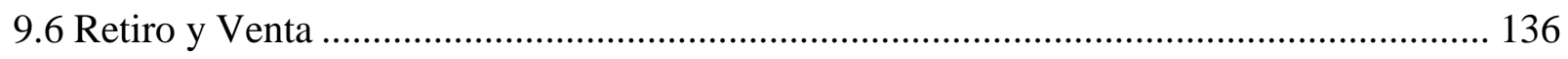

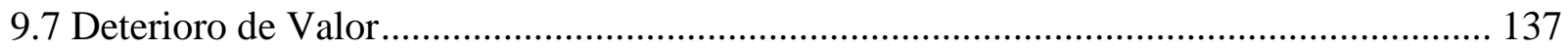

9.8 Presentación y Revelación ................................................................................................ 137

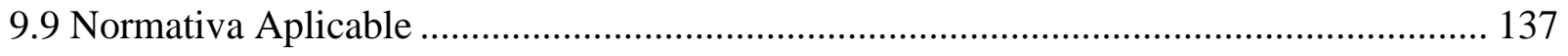

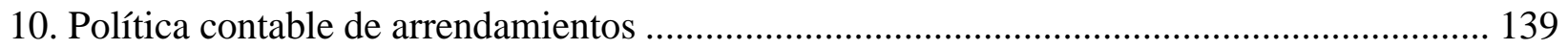

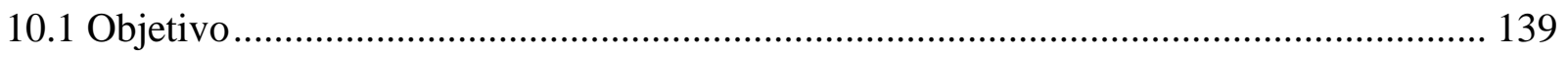

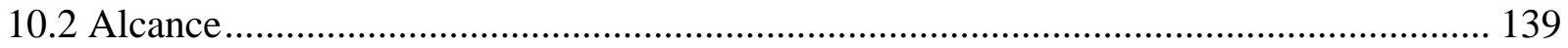




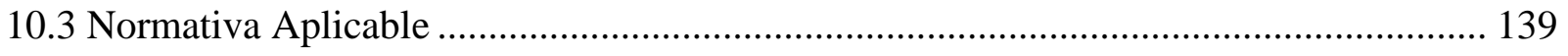

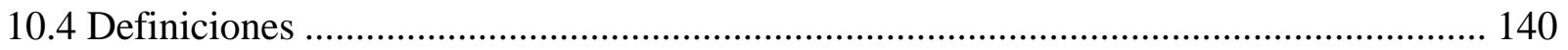

10.5 Clasificación de un Contrato de Arrendamiento ........................................................... 143

10.6 Arrendamiento Operativo............................................................................................. 146

10.6.1 Comercializadora Allcomputer S.A.S, como arrendatario ...................................... 146

10.6.1.1 Reconocimiento y Medición ............................................................................ 146

10.6.1.2 Presentación y Revelaciones........................................................................ 146

10.6.2.2 Presentación y Revelaciones.............................................................................. 147

11. Política contable de ingresos de actividades ordinarias ...................................................... 148

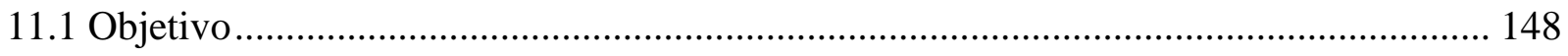

11.2 Alcance

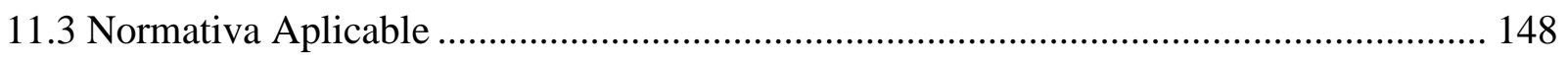

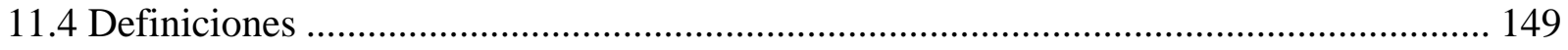

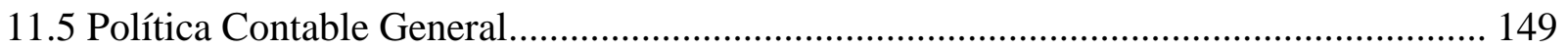

11.5.1 Ingresos por Ventas de Vidrios ................................................................... 149

11.5.3 Ingresos Rendimientos Financieros e Intereses ..................................................... 150

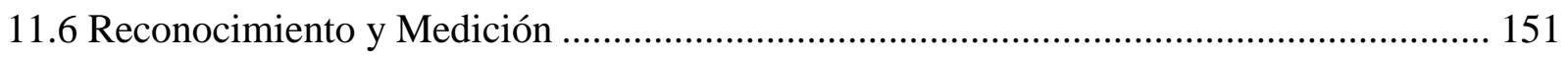

11.7 Presentación y Revelación ........................................................................................... 153

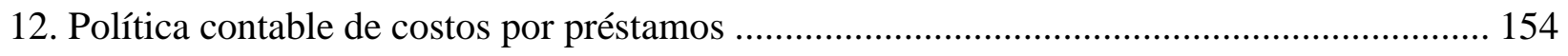

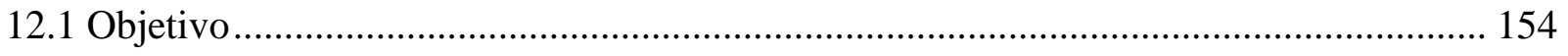

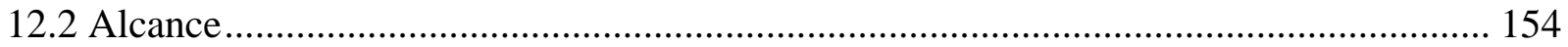

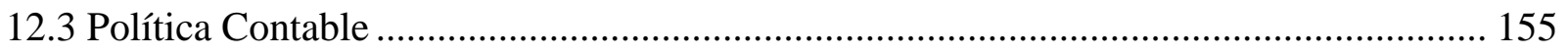

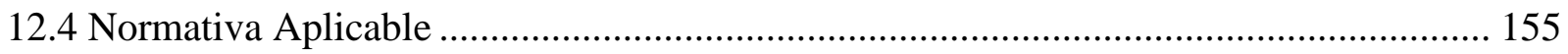




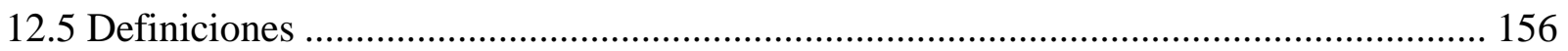

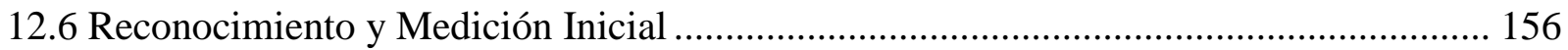

12.6.1 Medición Posterior .................................................................................... 157

12.6.2 Reconocimiento posterior de los costos financieros...................................... 158

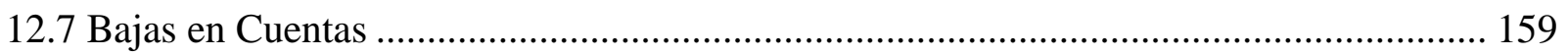

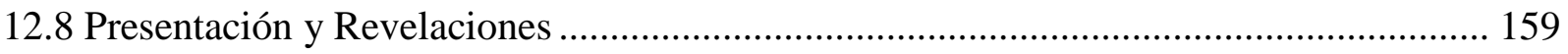

13. Política contable de deterioro del valor de los activos................................................... 161

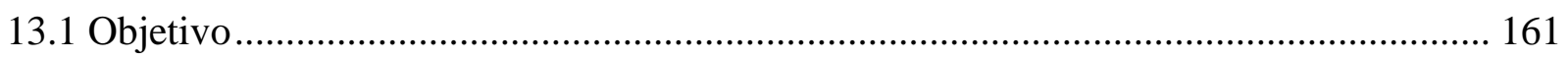

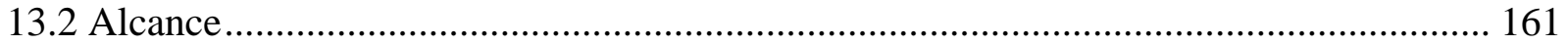

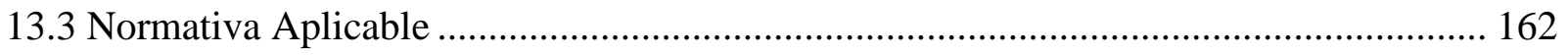

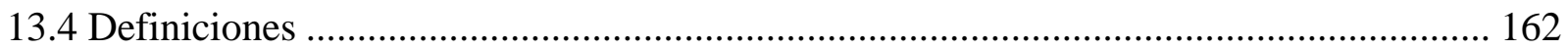

13.5 Identificación de Indicadores de Deterioro del Valor de los Activos ........................... 164

13.5.1 Fuentes Externas, Indicadoras de Deterioro ................................................. 164

13.5.2 Fuentes Internas, Indicadoras de Deterioro ................................................. 165

13.6 Medición del Valor Recuperable........................................................................ 166

13.7 Reconocimiento y Medición de la Perdida por Deterioro ......................................... 167

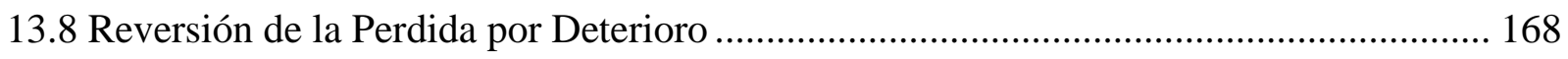

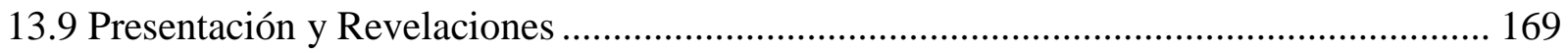

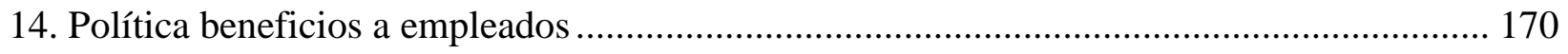

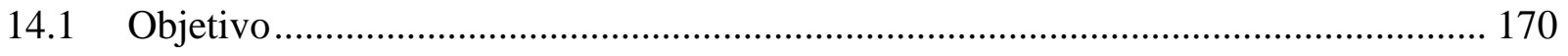

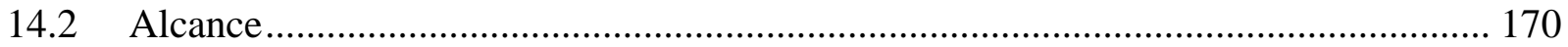

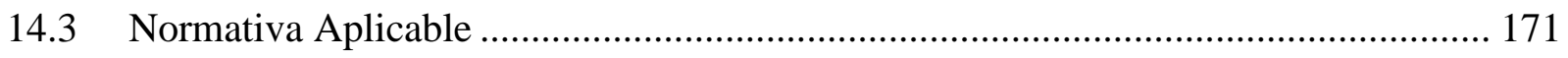

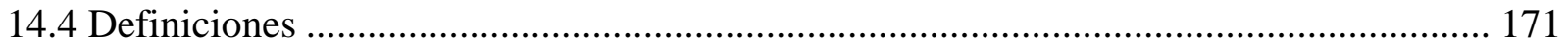


14.5 Reconocimiento y Medición de los Beneficios a Empleados 172

14.5.1 Beneficios a los Empleados a Corto Plazo 172

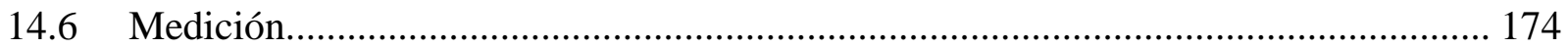

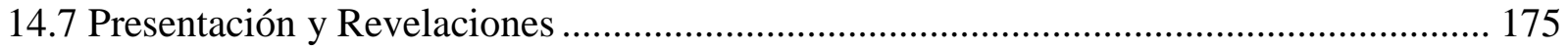

15. Política contable de impuesto a las ganancias .......................................................... 176

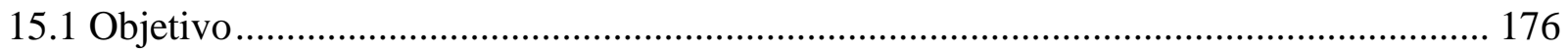

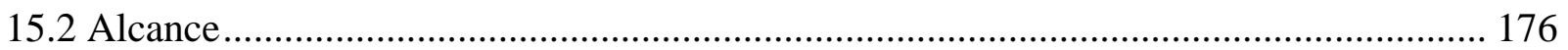

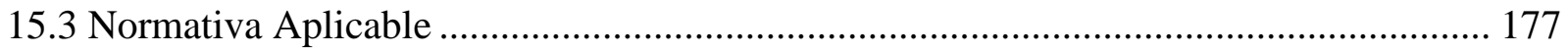

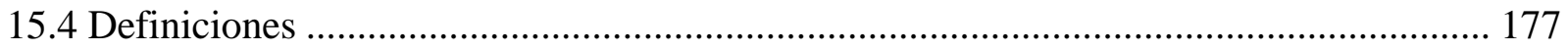

15.5 Reconocimiento de Activos y Pasivos por Impuestos Corrientes................................ 179

15.6 Reconocimiento Activos y Pasivos por Impuestos Diferidos ..................................... 179

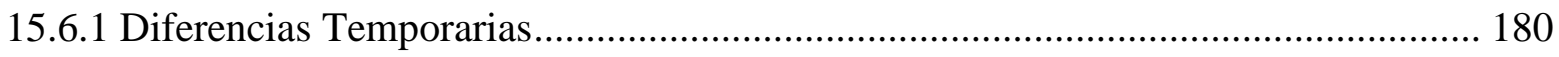

15.6.2 Pérdidas y Créditos Fiscales No Utilizados.................................................. 182

15.6.3 Pasivos y Activos por Impuestos Diferidos................................................... 182

15.6.4 Base Fiscal y Tasas Impositivas en Activos y Pasivos por Impuestos Diferidos ..... 183

15.7 Medición de Impuestos Corrientes y Diferidos..................................................... 184

15.8 Reconocimiento de Impuestos Corrientes y Diferidos........................................... 184

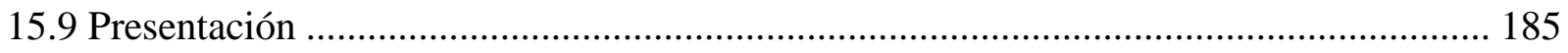

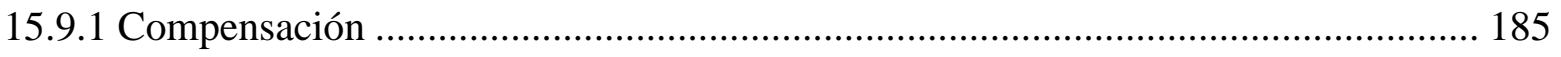

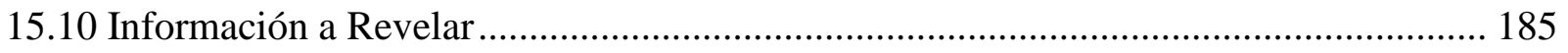

16. Política contable de hechos posteriores ..................................................................... 188

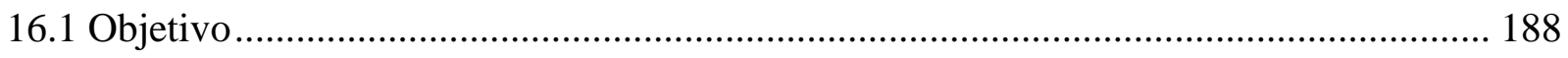

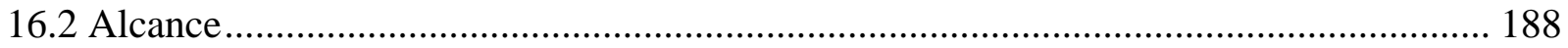




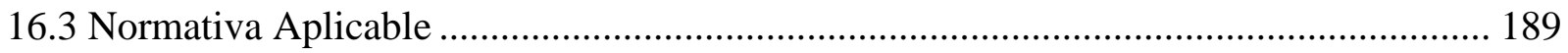

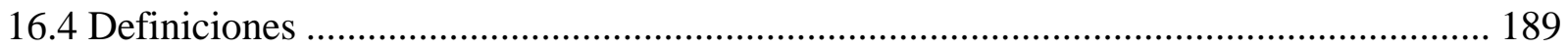

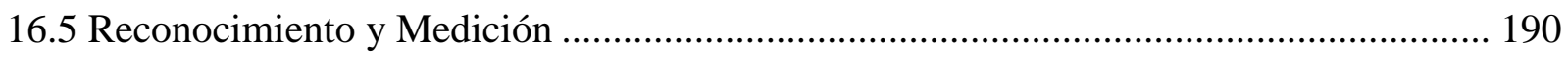

16.5.1 Hechos Posteriores que Implican Ajustes ....................................................... 190

16.2 Hechos Posteriores que no Implican Ajustes ...................................................... 191

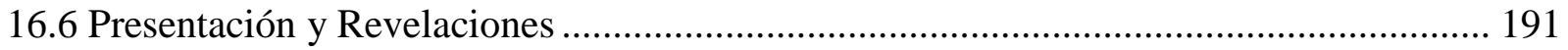

17. Política contable de adopción por primera vez de la niif para pymes ............................... 193

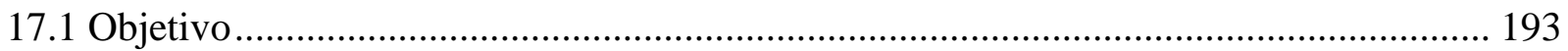

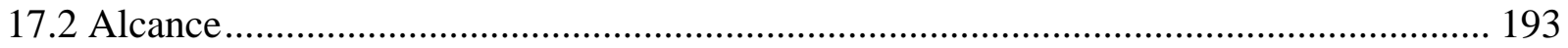

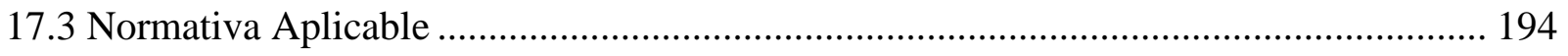

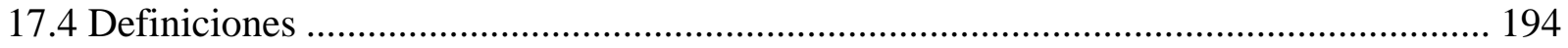

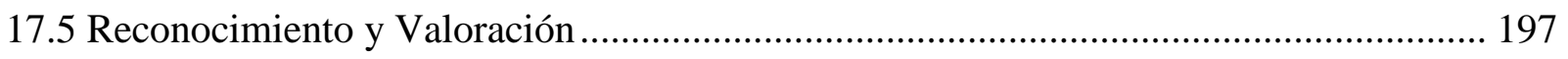

17.5.1 Estado de Situación Financiera de Apertura con Arreglo a las NIIF para PYMES . 197

17.5.2 Políticas Contables ................................................................................... 198

17.5.3 Exenciones y Excepciones a la Aplicación Retroactiva de las NIIF para Pymes .... 199

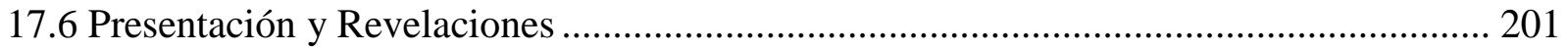




\section{Introducción}

Mediante la expedición de la ley 1314 de 2009 “Por la cual se regulan los principios y normas de contabilidad de información financiera y de aseguramiento de información aceptados en Colombia”, se abren las puertas al manejo contable bajo un estándar financiero internacional llevándonos a manejar el mismo idioma contable a nivel mundial.

COMERCIALIZADORA ALLCOMPUTER S.A.S, consciente de la necesidad de dar cumplimiento al proceso de convergencia, a la nueva normativa contable bajo el estándar de Normas Internacionales de Información Financiera, emitidas por el IASB, y mediante los parámetros establecidos por el direccionamiento estratégico del proceso de convergencia de las normas de contabilidad de información financiera y de aseguramiento de la información con estándares internacionales emitido por el Consejo Técnico de la Contaduría Pública el 5 de diciembre de 2012 y basándose en el decreto 3022 del 27 de diciembre de 2013, se acoge a los parámetros establecidos para clasificar dentro del grupo 2 de dichas normas, y aplicará la normativa NIIF para las PYMES.

Teniendo en cuenta la nueva normativa contable bajo NIIF para las PYMES vs los principios de contabilidad generalmente aceptados en el marco contable Colombiano de los decretos 2649 y 2650, se observa que las características cualitativas de reconocimiento, medición, información a revelar, presentación, y baja de cuentas en los diferentes hechos económicos realizados por la Compañía, difieren entre sí, resaltando la importancia en el análisis de la información, interpretación y elaboración de los estados financieros de propósito general. 
Como herramienta para la preparación y presentación de sus estados financieros, los cuales son base para la toma de decisiones gerenciales, COMERCIALIZADORA ALLCOMPUTER S.A.S, elaboró este Manual de Políticas Contables, el cual garantizará el cumplimiento de las características cualitativas de la información financiera, en cuanto a su reconocimiento, medición y presentación. 


\section{Reseña histórica de comercializadora Allcomputer S.A.S}

En sus 12 AÑOS de existencia, COMERCIALIZADORA ALLCOMPUTER S.A.S, ha en causado sus esfuerzos al mejoramiento de la vida de los santandereanos y otras regiones del país, ofreciendo productos de tecnología e informática que brinden las herramientas necesarias para el crecimiento de las empresas. Optimizando y automatizando procesos de atención al usuario.

\section{Domicilio Principal}

Calle 48 No 33-11 Oficina 203 Edificio Tempo II

\section{Objeto Social}

Nuestro objeto social es la comercialización y asesoramiento de productos tecnológicos e informáticos.

\section{Misión}

Incrementar la productividad y eficiencia de nuestros clientes a través de tecnología e innovación constantes de nuestros productos y servicios.

\section{Visión}

Ser una empresa líder en el 2021 a nivel nacional como proveedora de servicios de tecnología. Con productos de calidad que satisfagan las necesidades de nuestros clientes. 


\section{Marco legal de comercializadora Allcomputer S.A.S}

COMERCIALIZADORA ALLCOMPUTER SAS es una entidad jurídica constituida por documento privado No 1250 de asamblea de accionistas del 05 de noviembre de 2002, inscrita el 10 de noviembre de 2002, bajo el número 52781 del libro IX.

La empresa es de carácter comercial bajo la forma de Sociedad por acciones simplificada (SAS), del orden nacional, vigilada por la superintendencia de sociedades.

\section{Ámbito de Aplicación y Aprobación}

Los estados financieros presentan los resultados de la administración llevada a cabo por la Gerencia, y dan cuenta de la responsabilidad en la gestión de los recursos confiados a la misma; en consecuencia, la Gerencia de la Compañía es la principal responsable, en velar que dichos estados financieros estén preparados y presentados con los requerimientos que establecen las NIIF para las PYMES.

COMERCIALIZADORA ALLCOMPUTER SAS adopta como marco de referencia las Normas Internacionales de Información Financiera para Pequeñas y Medianas Entidades, para la preparación y presentación de sus estados financieros a partir del $1^{\circ}$ de enero de 2015 , de acuerdo con los requerimientos del decreto 3022 del 27 de diciembre de 2013.

De conformidad con el artículo $1^{\circ}$ del Decreto 3022 de 2013, las entidades que conforman el Grupo 2, son aquellas que no cumplan con los requisitos del artículo $1^{\circ}$ del Decreto 2784 de 2012 (modificado por el Decreto 3024 de 2013), ni con los requisitos del capítulo $1^{\circ}$ del marco técnico 
normativo de información financiera anexo al Decreto 2706 de 2012 (modificado por el Decreto 3019 de 2013).

En este sentido, se infiere que las entidades pertenecientes al Grupo 2 para la convergencia hacia las NIIF para las PYMES son las siguientes:

Entidades que No Cumplan con los requisitos del artículo $1^{\circ}$ del Decreto 2784 de 2012 y sus modificaciones o adiciones ni con los requisitos del capítulo $1^{\circ}$ del marco técnico normativo de información financiera anexo al Decreto 2706 de 2012.

- En primer lugar, entidades grandes que no cumplen ninguna de las siguientes condiciones:

- Ser subordinada o sucursal de una compañía extranjera que aplique NIIF plenas

- Ser subordinada o matriz de una compañía nacional que deba aplicar NIIF plenas

o Ser matriz, asociada o negocio conjunto de una o más entidades extranjeras que apliquen NIIF plenas

- Realizar importaciones o exportaciones que representen más del cincuenta por ciento (50\%) de las compras o de las ventas, respectivamente

- En segundo lugar, entidades medianas y pequeñas.

- En tercer lugar, microempresas que incumplan alguno de los siguientes requisitos:

- Contar con una planta de personal no superior a diez (10) trabajadores

○ Poseer activos totales, excluida la vivienda, por valor inferior a quinientos (500) salarios mínimos mensuales legales vigentes (SMMLV)

o Tener ingresos brutos anuales inferiores a 6.000 SMMLV

Además, los portafolios de terceros administrados por las sociedades comisionistas de bolsa de valores, los negocios fiduciarios y cualquier otro vehículo de propósito especial, administrados por entidades vigiladas por la Superintendencia Financiera de Colombia, que no establezcan 
contractualmente aplicar el marco técnico normativo establecido en el Anexo del Decreto 2784 de 2012 ni sean de interés público.

Por último, de acuerdo con lo establecido en el artículo $2^{\circ}$ de la Ley 1314 de 2009, la convergencia hacia las Normas Internacionales de Información Financiera será aplicable a todas las personas naturales y entidades obligadas a llevar contabilidad que cumplan los parámetros de los anteriores literales, independientemente de si tienen o no ánimo de lucro.

De acuerdo con la normativa NIIF para las PYMES, COMERCILIZADORA ALLCOMPUTER SAS, cumple con los requisitos para quedar clasificada en el Grupo 2.

Los órganos de dirección a nivel interno de COMERCILIZADORA ALLCOMPUTER SAS, para la aprobación de estados financieros son: Revisoría Fiscal, Contador Público, La Gerencia.

Entidades Gubernamentales de Vigilancia y Control a las cuales COMERCIALIZADORA ALLCOMPUTER S.A.S., tiene obligatoriedad de reporte:

- Superintendencia de Sociedades.

- Dirección de impuesto y aduanas nacionales - DIAN.

- Secretaria de Hacienda de Bucaramanga.

- Cámara de Comercio de Bucaramanga. 


\section{Manual de políticas contables}

\subsection{Definiciones}

Políticas Contables son los principios, bases, acuerdos, reglas y procedimientos específicos adoptados por la Compañía, en el reconocimiento y medición de las transacciones, operaciones y hechos, para la elaboración y presentación de sus estados financieros.

El Manual de Políticas Contables es el documento que incluye las directrices y lineamientos, fijados por COMERCILIZADORA ALLCOMPUTER SAS, para el registro contable y financiero de las operaciones comerciales de la Compañía, de acuerdo a la normativa aplicable (NIIF para las PYMES).

\subsection{Objetivo del Manual}

El Manual de Políticas Contables tiene por objetivo definir el tratamiento contable, para cada uno de los rubros que forman parte de los estados financieros, así como su estructura, estandarizando el cumplimiento de los requerimientos establecidos por la Norma Internacional de Información Financiera (NIIF) para las Pequeñas y Medianas Entidades, Secciones NIIF para las PYMES.

Este Manual de Políticas Contables, permitirá que la Compañía aplique políticas contables con criterios de reconocimiento, medición y exigencias de revelación basadas en la Norma 
Internacional de Información Financiera (NIIF). Así mismo, facilitara la interpretación de información contable haciéndola más confiable y útil para la toma de decisiones gerenciales.

Entre sus principales objetivos tenemos:

- Presentar una visión del conjunto de operaciones de la Compañía para administrarla en forma adecuada.

- Precisar conceptos generales para llevar a cabo acciones a realizar, según el tipo de transacción que se presente.

- Establecer una guía para orientar e informar al personal involucrado, en la armonización de las actividades contables.

- Facilitar la descentralización al suministrar a los niveles intermedios lineamientos claros a seguir en la toma de decisiones.

- Servir de base constante y efectiva en el registro de las operaciones.

\subsection{Alcance del Manual}

El presente Manual de Políticas Contables es de obligatorio cumplimiento por todas las instancias que preparan la información contable y financiera de COMERCILIZADORA ALLCOMPUTER SAS, para obtener estados financieros a partir del año 2015 de acuerdo a las Normas Internacionales de Información Financiera para Pequeñas y Medianas Entidades, NIIF para las PYMES, y el marco de aplicación ley 1314 de 2009. 


\subsection{Conceptos y Principios Fundamentales para la Información Financiera}

La Sección 2 NIIF para PYMES, Conceptos y Principios Generales para la información financiera, señala que el objetivo de los estados financieros con propósito general es proporcionar información sobre la situación financiera, el rendimiento financiero y los flujos de efectivo de la Compañía, que sea útil para la toma de decisiones económicas de los usuarios de estos, relevantes para el transcurrir de sus operaciones.

De acuerdo con los Conceptos y Principios Generales para la información financiera, la responsabilidad de la preparación y presentación de estados financieros recae en la Gerencia de la Compañía.

\subsection{Bases Generales de Medición bajo NIIF}

Medición es el proceso de determinación de los valores monetarios por los que se reconocen y llevan contablemente los elementos de los estados financieros, para su registro en el estado de situación financiera y en el estado de resultados.

Las bases generales de medición bajo NIIF, o determinación de los valores monetarios en los que se reconocen los elementos de los estados financieros son:

\section{Costo Histórico (Costo de Adquisición)}

Los activos son registrados por el valor de efectivo y otras partidas que representen obligaciones, o por el valor razonable de la contrapartida entregada a cambio en el momento de su adquisición. Los pasivos son registrados por el valor del producto recibido a cambio de incurrir en 
una obligación, o, en algunas circunstancias, por el valor de efectivo y otras partidas equivalentes que se espera pagar para satisfacer la obligación en el curso normal de la operación.

\section{Costo Corriente}

Los activos se registran por el valor en efectivo y otras partidas equivalentes al efectivo que se debería pagar si se adquiere en la actualidad el mismo activo u otro equivalente. Los pasivos se registran por el valor, sin descontar, de efectivo u otras partidas equivalentes al efectivo que se requiere para liquidar el pasivo en el momento presente.

\section{Valor Realizable}

Los activos son registrados por el valor en efectivo y otras partidas equivalentes al efectivo que podrían ser obtenidas, en el momento presente mediante la venta no forzada de los mismos. Los pasivos se llevan a su valor de liquidación; es decir, por los valores, no descontados de efectivo o equivalente al efectivo, que se espera pagar para cancelar las obligaciones.

\section{Valor Presente}

Los activos se registran al valor presente descontando las entradas de efectivo netas futuras que se espera genere la partida en el curso normal de la operación. Los pasivos se registran al valor presente, descontando las salidas netas de efectivo que se espera necesitar para pagar el pasivo, en el curso normal de las operaciones.

\section{Valor Razonable}

Significa el precio por el que puede ser adquirido un activo o pagado un pasivo, entre partes interesadas, debidamente informadas, en una transacción en condiciones de libre competencia. Es preferiblemente calculado en referencia a un mercado activo fiable; el precio de cotización en un mercado activo es la mejor referencia del valor razonable. 


\subsection{Responsabilidad del Manual de Políticas Contables}

La preparación y actualización del Manual de Políticas Contables, así como el monitoreo y el debido resguardo para velar por el cumplimiento y aplicación de las mismas, corresponderá al Revisor Fiscal, Contador de la Compañía, con autorización de la Gerencia; quienes deberán analizar periódicamente el alcance de cada política, a fin de que la totalidad de las operaciones existentes en COMERCILIZADORA ALLCOMPUTER SAS, se encuentren incluidas. Toda política adoptada será aprobada por la Gerencia de COMERCILIZADORA ALLCOMPUTER SAS.

Este Manual de Políticas Contables será actualizado cuando surjan nuevos hechos que no estén bajo su alcance, o por cada modificación que tengan las Normas Internacionales de Información Financiera, que lo afecten. COMERCILIZADORA ALLCOMPUTER SAS, deberá ceñirse a los criterios contables de general aceptación, que corresponden a las NIIF para las PYMES acordados por el Internacional Accounting Standard Boards (en adelante IASB).

3.7 Secciones NIIF para las PYMES Aplicables y Políticas Contables

\begin{tabular}{|c|c|c|c|}
\hline $\begin{array}{l}\text { Elemento de los } \\
\text { estados } \\
\text { financieros }\end{array}$ & Sección & $\begin{array}{c}\text { Normas internacionales de } \\
\text { información financiera } \\
\text { Para las pymes }\end{array}$ & Política contable \\
\hline General & 1 & Pequeñas y Medianas Entidades & \\
\hline General & 2 & $\begin{array}{lll}\text { Conceptos } & \text { y } & \text { Principios } \\
\text { Generales } & & \end{array}$ & \multirow{2}{*}{$\begin{array}{l}\text { Preparación y } \\
\text { Presentación de Estados } \\
\text { Financieros }\end{array}$} \\
\hline General & 3 & $\begin{array}{l}\text { Presentación de Estados } \\
\text { Financieros }\end{array}$ & \\
\hline
\end{tabular}




\begin{tabular}{|c|c|c|c|}
\hline $\begin{array}{l}\text { Elemento de los } \\
\text { estados } \\
\text { financieros }\end{array}$ & Sección & $\begin{array}{c}\text { Normas internacionales de } \\
\text { información financiera } \\
\text { Para las pymes }\end{array}$ & Política contable \\
\hline $\begin{array}{c}\text { Activo, Pasivo, } \\
\text { Patrimonio }\end{array}$ & 4 & Estado de Situación Financiera & \\
\hline $\begin{array}{l}\text { Ingresos, Costos, } \\
\text { Gastos }\end{array}$ & 5 & $\begin{array}{l}\text { Estado del Resultado Integral y } \\
\text { Estado de Resultados }\end{array}$ & \\
\hline General & 6 & $\begin{array}{lccc}\text { Estado de } & \text { Cambios en el } \\
\text { Patrimonio } & \text { y } & \text { Estado de } \\
\text { Resultados } & y & \text { Ganancias } \\
\text { Acumuladas } & & \end{array}$ & \\
\hline General & 7 & Estado de Flujos de Efectivo & \\
\hline General & 8 & Notas a los Estados Financieros & \\
\hline General & 10 & $\begin{array}{l}\text { Políticas Contables, } \\
\text { Estimaciones y Errores }\end{array}$ & \\
\hline Activo, Pasivo & 11 & $\begin{array}{l}\text { Instrumentos Financieros } \\
\text { Básicos }\end{array}$ & Instrumentos Financieros \\
\hline Activo & 13 & Inventarios & Inventarios \\
\hline Activo & 16 & Propiedades de Inversión & Propiedades, Planta y \\
\hline Activo & 17 & Propiedades, Planta y Equipo & Equipo \\
\hline Activo & 18 & $\begin{array}{l}\text { Activos Intangibles Distintos de } \\
\text { la Plusvalía }\end{array}$ & Activos Intangibles \\
\hline
\end{tabular}

\begin{tabular}{cclllll}
$\begin{array}{c}\text { Activo, Pasivo, } \\
\text { Ingresos, Gastos }\end{array}$ & 20 & Arrendamientos & Arrendamientos & \\
\hline Ingresos & 23 & $\begin{array}{l}\text { Ingresos de Actividades } \\
\text { Ordinarias }\end{array}$ & Ingresos & \\
\hline Gastos & 25 & $\begin{array}{l}\text { Costos por Prestamos } \\
\text { Acterioro del Valor de los } \\
\text { Activos }\end{array}$ & & Deterioro & \\
\hline Pasivo, Gastos & 27 & Beneficios a los Empleados & $\begin{array}{l}\text { Beneficios a } \\
\text { Empleados }\end{array}$ & los \\
\hline
\end{tabular}




\begin{tabular}{ccll}
\hline $\begin{array}{c}\text { Elemento de los } \\
\text { estados } \\
\text { financieros }\end{array}$ & Sección & $\begin{array}{c}\text { Normas internacionales de } \\
\text { información financiera } \\
\text { Gastos, Pasivos }\end{array}$ & \multicolumn{1}{c}{$\begin{array}{l}\text { Para las pymes } \\
\text { Política contable }\end{array}$} \\
General & 32 & $\begin{array}{l}\text { Impuesto a las Ganancias } \\
\text { Hechos Ocurridos después del }\end{array}$ & Impuestos \\
Periodo sobre el que se Informa & Hechos Posteriores \\
General & 35 & $\begin{array}{l}\text { Transición a la NIIF para las } \\
\text { PYMES }\end{array}$ & Adopción por Primera \\
\hline
\end{tabular}




\section{Política contable para la preparación y presentación de estados financieros}

\subsection{Objetivo}

Definir las bases para la presentación de los estados financieros de propósito general de COMERCILIZADORA ALLCOMPUTER SAS, en adelante la Compañía, siguiendo los requerimientos generales de presentación, las directrices para determinar su estructura y los requisitos mínimos sobre su contenido establecidos en la Normativa NIIF, para asegurar que los mismos sean comparables, tanto con los estados financieros de la misma compañía correspondientes a periodos anteriores, como con los de otras Entidades.

\subsection{Alcance}

Esta política contable ha sido elaborada con base a los estados financieros de propósito de información general, conforme a las Normas Internacionales de Información Financiera para Pequeñas y Medianas Entidades, NIIF para las PYMES:

- Estados Financieros Adopción por Primera Vez:

- Estado de Situación Financiera de Apertura (ESFA)

- Estado de Comparación Patrimonial

- Estado de Revelaciones 
- Estados Financieros Posteriores:

- Estado de Situación Financiera

- Estado de Resultados

- Estado de Cambios en el Patrimonio

- Estado de Flujo de Efectivo

- Estado de Revelaciones

Los estados financieros se prepararán de acuerdo con las Normas Internaciones de Información Financiera para Pequeñas y Medianas Entidades, NIIF para las PYMES, emitidas por el International Accounting Standards Board (IASB), las disposiciones del Direccionamiento Estratégico del Consejo Técnico de la Contaduría Pública, y a las funciones que sobre este ámbito de aplicación son asumidas por las Entidades de Vigilancia y Control.

En la preparación de estados financieros se utilizan determinadas estimaciones contables, para cuantificar los activos, pasivos, ingresos y gastos.

Las estimaciones y criterios usados son anualmente evaluados y se basan en la experiencia histórica y otros factores, incluyendo la expectativa de ocurrencia de eventos futuros que se consideran razonables de acuerdo con las circunstancias.

Las estimaciones se realizan en función de la mejor información disponible en la fecha de emisión de los estados financieros. Si ocurren, es posible que los acontecimientos que puedan tener lugar en el futuro y obliguen a modificarlas en futuros ejercicios, se trataran de forma prospectiva, reconociendo los efectos del cambio de estimación de los correspondientes estados financieros futuros. 


\subsection{Normativa Aplicable}

Las bases para la preparación de los estados financieros de COMERCILIZADORA ALLCOMPUTER SAS, se encuentran sustentadas bajo las siguientes Secciones NIIF para PYMES:

Sección 1, Pequeñas y Medianas Entidades

Sección 2, Conceptos y Principios Generales

Sección 3, Presentación de estados Financieros

Sección 4, Estado de Situación Financiera

Sección 5, Estado del Resultado Integral y Estado de Resultados

Sección 6, Estado de Cambios en el Patrimonio y Estado de Resultados y Ganancias Acumuladas

Sección 7, Estado de Flujos de Efectivo

Sección 8, Notas a los estados Financieros

Sección 10, Políticas Contables, Estimaciones y Errores

Sección 30, Conversión de la Moneda Extranjera

Sección 35, Transición a la NIIF para las Pymes

\subsection{Definiciones}

Estados financieros: representación estructurada de la situación financiera, el rendimiento financiero y los flujos de efectivo de la Compañía. 
Estados financieros con propósito de información general: son aquellos que tienen como propósito atender las necesidades generales de información financiera de los usuarios que no están en posición para requerir que la Compañía prepare informes a la medida de sus propias necesidades de información.

Fecha sobre la que se informa: fecha final del último periodo cubierto por los estados financieros presentados, o por un informe intermedio.

Activo: recurso controlado por la Compañía, como resultado de sucesos pasados, del que se espera obtener, en el futuro, beneficios económicos

Pasivo: obligación presente de la Compañía, surgida a raíz de sucesos pasados, a cuyo vencimiento y para cancelarla, se espera desprenderse de recursos que conllevan beneficios económicos.

Patrimonio: participación residual en los activos de la Compañía, una vez deducidos todos los pasivos. El patrimonio está formado por el conjunto de bienes, derechos y obligaciones pertenecientes a la Compañía, y que constituyen los medios económicos y financieros a través de los cuales ésta puede cumplir con sus fines sociales.

Ingreso: incremento en los beneficios económicos, producidos a lo largo del periodo sobre el que se informa, que dan como resultado aumento del patrimonio. No están relacionados con los aportes de los socios.

Gasto: decrementos en los beneficios económicos, producidos a lo largo del periodo contable, que dan como resultado disminución del patrimonio. No están relacionados con distribuciones a los socios por concepto de dividendos.

Estimación: son partidas de los estados financieros que no pueden ser cuantificadas con precisión; corresponde a la valoración de activos y pasivos que se produce tras la evaluación de la 
situación actual del elemento, así como de los beneficios futuros esperados y de las obligaciones asociadas con los activos y pasivos correspondientes. Los cambios y las estimaciones contables son el resultado de una nueva información o de un nuevo acontecimiento, en consecuencia, no son corrección de errores.

El efecto de una estimación contable será reconocido prospectivamente incluyéndolo en el resultado:

- Del periodo en que tiene el lugar el cambio si este afecta solo ese periodo; o

- Del periodo del cambio y periodos futuros, si el cambio afecta a todos ellos.

Las estimaciones no harán parte del manual de políticas contables, se llevarán a un memorando técnico el cual deberá ser actualizado anualmente según la revisión de estas por parte de la Compañía.

Los cambios en estimaciones o el mantenimiento de las adoptadas inicialmente, deberán ser reportadas en el nuevo memorando técnico y este será parte integral del grupo de estados financieros de adopción por primera vez y de estados financieros posteriores, es decir tiene vigencia de un año.

Re expresión retroactiva: consiste en corregir el reconocimiento, valoración e información a revelar, de los valores de los elementos de los estados financieros, desde la fecha en que se cometió un error, con el objetivo de actualizar la información contable y financiera errónea.

Aplicación retroactiva: consiste en aplicar un cambio de política contable a transacciones, otros eventos y condiciones, como si ésta se hubiera aplicado siempre.

Aplicación prospectiva: trata para nuevas políticas contables y cambios en estimaciones contables; consiste en reconocer y revelar las novedades a partir de la fecha del cambio, es decir 
la información no se re expresa, sino que el efecto del cambio es reconocido en el periodo actual y futuros.

Impracticable: la aplicación de un requerimiento es impracticable cuando la Compañía no pueda ejecutarlo, tras efectuar todos los esfuerzos razonables para hacerlo.

Materialidad (o Importancia Relativa): este principio se refiere a la relativa significación o merito que pueda tener un hecho económico, la contabilidad debe reconocer y presentar estos hechos de acuerdo a su importancia relativa. Un hecho económico es relevante o importante, cuando debido a su naturaleza o cuantía, su conocimiento o desconocimiento, teniendo en cuenta las circunstancias que lo rodean, puede alterar significativamente las decisiones económicas de los usuarios de la información financiera de la Compañía.

Las omisiones o inexactitudes de partidas son materiales o tienen importancia relativa si pueden, individualmente o en su conjunto, influir en las decisiones económicas tomadas por los usuarios sobre la base de la información financiera que la Compañía especifica. Los estados financieros deben tener un conocimiento razonable de la actividad económica y del mundo de los negocios, así como de su contabilidad.

La materialidad depende de la magnitud (cuantía) y la naturaleza (calidad) de la omisión o inexactitud, enjuiciada en función de las circunstancias particulares en que se hayan producido. El factor determinante podrá ser la magnitud o la naturaleza de la partida, o una combinación de ambas.

Notas o Revelaciones: contienen información adicional a la presentada en el estado de situación financiera, estado integral de resultados, estado de cambios en el patrimonio y estado de flujos de efectivo. Las notas proporcionan descripciones narrativas o análisis de partidas presentadas en esos estados financieros e información sobre partidas que no ameritan ser reconocidas en esos estados financieros. 
Otros resultados integrales: también se conoce como ingresos y gastos no realizados; son resultados no realizados manejados en el patrimonio y muestran flujos futuros de

Utilidades; por tanto, comprende todas aquellas partidas de resultado (ingresos y gastos), incluyendo ajustes por reclasificación, que no se reconocen en el estado de resultados de acuerdo con lo permitido en las NIIF.

Los compontes de otros resultados integrales incluyen:

- Ganancias y pérdidas actuariales en planes de beneficios definidos a los empleados, según Sección 28 Beneficios a Empleados

- Ganancias y pérdidas producidas por la conversión de los estados financieros de un negocio en el extranjero, véase la Sección 30 Conversión de la Moneda Extranjera

- La parte efectiva de ganancias y pérdidas en instrumentos de cobertura en una cobertura del flujo de efectivo, según Sección 12 Otros Temas Relacionados con los Instrumentos Financieros.

Propietarios: son poseedores de instrumentos clasificados como patrimonio.

Resultado: es el ingreso total menos gastos excluyendo los componentes de otros resultados integrales.

Ajustes por reclasificaciones: son los montos reclasificados en utilidad o pérdida en el período actual que fueron reconocidos como otros resultados integrales en el período actual o anterior.

Resultados integrales totales: es el cambio en el patrimonio durante un período resultante de transacciones y otros hechos distintos a aquellos cambios que resulten de transacciones con los propietarios, en su calidad de tales. Comprenden todos los componentes del "resultado" y de "otros resultados integrales". 


\subsection{Características Generales}

\subsubsection{Bases de Presentación}

Los estados financieros de COMERCILIZADORA ALLCOMPUTER SAS, deberán presentar razonablemente la situación financiera y el rendimiento financiero, así como los flujos de efectivo de la Compañía. Esta presentación razonable requiere la presentación fidedigna de los efectos de las transacciones, así como de otros sucesos y condiciones, de acuerdo con las definiciones y los criterios de reconocimiento de activos, pasivos, ingresos y gastos establecidos en los Conceptos y Principios Generales.

Los estados financieros de COMERCILIZADORA ALLCOMPUTER SAS, se presentarán según las Normas Internacionales de Información Financiera para Pequeñas y Medianas Entidades, NIIF para las PYMES, y representarán la adopción integral, explícita y sin reservas de las referidas normas internacionales, las que serán aplicadas de manera uniforme.

\subsubsection{Hipótesis de Negocio en Marcha}

Al elaborar los estados financieros, la Administración de COMERCILIZADORA ALLCOMPUTER SAS, evaluará la capacidad que tiene la Compañía para continuar en funcionamiento. Los estados financieros se prepararán y presentarán bajo la hipótesis de negocio en marcha, lo cual significa que no existe la intención de liquidar la Compañía, o hacer cesar sus operaciones. 
Cuando existan incertidumbres importantes, relativas a eventos o condiciones que puedan aportar dudas significativas sobre la posibilidad de que COMERCILIZADORA ALLCOMPUTER SAS, siga funcionando normalmente, se procederá a revelarlas en los estados financieros.

\subsubsection{Base Contable de Causación}

COMERCILIZADORA ALLCOMPUTER SAS, elaborará sus estados financieros, excepto en lo relacionado con la información sobre flujos de efectivo, utilizando la base contable de causación, es decir que causará los hechos y transacciones en el momento en que suceden y no cuando se pagan.

Esta base conlleva a que COMERCIALIZADORA ALLCOMPUTER S.A.S, reconozca partidas como activos, pasivos, patrimonio, ingresos y gastos, cuando satisfagan las definiciones y los criterios de reconocimiento previstos para tales elementos en los Conceptos y Principios Generales.

\subsubsection{Materialidad (Importancia Relativa) y Agrupación de Datos}

La presentación de los hechos económicos se hace de acuerdo con su materialidad o importancia relativa. Para efectos de revelación, una transacción, hecho u operación es material cuando, debido a su cuantía o naturaleza, su conocimiento o desconocimiento, considerando las circunstancias que lo rodean, incide en las decisiones que se puedan tomar o en las evaluaciones que puedan realizar los usuarios de la información contable. 
Los estados financieros son el producto del proceso de un gran número de transacciones y otros sucesos que se agrupan por clases de acuerdo con su naturaleza o su función. La etapa final del proceso de agregación y clasificación es la presentación de los datos condensados y clasificados, que constituyen las partidas de los estados financieros.

\subsubsection{Compensación de Activos y Pasivos e Ingresos y Gastos}

COMERCIALIZADORA ALLCOMPUTER S.A.S, no compensará activos con pasivos o ingresos con gastos, informará por separado sobre sus activos y pasivos, e ingresos y gastos. Excepto lo correspondiente a activos y pasivos por impuestos corrientes y diferidos.

La compensación en el estado de situación financiera o en el estado del resultado integral, limita la capacidad de los usuarios para comprender las transacciones y otros sucesos y condiciones que se hayan producido, así como para evaluar los flujos futuros de efectivo de la Compañía, excepto cuando la compensación sea un reflejo del fondo de la transacción o suceso.

\subsubsection{Frecuencia de la Información}

COMERCIALIZADORA ALLCOMPUTER S.A.S, presentará un juego completo de estados financieros (incluyendo información comparativa) al menos anualmente, con corte al 31 de diciembre.

Cuando la Compañía cambie el cierre del periodo sobre el que informa y presente los estados financieros para un periodo contable superior o inferior a un año, revelará, además del periodo cubierto por los estados financieros: 
- La razón para utilizar un periodo de duración inferior o superior, y

- El hecho de que los valores presentados en los estados financieros no son totalmente comparables.

\subsubsection{Información Comparativa}

COMERCIALIZADORA ALLCOMPUTER S.A.S, revelará información comparativa respecto del periodo anterior para todos los valores incluidos en los estados financieros del periodo corriente, incluyendo datos comparativos para la información descriptiva y narrativa, cuando esto sea relevante para la comprensión de los estados financieros del periodo corriente.

Cuando COMERCIALIZADORA ALLCOMPUTER S.A.S, aplique una política contable retroactivamente o realice una re-expresión retroactiva de partidas en sus estados financieros, o cuando reclasifique partidas en sus estados financieros, presentará como mínimo, tres estados de situación financiera y las notas relacionadas.

La Compañía presentará estados de situación financiera:

- Al cierre del periodo corriente

- Al cierre del periodo anterior (que es el mismo que el del comienzo del periodo corriente)

- Al principio del primer periodo comparativo (efecto de las re-expresiones)

\subsubsection{Uniformidad en la Presentación}

COMERCIALIZADORA ALLCOMPUTER S.A.S, mantendrá la presentación y clasificación de las partidas en los estados financieros de un periodo a otro, a menos que: 
- Tras un cambio en la naturaleza de las actividades de COMERCIALIZADORA ALLCOMPUTER S.A.S, o una revisión de sus estados financieros, se defina que sería más apropiada otra presentación o clasificación.

- La Normativa NIIF para PYMES requiera un cambio en la presentación.

Sólo se cambiará la presentación de los estados financieros de la Compañía, cuando dicho cambio proporcione información fiable y más relevante para los usuarios de los estados financieros, y la nueva estructura tenga visos de continuidad, de modo que la comparabilidad no quede perjudicada. Cuando se realicen estos cambios en la presentación, se deberá reclasificar su información comparativa.

\subsubsection{Moneda Funcional (Legal) y de Presentación}

Moneda funcional (legal) es la moneda del entorno económico principal en el que opera la Compañía, cual es aquél en el que ésta genera y emplea el efectivo principalmente. La moneda en la que se presentan los estados financieros es la moneda de presentación.

COMERCIALIZADORA ALLCOMPUTER S.A.S, utilizará el Peso Colombiano como moneda de presentación de sus estados financieros, la cual se ha determinado considerando:

- La moneda que influye fundamentalmente en los precios de venta

- La moneda del país que determine fundamentalmente los precios de venta

- La moneda que influye fundamentalmente en los costos de personal, insumos, y otros costos de producción de bienes o servicios

- La moneda en la cual se generan los fondos de las actividades de financiación 
- La moneda en que se reciben los montos cobrados por las actividades de operación

\subsubsection{Transacciones y Saldos}

Las transacciones en moneda extranjera se convertirán a la moneda funcional de reporte utilizando los tipos de cambio vigentes en las fechas de las transacciones. Las pérdidas y ganancias en moneda extranjera que resultan de la liquidación de estas transacciones y de la conversión a los tipos de cambio de cierre de los activos y pasivos monetarios denominados en moneda extranjera, se reconocen en el estado de resultados.

\subsection{Presentación e Identificación de los Estados Financieros}

COMERCIALIZADORA ALLCOMPUTER S.A.S, presentará el siguiente conjunto de estados financieros:

- Estado de Situación Financiera al final del periodo

- Estado de Resultado Integral del periodo

- Estado de Cambios en el Patrimonio del periodo

- Estado de Flujo de Efectivo del periodo

- Estado de Revelaciones del periodo

Cada estado financiero se identificará claramente, y se distinguirá de cualquier otra información publicada en el mismo documento, mostrando la siguiente información en lugar destacado: 
- El nombre de la Compañía u otra forma de identificación de la misma, así como los cambios relativos a dicha información desde el final del periodo precedente; “COMERCIALIZADORA ALLCOMPUTER S.A.S,”

- Si los estados financieros presentados son Individuales o Consolidados; "Estados Financieros Individuales"

- La fecha del cierre del periodo sobre el que se informa o el periodo cubierto por los estados financieros; ejemplo: "31 de diciembre de 2014"

- La moneda de presentación; "Peso Colombiano"

- El grado de redondeo practicado al presentar las cifras de los estados financieros; "cifras expresadas en pesos"

\subsection{Estado de Situación Financiera}

COMERCIALIZADORA ALLCOMPUTER S.A.S, presentará en el estado de situación financiera los activos, pasivos y patrimonio al final del periodo sobre el que se informa, mostrando partidas adicionales, encabezados y subtotales, cuando sea relevante para comprender la situación financiera; y clasificando los activos y pasivos en corrientes y no corrientes

Como mínimo, el Estado de Situación Financiera de COMERCIALIZADORA ALLCOMPUTER S.A.S, incluirá partidas que presenten los siguientes valores:

- Efectivo y equivalentes al efectivo

- Deudores comerciales y otras cuentas por cobrar

- Activos financieros

- Inventarios

- Propiedades, planta y equipo 
- Propiedades de inversión

- Activos intangibles

- Acreedores comerciales y otras cuentas por pagar

- Pasivos Financieros

- Activos y pasivos por impuestos corrientes

- Activos y pasivos por impuestos diferidos

- Provisiones

- Patrimonio

\section{Distinción entre Partidas Corrientes y No Corrientes}

COMERCIALIZADORA ALLCOMPUTER S.A.S, presentará sus activos y pasivos como corrientes y no corrientes, atendiendo su grado de liquidez, como categorías separadas en su estado de situación financiera. Por tanto, revelará el valor esperado a recuperar o a cancelar después de los doce (12) meses, para cada partida del activo o pasivo que combine valor a recuperar o a cancelar:

- Dentro de los doce meses siguientes después del periodo sobre el que se informa

- Después de doce meses tras esa fecha.

\section{Activos Corrientes}

COMERCIALIZADORA ALLCOMPUTER S.A.S, clasificará un activo como corriente cuando:

- Espere realizar el activo, o tenga la intención de venderlo o consumirlo en su ciclo normal de operación

- Mantenga el activo principalmente con fines de negociación 
- Espere realizar el activo dentro de los doce meses siguientes después del periodo sobre el que se informa

- El activo es efectivo o equivalente al efectivo, a menos que éste se encuentre restringido y no pueda ser intercambiado ni utilizado para cancelar un pasivo por un ejercicio mínimo de doce meses después del ejercicio sobre el que se informa.

Todos los demás activos se clasificarán como no corrientes.

\section{Pasivos Corrientes}

COMERCIALIZADORA ALLCOMPUTER S.A.S, clasificará un pasivo como corriente cuando:

- Espere liquidar el pasivo en su ciclo normal de operación

- Mantenga el pasivo principalmente con fines de negociación

- El pasivo deba liquidarse dentro de los doce meses siguientes a la fecha del periodo sobre el que se informa

- No tenga un derecho incondicional para aplazar la cancelación del pasivo durante, al menos, los doce meses siguientes a la fecha del periodo sobre el que se informa.

Todos los demás pasivos se clasificarán como no corrientes.

\section{Información a Presentar en el Estado de Situación Financiera o en las Revelaciones}

COMERCIALIZADORA ALLCOMPUTER S.A.S, revelará, ya sea en el estado de situación financiera o en las revelaciones, sub clasificaciones adicionales de las partidas presentadas, clasificadas de una manera que sea apropiada para las operaciones de la Compañía.

El detalle suministrado en las sub clasificaciones dependerá de los requerimientos de las NIIF para PYMES, así como del tamaño, la naturaleza y la función de los valores afectados. 
COMERCIALIZADORA ALLCOMPUTER S.A.S, presentará en su estado de situación financiera, entre otras, las siguientes sub clasificaciones:

- Efectivo y Equivalentes al Efectivo
○ Caja

- Cuentas bancarias (corrientes y de ahorros)

○ Inversiones (equivalentes al efectivo)

- Activos Financieros

- Inversiones

- Deudores Comerciales y Otras Cuentas por Cobrar
○ Deudores clientes
- Cuentas por cobrar a accionistas
- Cuentas por cobrar a trabajadores
○ Deudores varios
- Anticipos y avances entregados
○ Depósitos

- Inventarios
○ Importaciones
- Materia prima
○ Producto terminado

- Activos por Impuestos Corrientes
- Anticipos de impuestos
- Retenciones a favor
- Auto retenciones 
- Saldos a favor

- Activos por Impuestos Diferidos

- Propiedades, Planta y Equipo

- Construcciones y edificaciones

- Maquinaria y equipo

○ Muebles y equipo de oficina

- Equipo de computación y comunicación

- Flota y equipo de transporte

○ Depreciaciones

- Activos Intangibles

○ Software

- Gastos Pagados por Anticipado

○ Seguros

- Mantenimientos

- Pasivos Financieros

○ Obligaciones financieras

- Acreedores Comerciales y otras cuentas por pagar

○ Proveedores

- Costos y gastos por pagar

- Cuentas por pagar a accionistas

○ Dividendos por pagar

- Retenciones fiscales por pagar

- Retenciones de nómina por pagar 
- Acreedores varios

- Pasivos por Impuestos Corrientes

- Impuestos por pagar

- Pasivos por impuestos diferidos

- Beneficios a los Empleados

- Salarios por pagar

- Cesantías

- Intereses a las cesantías

- Prima de servicios

- Vacaciones

- Aportes de nomina

- Otros Pasivos

- Anticipos y avances recibidos

- Provisiones

- Patrimonio

○ Capital social

○ Reservas

○ Resultados del ejercicio

- Resultados de ejercicios anteriores 


\subsection{Estado del Resultado Integral}

Dentro de este estado financiero COMERCIALIZADORA ALLCOMPUTER S.A.S, presentará todas las partidas de ingresos, costos y gastos reconocidas en un periodo, en un Único Estado del Resultado Integral.

Los efectos de corrección de errores y cambios en políticas contables, se presentan como ajustes retroactivos de periodos anteriores y no como parte del resultado en el periodo en el que surgen.

Se reconocen tres tipos de otro resultado integral como parte del resultado integral total, fuera del resultado, cuando se producen:

- Ganancias y pérdidas que surjan de la conversión de estados financieros de un negocio en el extranjero (Sección 30 Conversión de Moneda Extranjera).

- Ganancias y pérdidas actuariales (Sección 28 Beneficios a los Empleados).

- Cambios en los valores razonables de los instrumentos de cobertura (Sección 12 Otros Temas relacionados con los Instrumentos Financieros).

\section{Información a Presentar en el Estado del Resultado Integral o en las Revelaciones}

COMERCIALIZADORA ALLCOMPUTER S.A.S, preparará este estado financiero utilizando una clasificación basada en la Función de los Gastos, en la cual los gastos se clasifican de acuerdo con su función como parte del costo de las ventas o, por ejemplo, de los costos de actividades de administración y producción.

Cuando las partidas de ingreso o gasto son materiales, COMERCIALIZADORA ALLCOMPUTER S.A.S, revelará de forma separada información sobre su naturaleza y valor. 
COMERCIALIZADORA ALLCOMPUTER S.A.S, presentará en su estado de resultado integral, entre otras, las siguientes sub clasificaciones:

- Ingresos de Actividades Ordinarias

○ Fabricación y comercialización de productos en aluminio

- Fabricación y comercialización de accesorios

- Servicio de temple de vidrio

- Costos de Producción

- Mano de obra

- Materias primas

- Otros costos de producción

- Gastos de Operación

○ Gastos de administración

- Gastos de ventas

- Otros Ingresos

○ Financieros

- Otros ingresos

- Otros Gastos

- Financieros

- Gastos diversos

- Impuestos 


\subsection{Estado de Cambios en el Patrimonio}

COMERCIALIZADORA ALLCOMPUTER S.A.S, presentará un estado de cambios en el patrimonio que muestre:

- El resultado integral total del periodo

- Para cada componente de patrimonio, los efectos de la aplicación retroactiva o la reexpresión retroactiva reconocidos por cambios en políticas o corrección de errores

- Para cada componente del patrimonio, una conciliación entre los valores en libros, al inicio y al final del periodo, revelando por separado los cambios resultantes de:

- El Resultado del periodo

- Cada partida de otro resultado integral

○ Los valores de las inversiones por los accionistas, de los dividendos y otras distribuciones hechas a estos

○ Cambios en la constitución o disminución de reservas

Al efectuar cambios en las políticas contables, se requiere realizar ajustes retroactivos, en la medida en que sean practicables, excepto cuando las disposiciones transitorias de alguna NIIF para Pymes requieran otra cosa. La Sección 10 también requiere que la re- expresión para corregir errores se efectúe retroactivamente, en la medida en que sea practicable. Los ajustes y las reexpresiones retroactivas no son cambios en el patrimonio sino ajustes al saldo inicial de las ganancias acumuladas, excepto cuando alguna NIIF para PYMES requiera el ajuste retroactivo de otro componente de patrimonio. Estos ajustes requieren la revelación de información en el estado de cambios en el patrimonio, sobre los ajustes totales en cada uno de sus componentes derivados 
de los cambios en las políticas contables y, por separado, de la corrección de errores. Se revelará información sobre estos ajustes para cada periodo anterior y para el principio del periodo.

\subsection{Estado de Flujos de Efectivo}

La información sobre los flujos de efectivo de COMERCIALIZADORA ALLCOMPUTER S.A.S, proporcionará a los usuarios de los estados financieros, una base para evaluar la capacidad de la Compañía para generar efectivo y equivalentes al efectivo; e informará acerca de los flujos de efectivo generados y utilizados durante el ejercicio económico, clasificándolos en actividades de operación, inversión y financiación.

\section{Actividades de Operación}

El valor de los flujos de efectivo procedentes de actividades de operación de COMERCIALIZADORA ALLCOMPUTER S.A.S, es un indicador clave de la medida en las que estas actividades han generado fondos líquidos suficientes para reembolsar los préstamos, mantener la capacidad de operación la Compañía, pagar dividendos y realizar nuevas inversiones sin recurrir a fuentes externas de financiación. La información acerca de los componentes específicos de los flujos de efectivo de las actividades de operación es útil, junto con otra información, para pronosticar los flujos de efectivo futuros de dichas actividades.

Los flujos de efectivo procedentes de las actividades de operación de COMERCIALIZADORA ALLCOMPUTER S.A.S, se derivan fundamentalmente de las transacciones que constituyen la principal fuente de ingresos ordinarios de la Compañía. Por tanto, proceden de las operaciones y otros sucesos relevantes para la determinación de las pérdidas o 
ganancias netas. También se incluyen otras actividades que no puedan ser clasificadas como de inversión o financiación.

Los flujos de efectivo procedentes de actividades de operación se presentarán utilizando el Método Indirecto, según el cual el resultado del ejercicio se ajusta, en términos netos, por los efectos de los cambios durante el periodo en los inventarios y en los derechos por cobrar y obligaciones por pagar de las actividades de operación, las partidas no monetarias como depreciación, provisiones, impuestos diferidos; y otras partidas cuyos efectos monetarios se relacionen con inversión y financiación.

\section{Actividades de Inversión}

Los flujos de efectivo procedentes de las actividades de inversión representan la medida en la cual se han hecho desembolsos por causa de los recursos económicos que van a producir ingresos y flujos de efectivo en el futuro.

Las actividades de inversión incluyen la compra o adquisición, enajenación o disposición por otros medios de activos no corrientes, retornos de préstamos y otras inversiones no incluidas en el efectivo y sus equivalentes a efectivo.

\section{Actividades de Financiación}

Es importante la presentación separada de los flujos de efectivo procedentes de actividades de financiación, puesto que resulta útil al realizar la proyección de necesidades de efectivo para cubrir compromisos de COMERCIALIZADORA ALLCOMPUTER S.A.S,

Los flujos de efectivo por actividades de financiación son aquellos que le permiten a la Compañía apalancarse financieramente. Esta adquisición de recursos puede provenir de terceros y genera un cambio en el tamaño y composición del patrimonio y de los pasivos, específicamente 
en las obligaciones financieras, ya que comprenden entradas y salidas de flujos relacionados con la obtención, mantenimiento y amortización de deudas y de las fuentes de financiación.

\section{Flujos de Efectivo en Moneda Extranjera}

Los flujos de efectivo procedentes de transacciones en moneda extranjera se convertirán a la moneda funcional de COMERCIALIZADORA ALLCOMPUTER S.A.S, aplicando al valor en moneda extranjera, el tipo de cambio entre ambas monedas en la fecha en que se produjo cada flujo en cuestión.

Las pérdidas o ganancias no realizadas, por diferencias de cambio en moneda extranjera, no producen flujos de efectivo. Sin embargo, el efecto que la variación en los tipos de cambio tiene sobre el efectivo y los equivalentes al efectivo, mantenidos o debidos, en moneda extranjera, será objeto de presentación en el estado de flujos de efectivo para permitir la conciliación entre las existencias de efectivo al principio y al final del ejercicio.

\section{Información a Presentar en el Estado de Flujo de Efectivo o en las Revelaciones}

COMERCIALIZADORA ALLCOMPUTER S.A.S, revelará los componentes de la partida de efectivo y equivalentes al efectivo, y deberá presentar una conciliación de los saldos que figuran en su estado de flujos de efectivo con las partidas equivalentes en el estado de situación financiera.

Así mismo, revelará cualquier valor significativo de sus saldos de efectivo y equivalentes al efectivo que no esté disponible para ser utilizado.

\subsection{Estado de Revelaciones}

Las notas o revelaciones contienen información adicional a la presentada en el estado de situación financiera, estado del resultado integral, estado de cambios en el patrimonio y estado de flujos de 
efectivo; suministran descripciones narrativas o desagregaciones de partidas presentadas en esos estados financieros e información sobre partidas que no cumplen las condiciones para ser reconocidas en ellos.

El estado de revelaciones a los estados financieros, de COMERCIALIZADORA ALLCOMPUTER S.A.S, se presentará según la siguiente estructura:

- Forma legal de la Compañía, domicilio, país en que se ha constituido, dirección de su sede social o domicilio principal, vigencia

- Una descripción de la naturaleza de las operaciones de la Compañía, así como de sus principales actividades

- Una declaración de cumplimiento con las NIIF para las PYMES

- Información acerca de las bases para la preparación de los estados financieros

- Las políticas contables utilizadas que sean relevantes para la comprensión de los estados financieros:

○ La base de medición utilizada para la elaboración de los estados financieros

○ Las otras políticas contables que no estén requeridas por las NIIF para las PYMES, pero utilizadas por la Compañía, al igual que los juicios que afecten significativamente los valores reconocidos en los estados financieros; que sean relevantes para la comprensión de los estados financieros.

- Información de respaldo para las partidas presentadas en los estados de situación financiera y del resultado integral, en los estados de cambios en el patrimonio y de flujos de efectivo, en el orden en que se presenta cada estado y cada partida.

- Otra información a revelar, incluyendo: 
○ Pasivos contingentes y compromisos contractuales no reconocidos; e incertidumbres significativas en las estimaciones al final del periodo que pudieran ocasionar ajustes relevantes en el valor en libros de los activos o pasivos dentro del periodo contable siguiente.

- Revelaciones de información no financiera, como los objetivos y políticas de gestión del riesgo financiero. 


\section{Política contable de instrumentos financieros}

\subsection{Objetivo}

Definir los criterios de reconocimiento, medición, baja en cuentas, presentación e información a revelar que COMERCIALIZADORA ALLCOMPUTER S.A.S, en adelante la Compañía, aplicará a los instrumentos financieros, con el fin de presentar información útil, fiable y relevante en los estados financieros financieros para la evaluación y proyección de los flujos de efectivo, la relevancia de estos en la situación financiera y rendimiento financiero de la Compañía, y la naturaleza y alcance de los riesgos procedentes de los instrumentos financieros y la forma de gestionarlos.

\subsection{Alcance}

Esta política contable ha sido elaborada con base en los instrumentos financieros con que cuenta COMERCIALIZADORA ALLCOMPUTER S.A.S, a la fecha de emisión de la misma, y aplicará a la contabilización de los siguientes:

- Efectivo y equivalentes al efectivo

- Caja general y caja menor en moneda funcional

- Cuentas bancarias corrientes y de ahorro en moneda funcional

○ Inversiones en títulos valores (máximo 90 días) 
- Activos financieros (Inversiones)

○ Otras Inversiones

- Cuentas comerciales por cobrar y otras cuentas por cobrar

○ Deudores clientes

- Cuentas por cobrar a accionistas

- Cuentas por cobrar a trabajadores

○ Reclamaciones

○ Deudores varios

- Gastos pagados por anticipado

- Licencias de software

- Pasivos financieros

$\circ$ Obligaciones financieras

- Cuentas comerciales por pagar y otras cuentas por pagar

○ Proveedores

- Costos y gastos por pagar

- Cuentas por pagar a accionistas

○ Dividendos por pagar

- Retenciones fiscales por pagar

○ Retenciones de nómina por pagar

○ Acreedores varios

Adicionalmente se han integrado los anticipos, que, sin ser instrumentos financieros, pueden ser reconocidos como cuentas por cobrar o cuentas por pagar de la operación: 
- Anticipos entregados

- A proveedores

- A contratistas

- A trabajadores

- Anticipos recibidos

Ingresos recibidos por anticipado

○ Clientes

\subsection{Normativa Aplicable}

La elaboración de esta política contable para los instrumentos financieros de COMERCIALIZADORA ALLCOMPUTER S.A.S, se sustenta en las siguientes normas:

Sección 3, Presentación de Estados Financieros

Sección 7, Estado de Flujos de Efectivo

Sección 10, Políticas Contables, Estimaciones y Errores

Sección 11, Instrumentos Financieros Básicos

Sección 12, Otros Temas Relacionados con los Instrumentos Financieros

Sección 27, Deterioro del Valor de los Activos

Sección 30, Conversión de la Moneda Extranjera

\subsection{Definiciones}

Efectivo: comprende los valores disponibles en caja y depósitos bancarios a la vista. 
Equivalentes al Efectivo: son inversiones a corto plazo de gran liquidez, que son fácilmente convertibles en efectivo, estando sujetos a un riesgo poco significativo de cambios en su valor.

Flujos de Efectivo: son las entradas y salidas de efectivo y equivalentes al efectivo.

Caja Menor: es un fondo creado por la Compañía para manejar pequeños desembolsos, asignando a una persona como responsable de su manejo.

Caja General: representa el efectivo que ha entrado o salido a la Compañía, por operaciones comerciales realizadas.

Cuenta Bancaria: es un acuerdo financiero de la Compañía con una entidad bancaria en la cual se registran todos los movimientos de efectivo de la misma.

Cuenta Corriente y de Ahorros: son los depósitos de dinero que sirven de soporte operativo para centralizar las operaciones bancarias habituales de la Compañía, como son los ingresos, los pagos, transferencias y giro de cheques.

Efectivo Restringido: está constituido por depósitos en efectivo o transferencias entre las mismas cuentas a nombre de la Compañía, los cuales puede disponerse, total o parcialmente, tan solo en condiciones o con fines específicos. Para el efecto se requiere generalmente, una cuenta bancaria separada.

Instrumento Financiero: es toda acción contractual que da lugar a un activo financiero (derecho a recibir) en una Compañía y a un pasivo financiero (obligación de pagar) o un instrumento de patrimonio en otra.

Activo financiero: cualquier activo que sea:

- Efectivo

- Un instrumento de patrimonio de otra Compañía

- Un derecho contractual 
- Un contrato que será o podrá ser liquidado utilizando instrumentos de patrimonio propio de la Compañía

Pasivo financiero: es una obligación contractual de entregar efectivo u otro activo financiero a una entidad financiera, o tercero que tenga pactada una tasa de interés.

Valor razonable: es el monto por el que un activo podría ser intercambiado o un pasivo liquidado, reconociendo las condiciones de mercado, entre partes interesadas y debidamente informadas, en una transacción realizada en condiciones de independencia mutua.

Baja en cuentas: es la eliminación de un activo financiero o de un pasivo financiero previamente reconocido en el estado de situación financiera.

Deterioro de valor: se da cuando el valor en libros de un activo es superior a su valor recuperable.

\subsection{Reconocimiento}

Una entidad reconoce un instrumento financiero solo cuando se convierte en una parte, según las cláusulas contractuales del instrumento, es decir cuando adquiera el derecho o la obligación de acuerdo a las condiciones del contrato.

En razón a lo anterior, COMERCIALIZADORA ALLCOMPUTER S.A.S, reconocerá los instrumentos financieros que constituyan cuentas por cobrar o cuentas por pagar, cuando la Compañía haga parte del acuerdo contractual, y, en consecuencia, tenga el derecho legal a recibir, o la obligación legal de pagar. 
Así mismo, un instrumento de patrimonio se reconocerá como activo financiero cuando COMERCIALIZADORA ALLCOMPUTER S.A.S, adquiera el derecho o la titularidad del instrumento.

Las transacciones de efectivo se reconocerán al valor nominal, y las equivalentes al efectivo al valor de adquisición, en la moneda funcional de COMERCIALIZADORA ALLCOMPUTER S.A.S, el Peso Colombiano.

Los saldos en moneda extranjera, se expresarán en la moneda funcional de COMERCIALIZADORA ALLCOMPUTER S.A.S, al tipo de cambio en la fecha de preparación de los estados financieros.

De existir sobregiros bancarios, estos se consideran como actividad de financiación, debido a su condición de exigibilidad por el banco y su reconocimiento será por el saldo que presente cada cuenta bancaria al final del período.

COMERCIALIZADORA ALLCOMPUTER S.A.S, posee los siguientes instrumentos financieros:

\section{Efectivo y Equivalentes al efectivo}

Está conformado por los saldos en caja, entidades bancarias, e inversiones, que se tienen para cumplir compromisos de pago y/o para propósitos de inversión.

Para cumplir con la definición de equivalentes al efectivo, una inversión en el curso normal de la operación deberá tener un corto período de madurez, no más de tres meses desde la fecha de adquisición de la inversión, además de un muy bajo riesgo de alteraciones en su valor y la calificación requerida para ser considerada como tal. El plazo de vencimiento de tres meses se considerará únicamente al momento de adquisición de la inversión. 
Así mismo, para que un recurso sea considerado como un equivalente al efectivo, no sólo debe ser fácilmente convertible y tener un vencimiento a corto plazo, sino que también debe ser considerado por COMERCIALIZADORA ALLCOMPUTER S.A.S, como un medio para la cancelación de pasivos y no como una inversión o para cualquier otro propósito.

Los fondos transferidos entre el efectivo y los equivalentes al efectivo y viceversa no dan lugar a entradas y salidas de efectivo.

En caso de existir fondos de efectivo y equivalentes al efectivo en cuentas de destinación específica, mantenidos en cuentas bloqueadas o en cuentas con restricciones, de manera que el dinero no sea libremente transferible; se deberá evaluar si dichos fondos cumplen la definición de efectivo y equivalentes al efectivo.

La esencia económica de las restricciones se deberá evaluar en cada caso particular, si los depósitos pueden ser usados en el corto plazo, aunque tengan restricciones sobre su uso, se presentarán como efectivo y equivalentes al efectivo; si los recursos no cumplen con los criterios para ser clasificados como efectivo y equivalentes al efectivo, se deberán presentar en una línea separada en el estado de situación financiera, distinguiéndolos claramente de los fondos que sí cumplen tales requisitos. Si los depósitos cumplen los criterios para ser clasificados como efectivo y equivalentes al efectivo, pero su uso está sujeto a restricciones, se requiere la inclusión de comentarios en las revelaciones a los estados financieros explicando dicha restricción.

Las cuentas bancarias para las cuales las entidades financieras obliguen a mantener en ellas un saldo promedio mínimo de forma continua, podrán ser consideradas como efectivo y equivalentes de efectivo, teniendo en cuenta que pueden ser retirados en cualquier momento; sin embargo, si el monto es significativo, será importante considerar la revelación de información sobre el acuerdo. 
Los componentes de efectivo y equivalentes al efectivo de COMERCIALIZADORA ALLCOMPUTER S.A.S, son:

\section{Caja Menor:}

Esta caja comprende un fondo fijo pagos menores que por su cuantía se requiere hacerlos por este medio. Su manejo está bajo la responsabilidad de un funcionario de la oficina principal de la Compañía, con autorización de la Gerencia. Dicho fondo deberá ser legalizado para su respetivo reembolso, de acuerdo al procedimiento interno establecido para su manejo, anexando los soportes de cada pago realizado.

\section{Caja General:}

En razón a las necesidades de operación propias de la Compañía, de realizar transacciones de recaudos y pagos en efectivo, se tienen cajas generales ubicadas en cada planta, es manejada por la parte administrativa de cada punto de producción, con previa autorización de la Gerencia.

\section{Cuentas Bancarias, Corrientes y de Ahorros:}

El control del manejo de las cuentas bancarias lo tiene la Gerencia de la Compañía, son utilizadas para el manejo de las operaciones comerciales en desarrollo de su objeto social.

\section{Inversiones}

Son instrumentos financieros que posee la Compañía con propósitos de inversión, para destinación específica, u otros propósitos que no cumplen las condiciones para ser efectivo y equivalentes al efectivo. En este grupo de activos financieros clasifican las carteras colectivas, inversiones en títulos valores a más de 90 días, participación y derechos en la composición de capital de otras entidades. Se reconocen cuando COMERCIALIZADORA ALLCOMPUTER S.A.S, adquiere el título respectivo que respalda la inversión, por el valor del depósito realizado o monto pagado para su adquisición. 


\section{Deudores Clientes}

Representan los activos financieros originados por la venta de bienes y prestación de servicios por las operaciones normales de la Compañía, específicamente venta de productos de aluminio, accesorios y demás. Regularmente los despachos del producto se hacen con remisión u orden de producción, y la factura de venta se elabora por despachos acumulados en periodos acordados con el cliente. En todo caso, COMERCIALIZADORA ALLCOMPUTER S.A.S, incluirá en este rubro todos los saldos adeudados por esta categoría de deudores, asegurando que representen los derechos que tiene la Compañía, sobre estas transacciones cuando se hayan cedido los riesgos y beneficios asociados a las mismas.

Su reconocimiento en los estados financieros se da cuando se haya realizado la entrega del producto vendido o prestado el servicio. Se reconocerá una cuenta por cobrar por el valor razonable de la transacción, el cual es el valor acordado entre COMERCIALIZADORA ALLCOMPUTER S.A.S, y el cliente, que corresponde al valor de la factura de venta.

\section{Cuentas por Cobrar a Accionistas}

Representan flujos de caja entregados a los accionistas en calidad de anticipo a los dividendos del periodo. Se reconocerá una cuenta por cobrar al accionista al momento de realizarse la operación, por el valor razonable de la transacción.

\section{Cuentas por Cobrar a Trabajadores}

Son préstamos que COMERCIALIZADORA ALLCOMPUTER S.A.S, otorga a sus empleados, los cuales son autorizados por la Gerencia y descontados por nómina. Las condiciones de estos créditos son fijadas en el momento de la transacción y generalmente son a corto plazo. Se firma carta de autorización para descuento por nómina. Se reconoce una cuenta por cobrar al 
empleado por el valor del préstamo otorgado, con el desembolso del dinero y formalización del préstamo.

\section{Reclamaciones}

Corresponde a recursos por recibir de otras entidades por concepto de indemnizaciones, como aseguradoras, entidades de salud y riesgos laborales y otros reclamos.

Para los valores por cobrar a las entidades de salud y riesgos laborales, por concepto de incapacidades y licencias de los empleados de la Compañía, se reconocerá una cuenta por cobrar a la entidad que corresponda por el valor de la novedad, una vez esta ha sido liquidada conforme al procedimiento establecido en COMERCIALIZADORA ALLCOMPUTER S.A.S, y pagada al empleado en la nómina del periodo correspondiente, esto siguiendo la normativa laboral vigente para este tipo de novedades.

Para otro tipo de reclamaciones, su reconocimiento en los estados financieros se hace en el momento en que COMERCIALIZADORA ALLCOMPUTER S.A.S, tiene la certeza de la entrada de beneficios económicos del hecho que la origino.

Periódicamente se debe conciliar este rubro para verificar que el saldo corresponda efectivamente a las reclamaciones pendientes de reembolso por parte de las entidades de salud y riesgos laborales, y demás a que haya lugar.

\section{Deudores Varios}

Son valores a favor de COMERCIALIZADORA ALLCOMPUTER S.A.S, por conceptos diferentes a los clasificados anteriormente, que representan un derecho legal de recibir un instrumento financiero. El concepto de la transacción debe estar claramente definido y existir la certeza de la recuperación del valor adeudado por el tercero. Se reconocerá una cuenta por cobrar 
al momento de realizarse la transacción, por el valor razonable del acuerdo contractual, que corresponde al valor acordado entre la Compañía y el deudor.

\section{Gastos Pagados por Anticipado}

Son gastos registrados como un activo y que deben ser amortizados en un ciclo financiero a corto plazo, sobre el cual COMERCIALIZADORA ALLCOMPUTER S.A.S, tiene el derecho a recibir el beneficio pagado anticipadamente, que en la medida que se haga uso de él se irá transformando en gasto. Se reconocen al momento de hacerse efectiva la acción contractual por el costo de la transacción, y se transfieren a resultados en el periodo durante el cual se reciben los servicios, se consumen los suministros o se obtienen los beneficios del pago hecho por anticipado.

Cuando algún gasto pagado por anticipado ya no tenga algún beneficio futuro, se debe registrar en los resultados del periodo en el que sucedan.

\section{Obligaciones Financieras}

Las obligaciones financieras se obtienen para capital de trabajo o financiación interna de la Compañía. Todo crédito será previamente analizado en sus condiciones y beneficios para la proyección de la inversión. La Gerencia tiene autonomía en el manejo de las obligaciones financieras, sin embargo, cuando el tope a comprometer supere el reglamento interno de la Compañía se requerirá autorización de la Asamblea General de Accionistas.

Para las obligaciones financieras la Compañía reconocerá una cuenta por pagar, por el valor presente por pagar al acreedor, que corresponde al valor del crédito obtenido

\section{Proveedores, y Costos y Gastos por Pagar}

Representan las cuentas por pagar a terceros por la adquisición de bienes y servicios para la operación de la Compañía. Se reconocen en el momento en que se dé la aceptación por parte de COMERCIALIZADORA ALLCOMPUTER S.A.S, de los bienes y servicios adquiridos y se 
asuman los riesgos y beneficios de estos; bien sea mediante factura, remisión o documento soporte de la compra del suministro o servicio adquirido.

Se reconocerá una cuenta por pagar por el valor acordado entre COMERCIALIZADORA ALLCOMPUTER S.A.S, y el proveedor o acreedor, que corresponde al precio de la factura de compra.

Estos instrumentos financieros, normalmente no generan cambios en su valor, sin embargo, se debe tener en cuenta si genera una financiación implícita o derivado implícito.

\section{Deudas con Accionistas}

Representan los recursos otorgados en calidad de préstamo a la Compañía por parte de los accionistas, para capital de trabajo o financiación interna de proyectos. Las condiciones contractuales son fijadas en el momento de la transacción. Se reconoce una cuenta por pagar por el valor de la transacción (dinero recibido en calidad de préstamo), al momento del recibo del dinero.

\section{Dividendos por Pagar}

Son dividendos decretados por la Asamblea General de Accionistas, y que a la fecha de presentación de los estados financieros no han sido pagados. Se reconocen en el momento de ser decretados por el máximo órgano social de la Compañía por el valor aprobado.

\section{Retenciones Fiscales por Pagar}

Representan los valores a favor de las entidades fiscales del orden nacional y municipal, efecto del cumplimiento de COMERCIALIZADORA ALLCOMPUTER S.A.S, en calidad de agente retenedor. Se reconocerá una cuenta por pagar por el valor de la transacción que corresponde al monto retenido al contribuyente aplicando la tasa fiscal vigente para cada tipo de operación. 


\section{Retenciones de Nomina por Pagar}

Son los descuentos de nómina autorizados por los trabajadores de COMERCIALIZADORA ALLCOMPUTER S.A.S, para ser reembolsados a terceros. Se reconocerá una cuenta por pagar por el valor de la transacción que corresponde al monto descontado autorizado.

\section{Acreedores Varios}

Son valores a cargo de COMERCIALIZADORA ALLCOMPUTER S.A.S, por conceptos pasivos diferentes a los clasificados anteriormente, que representan una obligación de entregar un instrumento financiero. El concepto de la transacción debe estar claramente definido y existir la certeza de la obligación de realizar el pago al tercero. Se reconocerá una cuenta por pagar al momento de realizarse la transacción, por el valor razonable del acuerdo contractual, que corresponde al valor acordado entre la Compañía y el acreedor.

\section{Anticipos y Avances Entregados y Recibidos}

NIIF para Pymes permite reconocer un anticipo como activo o un pasivo según corresponda, si no se han recibido o entregado los bienes o servicios contratados, siempre que se posea el derecho exigible a recibir o entregar los bienes o servicios reconocidos. No son considerados instrumentos financieros porque cuando se liquidan no se recibe o entrega dinero, ni otro instrumento financiero activo o pasivo. Para su reconocimiento se deben considerar las condiciones contractuales que dieron origen a dicho anticipo para su adecuada clasificación al concepto que corresponda, y que su permanencia en este rubro sea consecuente con los conceptos de activo y pasivo y los criterios de reconocimiento y medición. Estos Anticipos y Avances pueden ser tratados como Otras Cuentas por Cobrar u, Otras Cuentas por Pagar y se reconocen como tal por el valor de la transacción. 
En COMERCIALIZADORA ALLCOMPUTER S.A.S, generalmente el anticipo que se solicita al cliente es para cubrir los primeros despachos y tener conocimiento de éste. Se amortiza a lo largo del contrato según el acuerdo contractual.

\subsection{Medición}

El efectivo y equivalentes al efectivo se medirán al costo de la transacción. En el caso de tener efectivo y equivalentes al efectivo en otras monedas, se reconocerán a la moneda funcional de COMERCIALIZADORA ALLCOMPUTER S.A.S, El Peso Colombiano, aplicando la tasa de cierre entre ambas monedas de cada periodo, ya sea mensual o anual.

\subsubsection{Medición Inicial}

COMERCIALIZADORA ALLCOMPUTER S.A.S, medirá un instrumento financiero, en su reconocimiento inicial, por el precio de la transacción más los gastos de la misma; excepto en la medición inicial (ESFA) de los instrumentos financieros que se miden al valor razonable con cambios en resultados.

Si el acuerdo efectivamente constituye una transacción de financiación, COMERCIALIZADORA ALLCOMPUTER S.A.S, medirá el instrumento financiero al valor presente de los pagos futuros descontados a una tasa de interés de mercado para un instrumento de deuda similar.

Costos de Transacción: son los costos incrementales directamente atribuibles a la adquisición o emisión de un activo financiero, en los que no se habría incurrido si la Compañía no 
hubiera realizado la transacción. Se consideran costos de transacción: corretaje, comisiones, honorarios pagados a agentes e intermediarios, gastos de intervención de un notario, impuestos y otros derechos que recaigan sobre la transacción. Se excluyen: los gastos financieros, las primas o descuentos de deuda, remuneración de otros servicios.

Cuentas por Cobrar a Corto Plazo: Las cuentas por cobrar a corto plazo (máximo doce meses) se miden inicialmente por el valor razonable de la transacción, el cuál es el valor acordado entre COMERCIALIZADORA ALLCOMPUTER S.A.S, y el deudor, y corresponde al valor del documento soporte de la acción contractual.

En el caso que la transacción contemple deducciones por conceptos impositivos, estos valores se descontaran para el registro de la cuenta por cobrar.

Inversiones: Las inversiones se miden inicialmente por el valor de efectivo pagado para su adquisición, incluyendo los costos de transacción.

Cuentas por Pagar a Corto Plazo: Las cuentas por pagar a corto plazo (máximo doce meses) se miden inicialmente por el valor razonable de la transacción, el cuál es el valor acordado entre COMERCIALIZADORA ALLCOMPUTER S.A.S, y el acreedor, y corresponde al valor de la factura o documento soporte de la acción contractual.

En el caso que la transacción contemple deducciones por conceptos impositivos, estos valores se descontaran para el registro de la cuenta por pagar.

Obligaciones Financieras: Se miden inicialmente al valor de la transacción, que corresponde al valor del crédito adquirido.

Cuentas por Cobrar a Largo Plazo sin Intereses: Las cuentas por cobrar a largo plazo (superior a doce meses), se miden inicialmente al precio de venta en efectivo actual para esa partida (valor de la transacción). Si no se conoce el precio de venta en efectivo actual, se puede estimar 
como el valor presente de la cuenta por cobrar en efectivo descontado utilizando la tasa de interés de mercado vigente para una cuenta por cobrar similar, esto en razón a la pérdida del dinero en el tiempo.

Las cuentas por cobrar superiores a doce meses, se valoran a su costo amortizado. Por medio de este método, se determina la tasa de interés efectiva usando los flujos futuros del instrumento. Es decir, se busca la tasa de interés que iguale el flujo inicial del saldo deudor con los flujos futuros del mismo.

Si la cuenta por cobrar a largo plazo no contempla el cobro de intereses, o estos están por debajo del mercado, será valorada descontando los flujos futuros con base en tasas de mercado, las cuales deben considerar el plazo y riesgo del saldo deudor.

COMERCIALIZADORA ALLCOMPUTER S.A.S, estimará esta tasa dependiendo de la condición de riesgo de la operación, teniendo en cuenta:

- Que no se afecte el valor del dinero en el tiempo

- Garantizando la buena administración de los recursos de la Compañía

\subsubsection{Medición Posterior}

Posterior al reconocimiento inicial, los instrumentos financieros se medirán al costo amortizado utilizando el método de interés efectivo, menos el deterioro de valor para los activos financieros; excepto las inversiones que se requieran ser medidas al valor razonable reconociendo los cambios en resultados.

Costo Amortizado: El costo amortizado de un activo financiero o pasivo financiero es: el valor al que inicialmente fue medido el instrumento financiero, menos los recaudos o pagos del 
capital que se hubieran producido, más o menos, según proceda, la parte imputada en la cuenta de pérdidas y ganancias (amortización acumulada, intereses) mediante la utilización del método de tipo de interés efectivo, de la diferencia entre el valor inicial y el valor de reembolso en el vencimiento; y para el caso de activos financieros, menos cualquier reducción de valor por deterioro de valor reconocida, perdida que debe ser reconocida mediante una cuenta correctora o control del valor del activo.

El tipo de interés efectivo es el tipo de actualización que iguala el valor en libros de un instrumento financiero con los flujos de efectivo estimados a lo largo de la vida esperada del instrumento, a partir de sus condiciones contractuales y sin considerar las pérdidas por riesgo de crédito futuras.

El tipo de interés efectivo es un método para calcular el costo amortizado de un instrumento financiero, y, por tanto, un medio para distribuir el ingreso o gasto por intereses a lo largo del período de vida del activo o pasivo. La diferencia entre el tipo de interés efectivo y un método de amortización lineal es que el primero refleja un retorno o rendimiento constante sobre el valor en balance del activo o pasivo.

El costo amortizado se aplica en la valoración posterior de los siguientes instrumentos financieros:

- Préstamos y Cuentas por Cobrar

- Inversiones mantenidas hasta el vencimiento

- Obligaciones y Cuentas por Pagar

Los instrumentos financieros cuyo vencimiento sea inferior a un año y sobre los cuales no se haya pactado un tipo de interés contractual y cuyo valor se espera recibir o pagar, según 
corresponda, se medirán posterior al reconocimiento inicial por su valor nominal (precio de factura).

En algunos casos particulares, puede darse para ciertos activos financieros, un acuerdo de reestructuración de plazos, situación que no implica una perdida por deterioro del valor.

\subsection{Deterioro}

Al final de cada periodo sobre el que se informa, COMERCIALIZADORA ALLCOMPUTER S.A.S, evaluará si existe evidencia objetiva de deterioro del valor de los activos financieros que se midan al costo o al costo amortizado. Cuando exista evidencia objetiva de deterioro del valor, se reconocerá una pérdida por deterioro del valor en resultados. Perdida que deberá ser reconocida mediante una cuenta correctora o control del valor del activo.

COMERCIALIZADORA ALLCOMPUTER S.A.S, realizará un análisis de tipo comercial y financiero para verificar la existencia de evidencia objetiva que permita determinar si los saldos deudores se han deteriorado; es decir, si existen indicios de problemas de recuperabilidad del saldo deudor. Si con base en este análisis, se concluye que hay evidencia objetiva de pérdidas de valor se procederá a determinar el deterioro para los saldos deudores, que será igual a la diferencia entre el valor en libros del saldo deudor y el valor presente de los flujos futuros de efectivo esperados a recibir. 


\subsubsection{Indicadores de Deterioro}

Son criterios para determinar que existe evidencia objetiva de una perdida por deterioro los siguientes:

- Infracciones del contrato, tales como incumplimientos o moras en el pago

- Dificultades financieras significativas del deudor, que requieran otorgarle concesiones especiales

- Evidencia de que el deudor entro en quiebra o proceso de reorganización financiera

- Información perceptible que indica que existe una disminución significativa en los flujos de efectivo futuros esperados de la cartera, por condiciones económicas locales o nacionales presentes.

- Perdida de contacto con el deudor

COMERCIALIZADORA ALLCOMPUTER S.A.S, identifica riesgo de recuperabilidad de cartera con clientes que contratan con el estado, y los constructores organizados en consorcios o uniones temporales.

- Ver reconocimiento de deterioro en memorando técnico de estimaciones contables

\subsubsection{Medición del Deterioro}

Para un activo financiero medido al costo amortizado; la pérdida por deterioro es la diferencia entre el valor en libros del activo y el valor presente de los flujos de efectivo futuros esperados, descontados utilizando la tasa de interés efectivo original del activo. 
Para un activo financiero medido al costo menos el deterioro del valor; la pérdida por deterioro es la diferencia entre el valor en libros del activo y la mejor estimación del valor que la compañía recibiría por el activo en la fecha sobre la que se informa.

- Ver medición del deterioro en memorando técnico de estimaciones contables

\subsubsection{Reversión del Deterioro}

COMERCIALIZADORA ALLCOMPUTER S.A.S, reversará la pérdida por deterioro si, en un periodo posterior a su reconocimiento, el valor de la pérdida por deterioro disminuye y la disminución pueda ser objetivamente relacionada con un evento ocurrido después de que el deterioro fue reconocido.

La reversión del deterioro se reconocerá en resultados.

\subsection{Baja en Cuentas de los Instrumentos Financieros}

\subsubsection{Activos Financieros}

COMERCIALIZADORA ALLCOMPUTER S.A.S, dará de baja en cuentas un activo financiero cuando:

- Expiren o se liquiden los derechos contractuales sobre los flujos de efectivo del activo financiero

- La Compañía transfiera sustancialmente a terceros todos los riesgos y ventajas inherentes a la propiedad del activo financiero 
- La Compañía, a pesar de haber conservado algunos riesgos y ventajas inherentes a la propiedad significativos, ha transferido el control del activo a otra parte, y éste tiene la capacidad de vender el activo en su integridad a una tercera parte.

\subsubsection{Pasivos Financieros}

COMERCIALIZADORA ALLCOMPUTER S.A.S, dará de baja en cuentas a un pasivo financiero, o una parte de este, cuando:

- Se realice el pago de la obligación

- Se dé la cancelación de la obligación (condonación de la deuda)

- La obligación expire

La cancelación de un pasivo financiero se reconocerá en los resultados

\subsection{Presentación y Revelaciones}

COMERCIALIZADORA ALLCOMPUTER S.A.S, revelará la siguiente información en referencia a sus instrumentos financieros:

1. Resumen de las políticas contables significativas, indicando las bases de medición utilizadas para los instrumentos financieros y otras políticas contables utilizadas para instrumentos financieros que sean relevantes para la comprensión de los estados financieros.

2. Los saldos para cada categoría de efectivo por separado, el plazo de los equivalentes al efectivo, las tasas de interés y cualquier otra característica importante que tengan los 
depósitos a plazo, mostrados dentro de los estados financieros en una cuenta específica que determine su condición y naturaleza de efectivo y equivalentes al efectivo.

3. Los saldos de efectivo y equivalentes al efectivo significativos mantenidos por la compañía que no están disponibles para ser utilizados por ésta, por alguna causal de restricción, indicando las restricciones existentes.

4. Valor en libros para cada una de las categorías de instrumentos financieros

5. Información que permita a los usuarios de los estados financieros evaluar la importancia de los instrumentos financieros en la situación financiera y en el rendimiento financiero de la Compañía. Ejemplo: condiciones contractuales de los instrumentos financieros como: plazos, tasas de interés, vencimientos.

6. Para los instrumentos financieros medidos al valor razonable, información sobre la base utilizada para determinar dicho valor razonable. Cuando se utilice una técnica de valoración se detallará los supuestos aplicados en dicho procedimiento. Así mismo, deberá informar si no existe una medición fiable del valor razonable.

7. Cuando la Compañía haya pignorado activos financieros como garantía pasivos, informará el valor en libros de los activos financieros pignorados como garantía y las condiciones contractuales relacionadas con la pignoración

8. Para las obligaciones por pagar reconocidas en la fecha del estado de situación financiera, sobre las cuales haya una infracción o incumplimiento sobre las condiciones contractuales, que sea relevante para la evaluación de la situación financiera de la Compañía, se informará:

- Detalles de la infracción o incumplimiento

- Valor en libros de las obligaciones por pagar relacionadas con este hecho 
- Si ha habido renegociación de las condiciones de estas obligaciones

9. Valor de las partidas reconocidas como ingresos, gastos, ganancias o pérdidas, incluidos los cambios al valor razonable reconocidos en instrumentos financieros medidos al valor razonable con cambios en resultados, y medidos al costo amortizado.

10. Valor de los ingresos y gastos totales, calculados utilizando el método de interés efectivo, por los instrumentos financieros activos y pasivos que no se miden al valor razonable con cambios en resultados.

11. El valor de las pérdidas por deterioro de valor para cada clase de activo financiero. Así, como el valor de las reversiones del mismo.

12. El valor de los instrumentos financieros activos y pasivos dado de baja en el periodo, indicando las circunstancias que dieron origen a esta baja.

13. Cuando la Compañía haya pignorado activos financieros como garantía por pasivos o pasivos contingentes, se revelará el valor en libros de los activos financieros pignorados como garantía y los plazos y condiciones relacionados con la pignoración. 


\section{Política de inversiones}

\subsection{Objetivo}

El objetivo de esta política contable es definir los criterios para el reconocimiento y medición de los activos financieros o inversiones que posee COMERCIALIZADORA ALLCOMPUTER S.A.S

\subsection{Alcance}

Aplica para las siguientes inversiones en títulos de deuda de renta fija y variable:

a. Certificados de depósitos a término CDT.

b. Encargos fiduciarios o carteras colectivas que no cumplan con la definición de equivalentes de efectivo, citada en la política contable NIIF de efectivo.

c. Acciones.

d. Instrumento de deuda: Bonos ordinarios.

e. Otras inversiones aprobadas que no estén dentro del alcance de otra política contable NIIF. 


\subsection{Política Contable General}

COMERCIALIZADORA ALLCOMPUTER S.A.S, elige aplicar las disposiciones de la Sección 11, para el reconocimiento y medición de todos sus activos financieros, representados en inversiones.

La Sección 11 requiere un modelo de costo amortizado para todos los instrumentos financieros básicos excepto para las inversiones en acciones preferentes no convertibles y acciones preferentes sin opción de venta y en acciones ordinarias sin opción de venta que cotizan en bolsa o cuyo valor razonable se puede medir de otra forma con fiabilidad.

Las inversiones de COMERCIALIZADORA ALLCOMPUTER S.A.S, se miden en las siguientes categorías:

a. Inversiones a valor razonable con efecto en resultados.

b. Inversiones al costo amortizado.

\subsection{Reconocimiento y Medición}

a. Se reconocerán como instrumentos financieros negociables o "Inversiones al Valor Razonable con cambios en Resultados" los títulos participativos o de deuda que cotizan en bolsa.

b. Se reconocerán como instrumentos financieros Disponibles para la Venta o "Al Valor Razonable con cambios en Patrimonio (Otro Resultado Integral)”, las acciones y demás títulos participativos que no sean de baja o ninguna bursatilidad (que no cotizan en bolsas de valores). 


\subsubsection{Medición inicial}

Los instrumentos "negociables” se medirán por su valor razonable. Los costos de transacción, tales como las comisiones, son gastos, no se suman al costo, sino que se reconocen como gastos del periodo en el que se adquieren.

Los instrumentos "Disponibles para la Venta" o "Al Valor Razonable con cambios en Patrimonio (Otro Resultado Integral)" se medirán por su costo, incluyendo los costos de transacción.

\subsubsection{Medición Posterior}

Las inversiones "Negociables" o "Inversiones al Valor Razonable con cambios en Resultados" se medirán por su Valor Razonable en el Nivel 1, es decir, su valor en bolsa de valores o en otro "mercado activo" según lo señale un comisionista o un proveedor de precios debidamente autorizados.

Los instrumentos financieros que no coticen en bolsa se medirán por su valor razonable en un Nivel 2, es decir, según la cotización de un instrumento similar o por otros métodos de reconocido valor técnico.

\subsection{Presentación y Revelación}

COMERCIALIZADORA ALLCOMPUTER S.A.S, presenta las inversiones de acuerdo a las categorías descritas en esta política contable, y serán presentadas como activos corrientes cuando: 
a. Espera venderlo o tiene la intención de venderlo en el corto plazo o

b. mantiene el activo principalmente con fines de negociación; de lo contrario será clasificado como activo financiero no corriente.

- Información a revelar sobre las políticas contables:

c. Revela el resumen de las políticas contables significativas, las bases de medición utilizada para activos financieros.

d. Estado de situación financiera en las categorías de activos financieros.

e. Revela los valores en libros de cada una de las siguientes categorías de activos financieros en la fecha sobre la que se informa.

f. Activos financieros medidos al valor razonable con cambios en resultados.

g. Activos financieros que son instrumentos de deuda medidos al costo amortizado. 


\section{Política de inventarios}

\subsection{Objetivo}

Establecer las bases contables para el reconocimiento, medición y presentación de los inventarios de COMERCIALIZADORA ALLCOMPUTER S.A.S

\subsection{Alcance}

Esta política aplica para aquellos activos tangibles que COMERCIALIZADORA ALLCOMPUTER S.A.S, posee para ser utilizados en el proceso de transformación, consumo o venta dentro de sus actividades ordinarias y comprenden los siguientes conceptos:

\subsubsection{Inventario de materiales y suministros}

Corresponde a los insumos y materiales que serán consumidos en la elaboración de un producto tales como vidrio, aluminio, accesorios y otros materiales. 


\subsubsection{Inventario disponible para la venta}

Corresponde a los elementos fabricados por COMERCIALIZADORA ALLCOMPUTER S.A.S, que están disponibles para la venta, venta en las condiciones actuales tales como vidrio templado, laminado, curvo, etc.

\subsubsection{Inventario de producto en proceso}

Corresponde a los artículos semi-elaborados es decir que poseen cierto grado de terminación y para los cuales se ha incurrido en costos de materiales, mano de obra y costos indirectos de fabricación requiriendo procesos adicionales para ser convertidos en productos terminados.

\subsubsection{Inventario de Producto Terminado}

Corresponde a los inventarios que han terminado su proceso de producción, pero no se han transferidos los derechos y riesgos al comprador.

\subsection{Definiciones}

Inventarios: son activos:

a. poseídos para ser vendidos en el curso normal de la operación;

b. en proceso de producción con vistas a esa venta; o 
c. en la forma de materiales o suministros, para ser consumidos en el proceso de producción, o en la prestación de servicios.

Costo de inventario: costos de adquisición más costos de transformación más otros costos.

Valor neto realizable: Corresponde al precio de venta estimado del inventario menos los costos estimados para terminar su producción y los necesarios para llevar a cabo la venta (transporte, comisiones).

Costo de reposición: Corresponde al costo actual estimado de reemplazo de los inventarios existentes como si éstos fueran nuevos.

\subsection{Política Contable General}

COMERCIALIZADORA ALLCOMPUTER S.A.S, debe reconocer como inventarios los bienes corporales adquiridos, de los cuales espera obtener beneficios económicos en períodos futuros a través de su consumo o su venta, cuyo monto sea determinable.

\subsection{Reconocimiento y Medición}

\subsubsection{Reconocimiento Inicial}

Los inventarios se reconocen como tales en la contabilidad sólo si cumplen la totalidad de los siguientes requisitos:

- Que sean utilizados en la operación de COMERCIALIZADORA ALLCOMPUTER S.A.S 
- Que de ellos sea probable que se deriven beneficios económicos futuros consumo o venta.

- Que su valor pueda ser medido confiable y razonablemente.

- Que el bien se haya recibido a satisfacción por parte de COMERCIALIZADORA ALLCOMPUTER S.A.S, y se hayan transferido a su favor los riesgos y beneficios.

La incorporación de todo tipo de inventarios en el sistema de información se efectúa solamente cuando éstos sean recibidos físicamente en forma satisfactoria en cuanto a calidad y características definidas por parte de COMERCIALIZADORA ALLCOMPUTER S.A.S

Reconocimiento de los descuentos comerciales y financieros en la adquisición de inventarios:

- Los descuentos financieros y comerciales, se reconocen como menor valor del inventario en el momento de la compra en cada uno de los productos.

\subsubsection{Medición inicial}

Los inventarios son medidos inicialmente por su costo o valor nominal adicionado con el valor de las demás erogaciones necesarias para dejarlos listos para su uso o venta, hacen parte de su costo los siguientes conceptos.

- El precio de compra pactado con el proveedor menos descuentos comerciales y financieros (descuentos por pronto pago) y rebajas.

- $\mathrm{Si}$ es probable que la COMERCIALIZADORA ALLCOMPUTER S.A.S, obtenga descuentos por volumen y su importe puede determinarse en forma fiable, el descuento debe reconocerse como menor valor del inventario.

- Más el impuesto a las ventas - IVA, en la medida en que no sea descontable. 
- Fletes y seguros necesarios para dejarlo en las bodegas de la Empresa.

Inventario en tránsito: En caso de importación de insumos y materiales, los costos de adquisición comprenden el precio de compra, los aranceles de importación y otros impuestos (que no sean recuperables posteriormente), el transporte, la manipulación y otros costos directamente atribuibles a la adquisición de los materiales o servicios. Los descuentos comerciales, las rebajas y otras partidas similares se deducen para determinar el costo de adquisición.

Costo no incluido en los inventarios: Los siguientes conceptos corresponden a desembolsos que no deben ser incluidos como mayor valor de los inventarios $y$, por lo tanto, COMERCIALIZADORA ALLCOMPUTER S.A.S, reconoce como gastos en el estado de resultados integral del periodo en el que se incurren:

- Valores anormales de desperdicio de materiales, mano de obra u otros costos de producción de sus inventarios.

- Costos de almacenamiento y fletes que no sean directamente atribuibles a la producción de inventarios.

- Costos de almacenamiento del producto terminado.

\subsubsection{Medición posterior}

La valoración de los inventarios se realiza bajo el costo promedio ponderado de las unidades existentes. Este promedio se calcula automáticamente luego de cada entrada de mercancías, y se ajusta mensualmente en la contabilidad.

Perdidas por deterioro de valor: Los inventarios se miden posteriormente al final de cada periodo contable, al costo o al valor neto realizable, tomándose el menor valor. Este procedimiento 
lo realizará el responsable de Compras de cada dependencia al final de cada periodo, para ajustar el costo hasta alcanzar el valor neto realizable.

Para determinar el valor neto realizable de los inventarios tenemos los siguientes grupos de acuerdo al tipo de inventario en cuestión:

Inventarios para el consumo: Se busca el costo de reposición (valor de compra en la fecha del análisis) de cada uno de los ítems de inventario, su valor neto realizable podrá ser el último precio en el mercado suministrado por los proveedores, siempre y cuando el listado de precios no supere 90 días.

Inventario de producto en proceso: Se estima el precio de venta del inventario y sus costos de venta asociados y los costos estimados para su terminación.,

Inventarios para la venta: Se estima el precio de venta del inventario y sus costos de venta asociados.

Una vez se tenga el valor neto realizable para cada tipo de inventarios, se compara éste valor con el valor en libros y el resultado tendrá el siguiente tratamiento:

- Para las referencias de inventarios cuyo valor neto realizable sea superior al valor neto en libros, no se realiza ajuste contable.

- Para aquellos inventarios cuyo valor neto realizable sea inferior al valor en libros, se reconocerá un gasto por concepto de pérdida por deterioro de valor, contra la sub cuenta de deterioro del inventario.

Faltantes, daños y robos: Se deberá determinar si el inventario ha sufrido pérdida de valor por concepto de faltantes, daños, robos, obsolescencia o deterioro físico; para proceder a realizar el ajuste correspondiente en el sistema y en los estados financieros de COMERCIALIZADORA

\section{ALLCOMPUTER S.A.S}


Las pérdidas de unidades de inventarios o faltantes, son reconocidas en las siguientes circunstancias:

- Por robo: Se reconocen cuando se conoce el hecho, se cuantifican las cantidades perdidas y se establece el valor correspondiente, para tomar los correctivos necesarios y ajustes o cobro respectivo.

- Por faltantes: Se reconocen en el momento en el cual se detecta el faltante, que normalmente ocurre cuando se realiza un inventario físico. Se examinan los movimientos de inventarios y se hacen los correctivos necesarios, realizando el ajuste o el traslado necesario.

- Por daños: Se reconocen de acuerdo con un concepto técnico de los responsables de cada dependencia según el tipo de inventario, donde se determina que el inventario no puede ser utilizado y el costo de su reparación excede el costo de compra de un elemento nuevo.

El valor de las pérdidas de inventarios se reconoce por su costo promedio ponderado, mediante registro de naturaleza crédito a la cuenta de inventarios y la contrapartida a cuentas de resultados (cuando la pérdida es asumida por COMERCIALIZADORA ALLCOMPUTER S.A.S) o en cuentas por cobrar si el inventario se cobra al funcionario encargado de almacenes en cumplimiento de normas legales de carácter laboral, y otras cuentas por cobrar a la aseguradora o al transportador.

\section{Análisis de obsolescencia}

El retiro de los inventarios obsoletos, se reconoce como tal cuando:

- El inventario no puede generar beneficios económicos futuros, debido a que no tiene capacidad de uso y

- El valor a retirar es determinable en forma confiable (costo en libros). 
COMERCIALIZADORA ALLCOMPUTER S.A.S, debe determinar, si cada partida del inventario tiene capacidad de uso, siendo ésta la medida en que existan activos en operación sobre los cuales el inventario se puede utilizar. Si no existen activos en operación sobre los cuales se puedan utilizar los inventarios, éstos deberán ser considerados como obsoletos, para tomar la decisión de ser vendidos o castigados y, en consecuencia, proceder a su respectivo retiro de inventario físico y contable, reconociendo así la pérdida por deterioro de valor.

Si es posible la venta del inventario (porque es útil para otra entidad) se debe estimar el valor posible de venta, que, de llegar a ser inferior al costo en libros, se reconocerá la pérdida en resultados del periodo. Si no es posible su venta, se le deberá dar de baja descargándolo contra los resultados del período por pérdida en retiro de activos.

\subsection{Presentación y Revelación}

La presentación del rubro contable de inventarios en los estados financieros y sus revelaciones o notas, se efectúa teniendo en cuenta las siguientes consideraciones:

- Las políticas contables adoptadas para la medición de los inventarios, incluyendo la fórmula de costo utilizada.

- El importe total en libros de los inventarios y los importes en libros según la clasificación apropiada para la entidad.

- El importe de los inventarios reconocidos como gasto durante el periodo.

- Las pérdidas por deterioro de valor reconocidas o revertidas en el resultado de acuerdo con la Sección 27.

- El importe total en libros de los inventarios pignorados en garantía de pasivos. 
- Revelar las políticas contables para el reconocimiento y medición de los inventarios.

- Revelar el método de medición de los inventarios.

- Revelar el valor total en libros de los inventarios y los valores parciales según la clasificación que resulte apropiada para COMERCIALIZADORA ALLCOMPUTER S.A.S: Inventarios consumibles e inventarios para la venta.

- Revelar el valor de los inventarios reconocidos como gasto durante el período.

- Revelar el valor del inventario capitalizado y el valor reconocido contra costos y gastos en el período.

- Revelar el valor de las pérdidas por deterioro.

- Revelar el valor de los inventarios retirados o dados de baja en el período.

\subsection{Normativa Aplicable}

La elaboración de esta política contable para los inventarios de COMERCIALIZADORA ALLCOMPUTER S.A.S, se sustenta en las siguientes normas:

Sección 3, Presentación de Estados Financieros

Sección 10, Políticas Contables, Estimaciones y Errores

Sección 13, Inventarios

Sección 27, Deterioro del Valor de los Activos 


\subsection{Deterioro del Valor de los Inventarios}

COMERCIALIZADORA ALLCOMPUTER S.A.S, evaluará al cierre del periodo si ha habido un deterioro del valor de los inventarios. Para esto, realizará la evaluación comparando el valor en libros de cada partida del inventario, con su precio de venta menos los costos de venta (valor neto realizable).

Si una partida del inventario ha deteriorado su valor, la compañía reducirá el valor en libros del inventario a su precio de venta. Esa reducción es una pérdida por deterioro del valor y se reconoce inmediatamente en resultados.

\subsection{Baja en Cuentas de los Inventarios}

COMERCIALIZADORA ALLCOMPUTER S.A.S, dará de baja en libros del valor de los inventarios por los siguientes eventos:

- Por venta; en ese momento se reconoce el costo de ventas en el estado de resultados, de manera simultánea con el ingreso reconocido por la venta

- Por consumo; se reconocerá el costo correspondiente en el estado de resultados

- Cuando no se espere obtener beneficios económicos futuros por su uso o disposición; evento en el cual se debe reconocer una perdida en el estado de resultados. Algunos conceptos por los cuales se da este caso son:

- Obsolescencia

- Por daño total o parcial 


\subsection{Presentación y Revelaciones}

COMERCIALIZADORA ALLCOMPUTER S.A.S, revelará la siguiente información con relación a sus inventarios:

1. Las políticas contables adoptadas para la medición de los inventarios, incluyendo la fórmula de medición de los costos que se haya utilizado.

2. El valor total en libros de los inventarios, y los valores parciales según la clasificación que resulte apropiada para la Compañía.

3. El valor en libros de los inventarios que se miden al valor razonable menos los costos de venta (valor neto realizable).

4. El valor de los inventarios reconocidos como costo o gasto durante el periodo

5. El valor de las rebajas de valor de los inventarios que se ha reconocido como gasto en el periodo, por su ajuste al valor neto realizable

6. El valor de las reversiones en las rebajas de valor anteriores

7. Las circunstancias o eventos que han dado lugar a las rebajas de valor y a las reversiones de estas.

8. Las pérdidas por deterioro del valor reconocidas o revertidas en el resultado

9. El valor en libros de los inventarios obsoletos que la compañía posee 


\section{Política contable de propiedades, planta y equipo}

\subsection{Objetivo}

Determinar las pautas para el reconocimiento, medición, baja en cuentas y presentación de los elementos que, en COMERCIALIZADORA ALLCOMPUTER S.A.S, se clasifican como propiedades, planta y equipo, mediante la determinación de su valor en libros, los cargos por depreciación y pérdidas por deterioro de valor que deben reconocerse en relación con ellos.

Definir los criterios que se deberán aplicar para efectuar el reconocimiento contable inicial, la determinación de su valor en libros, los cargos por depreciación y pérdidas por deterioro a reconocer con relación a los mismos.

\subsection{Alcance}

Esta política contable ha sido elaborada con base en las propiedades, planta y equipo, los activos no corrientes mantenidos para la venta, con que cuenta COMERCIALIZADORA ALLCOMPUTER S.A.S, a la fecha de emisión de la misma.

Aplicará a la contabilización de los elementos de propiedades, planta y equipo, poseídos para su uso en el suministro de bienes y servicios, para arrendarlos a terceros o para propósitos administrativos; y que se esperan usar durante más de un período; entre los cuales se incluyen las siguientes clasificaciones: 
- Construcciones y edificaciones

○ Oficinas

- Bodegas

- Maquinaria y equipo

- Maquinaria y equipos

- Bodega contenedor

- Equipo de oficina

- Muebles y enseres

○ Equipos

- Otros

- Equipo de computación y comunicación

- Equipo de procesamiento de datos

- Equipo de telecomunicaciones

- Otros

- Flota y equipo de transporte

- Autos, camionetas y camperos

- Camiones, volquetas y furgones

- Motocicletas

- Camiones 


\subsection{Normativa Aplicable}

La elaboración de esta política contable para las propiedades, planta y equipo, los activos no corrientes mantenidos para la venta y las propiedades de inversión, se sustenta en las siguientes normas:

Sección 3, Presentación de Estados Financieros

Sección 10, Políticas Contables, Estimaciones y Errores

Sección 17, Propiedades, Planta y Equipo

Sección 20, Arrendamientos

Sección 27, Deterioro del Valor de los Activos

\subsection{Definiciones}

Propiedades, planta y equipo: son activos tangibles mantenidos por la Compañía, para su uso en la producción o suministro de bienes y servicios, para arrendarlos a terceros o con propósitos administrativos y se esperan usar durante más de un periodo.

Valor en libros: es el valor por el que se reconoce un activo, una vez deducida la depreciación acumulada y las pérdidas por deterioro del valor acumuladas.

Costo: es el monto de efectivo o equivalentes al efectivo pagado, o el valor razonable de la contraprestación entregada, para comprar un activo en el momento de su adquisición o construcción; o cuando sea aplicable, el valor atribuido a ese activo cuando sea inicialmente reconocido de acuerdo con los requerimientos específicos de otras NIIF. 
Valor depreciable: es el costo de un activo, u otro valor que lo haya sustituido, menos su valor residual.

Valor residual: es el valor estimado que la Compañía podría obtener actualmente por la disposición del elemento, después de deducir los costos estimados por tal disposición, si el activo ya hubiera alcanzado la antigüedad y las demás condiciones esperadas al término de su vida útil.

Vida útil: es el periodo durante el cual se espera utilizar el activo por parte de la Compañía, o el número de unidades de producción o similares que se espera obtener del mismo por parte de una entidad.

Depreciación: es la distribución sistemática del valor depreciable de un activo a lo largo de su vida útil.

Pérdida por deterioro: es el exceso del valor en libros de un activo sobre su valor recuperable.

Valor recuperable: es el mayor entre el valor razonable menos los costos de venta y el valor en uso de un activo.

Costos de venta: son los costos incrementales directamente atribuibles a la venta de un activo, excluyendo los costos financieros y los impuestos a las ganancias.

Valor en uso: es el valor presente de los flujos futuros de efectivo estimados que se espera obtener de un activo

Valor razonable menos los costos de venta: es el monto que se puede obtener por la venta de un activo, en una transacción realizada en condiciones de independencia mutua, entre partes interesadas y debidamente informadas, menos los costos de disposición

Cambio de estimación contable: es el ajuste al valor en libros de un activo o de un pasivo, o al valor del consumo periódico de un activo, procedente de la evaluación de su situación actual, 
así como de los beneficios futuros esperados y de las obligaciones asociadas con dichos activos y pasivos. Los cambios de estimaciones contables son el resultado de nueva información o de nuevos acontecimientos y, en consecuencia, no son correcciones de errores.

Baja en cuentas: es la supresión de un activo o un pasivo previamente reconocido en el estado de situación financiera.

Activos no corrientes disponibles para la venta: un activo no corriente se clasificará como mantenido para la venta, siempre que su valor en libros se recupere a través de una transacción de venta, en lugar de por su uso continuado.

Propiedad de inversión: es una propiedad, terreno o edificio, o parte de un edificio, o ambos, mantenida por el dueño o por el arrendatario financiero, para ganar rentas o generar plusvalías, o con ambos fines, y no para:

- Su uso en la producción o suministro de bienes o servicios, o para fines administrativos, o

- Su venta en el curso ordinario de los negocios

Mercado activo: es un mercado en el que se dan todas las siguientes condiciones:

- Las partidas negociadas en el mercado son homogéneas,

- Normalmente se pueden encontrar en todo momento compradores y vendedores, y

- Los precios están disponibles al público.

\subsection{Reconocimiento}

Las propiedades, planta y equipo se reconocen en la contabilidad sólo si es probable que los beneficios económicos futuros asociados con los elementos vayan a fluir a la entidad y el costo del elemento pueda determinarse de forma fiable. 
COMERCIALIZADORA ALLCOMPUTER S.A.S, reconocerá un elemento de propiedades, planta y equipo como activo, si cumple con la totalidad de los siguientes requisitos:

- Que sea un recurso tangible controlado por la entidad; adquirido, construido o en proceso de construcción o montaje

- Que sea probable que la Compañía obtenga los beneficios económicos futuros asociados con el elemento

- Que el costo del elemento se pueda determinar de forma fiable

- Que se espere utilizar durante más de un periodo

- Que se asuman los riesgos y se reciban los beneficios inherentes al elemento, de acuerdo con las condiciones de la negociación

Tratándose de equipos de cómputo, cuyo software o aplicativos están incorporados en el activo tangible y cuyo valor no es posible separar o identificar, son tratados como mayor valor del activo.

El control de un elemento de propiedad, planta y equipo es asumido por la Compañía cuando se realiza la entrega de este por parte del proveedor, momento en cual asume los riesgos y beneficios inherentes a la propiedad del activo. El control de un activo se puede evidenciar por medio de traspaso de la titularidad del bien o de acuerdo a lo establecido en el contrato de compra y venta.

Las obtenciones de beneficios económicos futuros se pueden evidenciar por medio del análisis de flujo de efectivo y presupuesto realizado por la Compañía.

La medición fiable de un elemento de propiedades, planta y equipo adquirido dependerá del precio de compra y los costos incurridos para que éste quede disponible para su uso en las condiciones previstas por la administración de la Compañía. 


\subsubsection{Costo Atribuido para el Balance de Apertura}

El valor por el que se reconocerán los elementos de propiedad, planta y equipo en el balance de apertura es el Costo Atribuido; que, para COMERCIALIZADORA ALLCOMPUTER S.A.S, será el Valor Razonable, definido según criterio propio de la compañía y avalado por la Gerencia.

\subsection{Medición Inicial}

COMERCIALIZADORA ALLCOMPUTER S.A.S, medirá un elemento de propiedades, planta y equipo en el momento de su reconocimiento inicial, por su costo.

El costo de un elemento de propiedades, planta y equipo se define como: el valor de efectivo o equivalentes al efectivo pagados, o el valor razonable de la contraprestación entregada, para comprar un activo en el momento de su adquisición o construcción o, en su caso, el valor atribuido en un intercambio.

El costo de un elemento de propiedad, planta y equipo comprende:

- El precio de adquisición, incluidos los siguientes conceptos: honorarios legales y de intermediación, aranceles de importación, impuestos no recuperables; menos los descuentos comerciales y las rebajas.

- Los costos directamente atribuibles a la ubicación del activo, en el lugar y condiciones necesarias para que pueda operar de la forma prevista por la administración. Estos costos pueden incluir: costos de preparación del emplazamiento, costos de entrega y manipulación inicial, costos de instalación y montaje, costos de comprobación de que el activo funciona adecuadamente. 
No son costos de un elemento de propiedades, planta y equipo; y por tanto COMERCIALIZADORA ALLCOMPUTER S.A.S, los reconocerá como gastos cuando se incurra en ellos, los siguientes:

- Los costos de introducción en el mercado de un nuevo producto o servicio; como publicidad y actividades promocionales

- Los costos de apertura del negocio en una nueva localización, o los de redirigirlo a un nuevo tipo de clientela; incluyendo los costos de formación de personal

- Los costos de administración y otros costos indirectos generales

- Los costos por préstamos; incluyendo intereses y demás gastos financieros relacionados

\subsubsection{Materialidad para el Reconocimiento}

Para el reconocimiento de propiedades, planta y equipo de menor cuantía COMERCIALIZADORA ALLCOMPUTER S.A.S, estimará un monto mínimo para la capitalización de estos elementos.

La compra de propiedades, planta y equipo que no superen este valor se trataran como gastos del periodo, llevando un control administrativo mediante inventario de cada elemento.

- Ver materialidad para el reconocimiento de PP\&E en memorando técnico estimaciones contables 


\subsubsection{Pago a Plazo}

El costo de un elemento de propiedades, planta y equipo será el precio equivalente al pago de contado en la fecha que se reconoce el activo. Cuando la Compañía adquiera elementos de propiedades, planta y equipo con condiciones de pago que consideren plazos más allá de los términos normales de crédito, el costo será el valor presente de los pagos futuros y la diferencia entre este valor y el total de pagos, se reconocerá como intereses a pagar durante el plazo para el pago.

\subsubsection{Costos Posteriores}

Los costos adicionales relacionados con un elemento de propiedades, planta y equipo, posteriores a su reconocimiento serán capitalizados cuando cumplan los siguientes criterios de reconocimiento:

- Que incrementen la capacidad de generación de beneficios económicos futuros

- Que incrementen la vida útil esperada

- Que la adición o mantenimiento supere el monto estimado para esta condición.

Los costos y gastos de mantenimientos y reparaciones del día a día de un elemento de propiedades, planta y equipo, se reconocerán en los resultados del ejercicio en el periodo que se incurren. 


\subsection{Medición Posterior}

Con posterioridad al reconocimiento inicial COMERCIALIZADORA ALLCOMPUTER S.A.S, aplicará el modelo del costo para medir todas sus propiedades, planta y equipo.

El modelo del costo requiere que, después del reconocimiento inicial, las propiedades, planta y equipo deben ser valuados a su costo menos la depreciación acumulada y las pérdidas por deterioro del valor acumuladas.

\subsubsection{Vida Útil}

La vida útil de una propiedad, planta y equipo, es el tiempo de uso estimado del activo por parte de COMERCIALIZADORA ALLCOMPUTER S.A.S Los beneficios económicos futuros implícitos en un activo se consumen mediante su uso, pero existen otros factores que deben ser considerados para establecer su vida útil, debido a que pueden disminuir esos beneficios económicos:

- La utilización prevista del activo; el uso del activo se estima por referencia a la capacidad o al rendimiento físico que se espere del mismo.

- La obsolescencia técnica o comercial derivada de los cambios en la demanda del mercado de los productos o servicios que se obtienen con el activo.

- El desgaste físico esperado, que dependerá de factores operativos, tales como: el programa de reparaciones y mantenimiento, y el grado de cuidado y conservación mientras el activo no está siendo utilizado. 
- Ver estimación de vidas útiles para cada categoría de propiedades, planta y equipo, en memorando técnico de estimaciones contables

\subsubsection{Depreciación}

Los elementos de propiedades, planta y equipo tendrán un monto a depreciar que se asignará sistemáticamente a lo largo de la vida útil estimada del bien. La depreciación comenzará cuando el elemento esté disponible para su uso, esto es, cuando se encuentre en la ubicación y en las condiciones necesarias para operar de la forma prevista por la administración de la Compañía; y cesa cuando el activo se da de baja o se traslade a activos no monetarios mantenidos para la venta.

El método de depreciación utilizado reflejará el patrón con el cual se espera sean consumidos, por parte de la Compañía, los beneficios económicos futuros. Cuando se opte por un método de depreciación diferente al de unidades de producción, la depreciación no se suspenderá cuando el activo esté fuera de uso.

El cargo por depreciación se reconocerá en el resultado del periodo, a menos que se requiera que el costo se reconozca como parte del costo de un activo.

\subsubsection{Valor Residual}

Es la parte del costo de un activo que se recupera mediante venta o permuta del bien al fin de su vida útil. El valor depreciable de una propiedad, planta y equipo se determina después de deducir su valor residual. 


\subsubsection{Deterioro del Valor}

En cada fecha en la que se informa, COMERCIALIZADORA ALLCOMPUTER S.A.S, determinará si un elemento de propiedades, planta y equipo ha presentado deterioro en su valor y, en tal caso deberá reconocer y medir la pérdida por deterioro de valor.

La Compañía reconocerá un gasto por deterioro de valor cuando el valor neto en libros de un elemento de propiedades, planta y equipo sea mayor que su valor recuperable, cual es, el mayor valor entre el valor razonable del activo menos los costos de venta; y el valor de uso del respectivo activo; siendo su valor de uso el valor presente de los flujos futuros estimados de efectivo que se espera obtener del activo.

\subsection{Activos No Corrientes Mantenidos para la Venta}

COMERCIALIZADORA ALLCOMPUTER S.A.S, clasificará un activo no corriente como mantenido para la venta, si su valor en libros se recuperará fundamentalmente a través de una transacción de venta, en lugar de por su uso continuado.

Para aplicar a la clasificación anterior, el activo deberá estar disponible, en sus condiciones actuales, para su venta inmediata, sujeto exclusivamente a los términos usuales y habituales para la venta de estos activos y su venta debe ser altamente probable.

Se entenderá por altamente probable aquel nivel apropiado de la administración de la Compañía, para estar comprometido con un plan para vender el activo, y debe haberse iniciado de forma activa un programa para encontrar un comprador y completar dicho plan. 
COMERCIALIZADORA ALLCOMPUTER S.A.S, medirá los activos no corrientes clasificados como mantenidos para la venta, por su valor en libros, o por su valor razonable menos los costos de venta, el que resulte menor entre ambos.

En aquellos casos en que la Compañía haya clasificado un activo como mantenido para la venta, pero deja de cumplir con los requerimientos respectivos para ser clasificados como tal, se deberán valorizar al menor valor entre:

- Su valor libros antes de que el activo fuera clasificado como mantenido para la venta, ajustado por cualquier depreciación, amortización o revaluación que se hubiera reconocido si el activo no se hubiera clasificado como mantenido para la venta, o

- Su valor recuperable en la fecha de la decisión posterior de no venderlo.

\subsection{Baja en Cuentas de PP\&E}

Previas las acciones administrativas que sean del caso, COMERCIALIZADORA ALLCOMPUTER S.A.S, procederá a dar de baja del inventario de propiedades, planta y equipo, los elementos que cumplan las siguientes características:

- Que no se requieran para el normal desarrollo de las actividades empresariales

- Que por su desgaste, deterioro u obsolescencia no son útiles para el servicio al cual se destinaron

- Que no sean susceptibles de adaptación o reparación, o

- Que hayan sido perdidos o hurtados

En razón a lo anterior, COMERCIALIZADORA ALLCOMPUTER S.A.S, dará de baja en cuentas un elemento de propiedades, plata y equipo: 
- Cuando se enajene, o

- Cuando no se espere obtener beneficios económicos futuros por su uso o enajenación.

La ganancia o pérdida surgida al eliminar de las cuentas una partida de propiedades, planta y equipo se incluirá como utilidad o pérdida del período; y se determinará como la diferencia entre el monto neto que se obtenga por la enajenación y el valor en libros de la partida. Las ganancias no se clasificarán como ingresos ordinarios 


\section{Política de activos intangibles}

\subsection{Objetivo}

Establecer las bases contables para el reconocimiento, medición, presentación y revelación de los activos intangibles de COMERCIALIZADORA ALLCOMPUTER S.A.S

\subsection{Alcance}

Esta política contable aplica para aquellas erogaciones que tengan el carácter de intangible y sobre las cuales:

a) se espera obtener beneficios económicos futuros,

b) se posea el control y

c) sean plenamente identificables.

Incluye las siguientes clases de activos intangibles, siempre y cuando cumplan con los lineamientos indicados anteriormente:

Las licencias y derechos de software: Las licencias de programas informáticos y software adquiridos, son derechos que se obtienen para utilizar un software cumpliendo los términos y condiciones establecidas dentro del contrato que celebran el proveedor o titular de los derechos y COMERCIALIZADORA ALLCOMPUTER S.A.S 


\subsection{Política Contable General}

Los activos intangibles son activos identificables, de carácter no monetario, y sin sustancia o contenido físico, que surgen a través de la adquisición.

\subsection{Reconocimiento y Medición}

\subsubsection{Reconocimiento Inicial}

COMERCIALIZADORA ALLCOMPUTER S.A.S, reconoce en sus estados financieros un elemento como activo intangible cuando estos cumplen la totalidad de los siguientes requisitos:

a. Que sean identificables, es decir, que sea separable, susceptible de ser separado o dividido, de COMERCIALIZADORA ALLCOMPUTER S.A.S y vendido, transferido, dado en explotación, arrendado o intercambiado, ya sea individualmente junto con un contrato, un activo o un pasivo relacionado, o surge de un contrato o de otros derechos legales, independiente de que estos sean trasferibles o separables de la entidad.

b. Que sean controlables: Se refiere a la capacidad que tiene COMERCIALIZADORA ALLCOMPUTER S.A.S para obtener los beneficios económicos futuros que proceden del activo intangible, bien sea por derechos de tipo legal u otro tipo, además la capacidad de COMERCIALIZADORA ALLCOMPUTER S.A.S de restringir el acceso a dichos beneficios a otras personas.

c. Que su costo pueda ser medido fiable y razonablemente, lo anterior hace referencia al valor acordado con el proveedor. 
d. Que genere beneficios económicos futuros: bien sea por el incremento de los ingresos de COMERCIALIZADORA ALLCOMPUTER S.A.S o debido a una reducción de los costos.

e. Que el activo intangible no sea resultado de un desembolso incurrido internamente.

Las erogaciones que no cumplan todas las condiciones para el reconocimiento como activos intangibles en el estado de situación financiera, deben ser reconocidas como gastos en el estado de resultados, en el periodo en que ellas se incurran.

\subsubsection{Medición Inicial}

Los activos intangibles se registran inicialmente al costo de adquisición que incluye todos los desembolsos identificables directamente.

El reconocimiento de los costos del activo intangible finaliza cuando el activo se encuentre en el lugar y condiciones necesarias para operar de la forma prevista por COMERCIALIZADORA ALLCOMPUTER S.A.S Por ello, los costos soportados por la utilización o por la reprogramación del uso de un activo intangible no se incluyen como parte del activo.

Otros Activos Intangibles Generados Internamente

Ningún activo intangible generado internamente debe ser reconocido como activo intangible en los estados financieros de COMERCIALIZADORA ALLCOMPUTER S.A.S Sólo las adquisiciones de intangibles de manera separada pueden ser reconocidas como tal en los estados financieros de COMERCIALIZADORA ALLCOMPUTER S.A.S 


\subsubsection{Medición Posterior}

Para la medición posterior de los activos intangibles se aplica el modelo del costo el cual incluye el costo de adquisición menos cualquier amortización acumulada y cualquier pérdida por deterioro de valor acumulada (de acuerdo a la política NIIF de deterioro del valor de los activos de la COMERCIALIZADORA ALLCOMPUTER S.A.S).

\subsection{Amortización}

La amortización comienza cuando el activo intangible esté disponible para su utilización, es decir, cuando se encuentre en la ubicación y condiciones necesarias para que se pueda usar de la forma prevista. La amortización cesa cuando el activo se da de baja en cuentas.

La amortización mensual se reconoce directamente en el gasto del periodo.

Los activos intangibles de COMERCIALIZADORA ALLCOMPUTER S.A.S se amortizarán por el método de línea recta sobre el $100 \%$ de su costo según la vida útil proyectada, la cual se establece así:

a. Licencias de Software: entre 1 y 10 años. El área de sistemas determinará la vida útil del software que usa en sus instalaciones e informará estos datos a la administración.

b. Actualizaciones: cuando se haga una actualización la Dirección de sistemas informará al área contable mediante memorando el tiempo en que se incrementa la vida útil del activo principal y se amortizará de acuerdo a la nueva vida útil recalculada.

c. Si la vida útil del activo intangible no se puede estimar confiablemente se presume que es de diez (10) años. 
d. Independiente de la intención que se tenga con el activo la amortización solo cesa en el momento en el que COMERCIALIZADORA ALLCOMPUTER S.A.S realice la transferencia de riesgos y beneficios a un tercero, o bien dar de baja al activo por alguna otra condición.

Factores tales como un cambio en el uso de un activo intangible, avances tecnológicos y cambios en los precios de mercado podrían indicar que ha cambiado la vida útil de un activo intangible desde la fecha sobre la que se informa correspondiente al periodo anual más reciente. Por tanto, al cierre contable anual, el responsable de contabilidad de COMERCIALIZADORA ALLCOMPUTER S.A.S, debe revisar la vida útil de acuerdo a los conceptos de las áreas pertinentes y el método de amortización de todos los activos intangibles.

COMERCIALIZADORA ALLCOMPUTER S.A.S contabiliza cualquier cambio en el método de amortización o la vida útil como un cambio en una estimación contable, de acuerdo con los párrafos 10.15 a 10.18 de la sección 10 de NIIF para PYMES.

\subsection{Retiro y Venta}

Se retira un activo intangible de los estados financieros cuando COMERCIALIZADORA ALLCOMPUTER S.A.S espere no obtener beneficios económicos futuros o por su uso por su venta, o bien cuando COMERCIALIZADORA ALLCOMPUTER S.A.S decida vender el activo. Se reconoce la pérdida o ganancia por la disposición del activo en el estado de resultados del periodo correspondiente. 


\subsection{Deterioro de Valor}

Al final del periodo contable anual, COMERCIALIZADORA ALLCOMPUTER S.A.S debe asegurar que el costo neto en libros de los activos no exceda su valor recuperable, según lo establecido en la política contable de pérdida por deterioro de valor de los activos bajo NIIF.

\subsection{Presentación y Revelación}

COMERCIALIZADORA ALLCOMPUTER S.A.S debe revelar la siguiente información de cada grupo de activos intangibles, así:

a. Vidas útiles utilizadas o tasas de amortización utilizadas.

b. Métodos de amortización utilizados.

c. El valor en libros y la amortización acumulada (con su respectivo valor acumulado de pérdidas por deterioro de valor) en el inicio y al final del periodo sobre el que se informe.

d. Una conciliación entre los valores en libros de los activos intangibles al principio y al final del periodo sobre el que se informa.

\subsection{Normativa Aplicable}

La elaboración de esta política contable se sustenta en las siguientes normas:

Sección 3. Presentación de Estados Financieros

Sección 10. Políticas Contables, estimaciones y Errores

Sección 18. Activos Intangibles distintos de la Plusvalía 
Sección 27. Deterioro del Valor de los Activos 


\section{Política contable de arrendamientos}

\subsection{Objetivo}

Definir los criterios que COMERCIALIZADORA ALLCOMPUTER S.A.S, en adelante la Compañía, aplicará para el reconocimiento, clasificación, medición, presentación e información a revelar de los arrendamientos, bajo la modalidad de financiero y, operativo.

\subsection{Alcance}

Esta política contable ha sido elaborada con base en los contratos de arrendamientos con que cuenta S.A.S., a la fecha de emisión de la misma. Aplicará a la contabilización de los arrendamientos en la modalidad de:

- Arrendamiento financiero

- Arrendamiento operativo

\subsection{Normativa Aplicable}

La elaboración de esta política contable para los arrendamientos de COMERCIALIZADORA ALLCOMPUTER S.A.S, se sustenta en las siguientes normas:

Sección 3. Presentación de Estados Financieros 
Sección 20. Arrendamientos

\subsection{Definiciones}

Arrendamiento: es un acuerdo por el que el arrendador cede al arrendatario, a cambio de percibir una suma única de dinero, o una serie de pagos o cuotas, el derecho a utilizar un activo durante un periodo de tiempo determinado.

Arrendatario: es quien toma o tiene el derecho a utilizar el activo

Arrendador: es quien cede al arrendatario, a cambio de recibir una suma única de dinero o una serie de pagos o cuotas, el derecho a utilizar el activo

Arrendamiento financiero: es un tipo de arrendamiento en el que se transfieren sustancialmente todos los riesgos y ventajas inherentes a la propiedad del activo. La propiedad del mismo, en su caso, puede o no ser transferida.

Arrendamiento operativo: es cualquier acuerdo de arrendamiento distinto al arrendamiento financiero.

Inicio del arrendamiento: es la fecha más temprana entre la del acuerdo del arrendamiento y la fecha en que se comprometen las partes en relación con las principales estipulaciones del mismo. En esta fecha:

- Se clasificará el arrendamiento como operativo o financiero; y

- En el caso de tratarse de un arrendamiento financiero, se determinarán los valores que se reconocerán al comienzo del plazo de arrendamiento.

Comienzo del plazo del arrendamiento: es la fecha a partir de la cual el arrendatario tiene el derecho de utilizar el activo arrendado. Es la fecha del reconocimiento inicial del arrendamiento 
(es decir, del reconocimiento de activos, pasivos, ingresos o gastos derivados del arrendamiento, según proceda).

Plazo del arrendamiento: es el periodo no revocable por el cual el arrendatario ha contratado el arrendamiento del activo, junto con cualquier periodo adicional en el que éste tenga derecho a continuar con el arrendamiento, con o sin pago adicional, siempre que al inicio del arrendamiento se tenga la certeza razonable de que el arrendatario ejercitará tal opción.

Pagos mínimos por el arrendamiento: son los pagos que se requieren o pueden requerírsele al arrendatario durante el plazo del arrendamiento, excluyendo tanto las cuotas de carácter contingente como los costos de los servicios y los impuestos que ha de pagar el arrendador y le hayan de ser reembolsados.

Costos directos iniciales: son los costos incrementales directamente imputables a la negociación y contratación de un arrendamiento, salvo si tales costos han sido incurridos por un arrendador que sea a la vez fabricante o distribuidor.

Tasa de interés implícita en el arrendamiento: es la tasa de descuento que, al inicio del arrendamiento, produce la igualdad entre el valor presente total de:

- Los pagos mínimos por el arrendamiento

- El valor residual no garantizado, y la suma del valor razonable del activo arrendado y cualquier costo directo inicial del arrendador.

Tasa de interés incremental del endeudamiento del arrendatario: es la tasa de interés que el arrendatario habría de pagar en un arrendamiento similar o, si éste no fuera determinable, la tasa en la que éste incurriría si pidiera prestados, en un plazo y con garantías similares, los fondos necesarios para comprar el activo. 
Cuotas contingentes del arrendamiento: son la parte de los pagos por arrendamiento cuyo valor no es fijo, sino que se basa en el valor futuro de un factor que varía por razones distintas del solo paso del tiempo

Inversión bruta en el arrendamiento: es la suma de:

- Los pagos mínimos a recibir por el arrendamiento financiero, y

- Cualquier valor residual no garantizado que corresponda al arrendador

Inversión neta en el Arrendamiento: Es la inversión bruta del arrendamiento descontada al tipo de interés implícito en el arrendamiento

\section{Valor residual garantizado: es:}

- Para el arrendatario; la parte del valor residual que ha sido garantizada por él mismo o por un tercero vinculado con él (el valor de la garantía es la cuantía máxima que podrían, en cualquier caso, tener que pagar; $y$

- Para el arrendador; la parte del valor residual que ha sido garantizada por el arrendatario o por un tercero, no vinculado con el arrendador, y que sea financieramente capaz de atender las obligaciones derivadas de la garantía prestada.

Valor residual no garantizado: es la parte del valor residual del activo arrendado, cuya realización por parte del arrendador no está asegurada o bien queda garantizada exclusivamente por un tercero vinculado con el arrendador.

\section{Vida económica: es:}

- El periodo durante el cual se espera que un activo sea utilizable económicamente, por parte de uno o más usuarios; o

- La cantidad de unidades de producción o similares que se espera obtener del activo por parte de uno o más usuarios 
Vida útil: es el periodo de tiempo estimado que se extiende, desde el comienzo del plazo del arrendamiento, pero sin estar limitado por éste, a lo largo del cual la entidad espera consumir los beneficios económicos incorporados al activo arrendado

Valor razonable: valor por el que puede ser intercambiado un activo, o cancelado un pasivo, entre partes interesadas y debidamente informadas, en una transacción realizada en condiciones de independencia mutua.

\subsection{Clasificación de un Contrato de Arrendamiento}

La clasificación de un arrendamiento se hace al inicio del mismo y no se cambia durante su plazo salvo que el arrendatario y el arrendador acuerden cambiar las cláusulas del arrendamiento (distintas de la simple renovación del mismo), en cuyo caso la clasificación del contrato de arrendamiento deberá ser evaluada nuevamente.

- Un arrendamiento se clasificará como arrendamiento financiero si transfiere sustancialmente todos los riesgos y ventajas inherentes a la propiedad del activo, y contempla una opción de compra.

- Un arrendamiento se clasificará como arrendamiento operativo si no transfiere sustancialmente todos los riesgos y ventajas inherentes a la propiedad del activo.

La clasificación de si un arrendamiento es financiero u operativo, depende de la esencia de la transacción y no de la forma del contrato.

Además de lo anterior, la normativa señala otros indicadores para clasificar un contrato de arrendamiento como financiero: 
- Si el arrendatario puede cancelar el contrato de arrendamiento, y las pérdidas sufridas por el arrendador a causa de tal cancelación fueran asumidas por el arrendatario

- Las pérdidas o ganancias derivadas de fluctuaciones en el valor residual del activo recaen sobre el arrendatario

- El arrendatario tiene la posibilidad de prorrogar el arrendamiento durante un segundo periodo, con unos pagos por arrendamiento que son sustancialmente inferiores a los habituales del mercado

Es claro, por otras características, que, si el contrato de arrendamiento no transfiere sustancialmente todos los riesgos y ventajas inherentes a la propiedad del bien entregado y recibido en arriendo, se clasificará como operativo.

En la gráfica siguiente, se indican las situaciones bajo las cuales un contrato de arrendamiento se clasificará como arrendamiento financiero o arrendamiento operativo. 


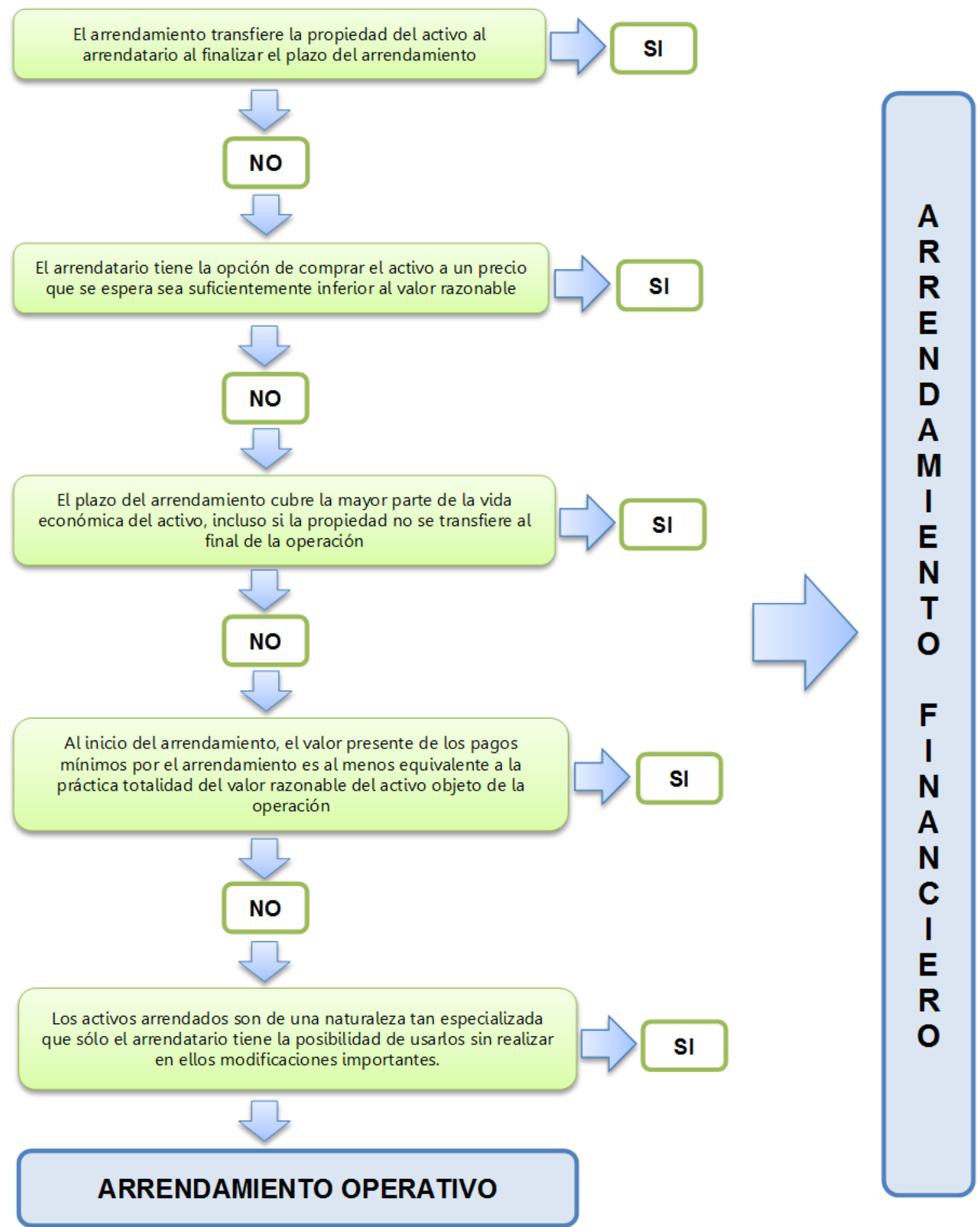




\subsection{Arrendamiento Operativo}

\subsubsection{Comercializadora Allcomputer S.A.S, como arrendatario}

\subsubsection{Reconocimiento y Medición}

COMERCIALIZADORA ALLCOMPUTER S.A.S, reconocerá los pagos de arrendamientos bajo la modalidad de arrendamientos operativos, excluyendo los costos por servicios tales como seguros o mantenimientos, como un gasto, de forma lineal durante el transcurso del plazo del arrendamiento.

\subsubsection{Presentación y Revelaciones}

Como arrendatario, COMERCIALIZADORA ALLCOMPUTER S.A.S, revelará la siguiente información para los arrendamientos operativos:

1. El total de pagos futuros mínimos del arrendamiento, bajo contratos de arrendamiento operativo no cancelables para cada uno de los siguientes periodos:

- Hasta un año

- Entre uno y cinco años; y

- Más de cinco años.

2. Los pagos por arrendamiento reconocidos como un gasto.

3. Una descripción general de los acuerdos contractuales del arrendamiento significativos para la Compañía, incluyendo: información sobre cuotas contingentes, opciones de 
renovación o adquisición y cláusulas de revisión, subarrendamientos y restricciones impuestas por los acuerdos de arrendamiento.

\subsubsection{Presentación y Revelaciones}

COMERCIALIZADORA ALLCOMPUTER S.A.S, en su calidad de arrendador, revelará la siguiente información para los arrendamientos operativos:

1. Los ingresos futuros mínimos del arrendamiento en arrendamientos operativos no cancelables, para cada uno de los siguientes periodos:

- Hasta un año

- Entre uno y cinco años; y

- Más de cinco años.

2. Las cuotas contingentes totales reconocidas como ingreso.

3. Una descripción general de los acuerdos contractuales de arrendamiento significativos para la Compañía, incluyendo: información sobre cuotas contingentes, opciones de renovación o adquisición y cláusulas de revisión, y restricciones impuestas por los acuerdos de arrendamiento.

4. Los demás requerimientos de información a revelar sobre activos de acuerdo con las secciones 17 propiedades planta y equipo, 18 activos intangibles, y 27 deterioro del valor de los activos, a los arrendadores por los activos suministrados en arrendamiento operativo 


\section{Política contable de ingresos de actividades ordinarias}

\subsection{Objetivo}

Establecer las bases contables para el reconocimiento, medición, presentación y revelación de la información relacionada con los ingresos generados en el curso de las actividades ordinarias de la COMERCIALIZADORA ALLCOMPUTER S.A.S, siempre que tal entrada dé lugar a un aumento en el patrimonio (que no esté relacionado con los aportes de los propietarios de ese patrimonio).

\subsection{Alcance}

Esta política contable debe ser aplicada al reconocer ingresos procedentes de las siguientes transacciones:

a. Ingresos por ventas y servicios propios de la actividad económica.

b. Rendimientos financieros por intereses generados en inversiones y préstamos.

c. Otros ingresos.

\subsection{Normativa Aplicable}

La elaboración de esta política contable para los ingresos por actividades ordinarias de COMERCIALIZADORA ALLCOMPUTER S.A.S, se sustenta en las siguientes normas: 
Sección 3, Presentación de Estados Financieros

Sección 23, Ingresos de Actividades Ordinarias

\subsection{Definiciones}

Ingreso de actividades ordinarias: es la entrada bruta de beneficios económicos, producidos a lo largo del periodo sobre el que informa, surgidos en el curso de las actividades ordinarias de la Compañía, siempre que tal entrada de lugar a un aumento en el patrimonio, que no esté relacionado con las aportaciones de los propietarios de ese patrimonio.

Venta de bienes: acción por la cual se intercambian suministros a un precio determinado.

Prestación de servicios: actividades, beneficios o satisfacciones; identificables e intangibles que son el objeto principal de una transacción ideada para brindar a los clientes satisfacción de deseos o necesidades.

Valor razonable: es el monto por el que un activo podría ser intercambiado o un pasivo liquidado, entre partes interesadas y debidamente informadas, en una transacción realizada en condiciones de independencia mutua.

\subsection{Política Contable General}

\subsubsection{Ingresos por Ventas de Vidrios}

Corresponden a los ingresos por venta de:

- Vidrio Templado 
- Vidrio Laminado

- Vidrio Curvo

- Vidrios Inteligentes

- Ventanas

- Pasamanos o barandas

- Fachadas

- Divisiones de baño

- Accesorios Inoxidables

- Puertas

- Otros

\subsubsection{Ingresos por Prestaciones de Otros Servicios}

Corresponden a los diferentes tipos de servicios que ofrece COMERCIALIZADORA ALLCOMPUTER S.A.S, a sus clientes como son la instalación de los artículos vendidos.

\subsubsection{Ingresos Rendimientos Financieros e Intereses}

Corresponden a los valores que obtiene COMERCIALIZADORA ALLCOMPUTER S.A.S por concepto de rendimientos en el uso de efectivo, de equivalentes al efectivo o inversiones y préstamos. 


\subsection{Reconocimiento y Medición}

El reconocimiento de ingresos se aplica por separado a cada transacción (venta de bienes, prestación de servicios, entre otros), con el fin de reflejar la esencia de cada operación y se miden a valor razonable de la contraprestación.

COMERCIALIZADORA ALLCOMPUTER S.A.S debe reconocer los ingresos en sus estados financieros si sus valores son estimados confiablemente, y se cumplen las siguientes condiciones expuestas en las NIIF para PYMES:

a. El valor de los ingresos de actividades por la prestación del servicio pueda ser medido con fiabilidad.

b. Es probable que la entidad reciba los beneficios económicos asociados con la transacción.

c. Que el grado de realización de la transacción, al final del periodo sobre el que se informa, pueda ser medido con fiabilidad.

d. Los costos incurridos en la prestación del servicio, así como los que falten por incurrir hasta completarlo, puedan ser medidos con fiabilidad.

Los ingresos de años anteriores deben ser reconocidos como mayor valor del patrimonio en cuenta separada del patrimonio.

Los ingresos de actividades ordinarias procedentes de la venta de bienes deben ser reconocidos y registrados en los estados financieros cuando se cumplen todas y cada una de las siguientes condiciones:

a. COMERCIALIZADORA ALLCOMPUTER S.A.S, ha transferido al comprador los riesgos y ventajas, de tipo significativo, derivados de la propiedad de los bienes. 
b. COMERCIALIZADORA ALLCOMPUTER S.A.S, no conserva para sí ninguna implicación en la gestión corriente de los bienes vendidos, en el grado usualmente asociado con la propiedad, ni retiene el control efectivo sobre los mismos.

c. El importe de los ingresos de actividades ordinarias pueda medirse con fiabilidad.

d. Sea probable que la entidad reciba los beneficios económicos asociados con la transacción; $\mathrm{y}$

e. Los costos incurridos, o por incurrir, en relación con la transacción pueden ser medidos con fiabilidad.

El valor de los ingresos de actividades ordinarias derivados de una transacción se determina, normalmente, por acuerdo entre COMERCIALIZADORA ALLCOMPUTER S.A.S, y los terceros. Se medirán al valor razonable de la contrapartida recibida o por recibir, teniendo en cuenta el importe de cualquier descuento, bonificación o rebaja comercial que la entidad pueda otorgar, los cuales se deben llevar como un menor valor del ingreso.

La facturación se realiza de acuerdo a la solicitud por los diferentes conceptos, por tanto, el ingreso queda reconocido al término de la operación.

Como parámetro general, la cuantificación de los ingresos debe hacerse utilizando el valor razonable de la contrapartida, recibida o por recibir, derivada de los mismos, deduciendo el importe de cualquier descuento o rebaja.

Los descuentos y similares se contabilizarán en la cuenta de descuentos comerciales de ventas, los descuentos y similares posteriores a la emisión de la factura originados por otros conceptos como incumplimiento de los plazos de entrega u otras causas, se contabilizarán en cuentas de bonificaciones y descuentos o de devoluciones, según se trate. Estas partidas se presentarán dentro de la línea de ingresos, disminuyendo, por tanto, el valor de la venta. 
Los descuentos y similares incluidos en factura que obedezcan a pronto pago se considerarán como menor valor de la venta.

Se entiende por descuentos por pronto pago aquellos motivados por adelantar el cobro sobre los plazos de cobro establecidos en las condiciones del contrato. Este tipo de descuentos se deberán estimar en el momento de la venta y presentarse como menor valor de la misma.

\subsection{Presentación y Revelación}

COMERCIALIZADORA ALLCOMPUTER S.A.S, debe presentar por separado los valores de los diferentes tipos de ingresos que genere.

COMERCIALIZADORA ALLCOMPUTER S.A.S, debe revelar en los estados financieros o por medio de notas que serán parte integral del juego de estados financieros:

a. Las políticas contables adoptadas para el reconocimiento de los ingresos de actividades ordinarias, incluyendo los métodos utilizados para determinar el porcentaje de terminación de las transacciones involucradas en la prestación de servicios.

b. El importe de cada categoría de ingresos de actividades ordinarias reconocida durante el periodo. 


\section{Política contable de costos por préstamos}

\subsection{Objetivo}

Establecer las bases contables para el reconocimiento, medición, presentación y revelación de los pasivos financieros de COMERCIALIZADORA ALLCOMPUTER S.A.S

\subsection{Alcance}

Esta política contable aplica para los pasivos financieros presentados en el estado de situación financiera de COMERCIALIZADORA ALLCOMPUTER S.A.S, así:

- Obligaciones financieras: Corresponde a préstamos solicitados a entidades financieras o con terceros en condiciones financieras del mercado.

- Proveedores: Corresponde a las obligaciones contraídas por COMERCIALIZADORA ALLCOMPUTER S.A.S, para la adquisición de bienes y/o servicios recibidos de proveedores, en desarrollo de su objeto social.

- Acreedores: Corresponde a las obligaciones adquiridas por COMERCIALIZADORA ALLCOMPUTER S.A.S, en cumplimiento de su objeto social, por concepto de: honorarios, servicios, arrendamientos, transportes y fletes, seguros, gastos de viaje, impuestos, entre otros. 
No está bajo el alcance de esta política los pasivos que no tengan origen contractual, tales como el impuesto a las ganancias y otros impuestos por pagar, que se crean como resultado de un requerimiento legal impuesto por el Gobierno, así mismo los anticipos recibidos de terceros (acumulados y valores para venta de bienes), no son activos financieros o pasivos financieros. Ver política de impuestos por pagar y anticipos recibidos por tercero.

La contabilización de los impuestos se realiza conforme a la política contable bajo NIIF de impuestos por pagar, dado que como se mencionó no proceden de contratos y no son pasivos financieros.

\subsection{Política Contable}

Los pasivos financieros mencionados en el alcance de esta política son instrumentos financieros básicos bajo NIIF para pymes, de los cuales surge la obligación de COMERCIALIZADORA ALLCOMPUTER S.A.S, a transferir efectivo u otro activo financiero a terceros, para cancelar las obligaciones surgidas en dichos contratos financieros.

\subsection{Normativa Aplicable}

La elaboración de esta política contable para los costos por préstamos de COMERCIALIZADORA ALLCOMPUTER S.A.S, se sustenta en las siguientes normas:

Sección 5. Estado de Resultados Integral y Estado de Resultados

Sección 11. Instrumentos Financieros Básicos

Sección 25. Costos por Préstamos 


\subsection{Definiciones}

Método de Interés Efectivo: Es el método de cálculo del costo amortizado de un activo financiero o de un pasivo financiero (o de un grupo de activos financieros o pasivos financieros) y de imputación del ingreso o gasto financiero a lo largo del periodo relevante.

Costos por Préstamos: Intereses y otros costos, incurridos por la entidad, que están relacionados con los préstamos de fondos recibidos.

\subsection{Reconocimiento y Medición Inicial}

COMERCIALIZADORA ALLCOMPUTER S.A.S reconoce sus pasivos financieros, en el momento en que se convierte en parte obligada (adquiere obligaciones), según los términos contractuales de la operación, lo cual sucede usualmente cuando se recibe el dinero para el caso de las Obligaciones Financieras.

También se reconocen pasivos por concepto de proveedores y acreedores por pagar, en la medida que el tercero le preste un servicio o venda un producto a COMERCIALIZADORA ALLCOMPUTER S.A.S

Se miden inicialmente por su valor nominal menos los costos de transacción directamente atribuibles al pasivo financiero. 


\subsubsection{Medición Posterior}

Los pasivos financieros son valorados mensualmente al costo amortizado, utilizando el método de la tasa de interés efectiva, esto independiente de la periodicidad con la que se cancelen los intereses o rendimientos o se abone al capital del crédito de acuerdo a las cuotas pactadas con el tercero.

Para esto se debe preparar un flujo de efectivo estimado (considerando las entradas y salidas reales de efectivo) para cada pasivo financiero de COMERCIALIZADORA ALLCOMPUTER S.A.S, donde se tiene en cuenta todos los costos de transacción atribuibles al pasivo financiero, las proyecciones de las cuotas (interés o rendimientos y abono a capital), que se cobren durante el plazo del instrumento.

El siguiente procedimiento aplica para los dos casos mencionados anteriormente:

\section{Procedimiento:}

- Elaborar una tabla de amortización por pasivo financiero, teniendo en cuenta: el plazo, fecha de inicio, fecha de vencimiento, el tipo de interés a utilizar y la forma de pagar capital e intereses.

- Se debe incluir cualquier costo financiero pactado, hasta la fecha de vencimiento del pasivo.

- Elaborar una proyección del flujo de efectivo mensual por pasivo, teniendo en cuenta la entrada del dinero (o entradas de dinero cuando sea el caso) y las salidas de efectivo correspondientes a: pagos de interés y capital.

- Calcular la tasa que iguala todos los flujos en un mismo periodo (mes), que corresponde a la TIR (Tasa Interna de Retorno) del mismo. 
- Actualizar mensualmente para el cierre contable, la proyección de los flujos de efectivo para los pasivos financieros que hayan sufrido variaciones con respecto a las condiciones pactadas inicialmente: tasa de interés, plazo y monto.

\subsubsection{Reconocimiento posterior de los costos financieros}

Los intereses por pagar se reconocen mensualmente, calculados según lo pactado con el tercero.

Se calculan tomando el saldo adeudado multiplicado por la tasa de interés efectiva expresada en términos mensuales. El reconocimiento se realiza debitando el gasto financiero contra un mayor valor del pasivo financiero (sub cuenta contable de intereses de pasivos financieros de naturaleza crédito).

A continuación, se exponen los registros contables para el pago del capital y de intereses relacionados con los pasivos financieros:

Pago de capital: Los abonos al capital se reconocen en el momento en que ocurran y se registran como un menor valor del pasivo financiero.

Pago de intereses: Cuando se pagan los intereses se debita la subcuenta contable de intereses de pasivos financieros (donde se han causado mediante la tasa de interés efectiva expresada en términos mensuales) por el valor a cancelar en el periodo correspondiente contra la salida del efectivo; en este pago se podrán presentar las siguientes situaciones:

- Que el interés causado con la tasa de interés efectiva sea superior al valor a cancelar en el periodo correspondiente, por lo cual se generará un saldo remanente en la subcuenta contable de pasivos financieros que será revertido en periodos posteriores. 
- Que el interés causado sea inferior al valor a cancelar por el periodo correspondiente, por lo tanto, la subcuenta de intereses de pasivos financieros tendrá un saldo débito si en periodos anteriores no se generó un remanente que pueda ser revertido.

- Que el interés causado sea igual al valor a cancelar por el periodo correspondiente, caso en el cual, la subcuenta contable de intereses de pasivos financieros no deberá tener saldo al final del periodo.

\subsection{Bajas en Cuentas}

COMERCIALIZADORA ALLCOMPUTER S.A.S, retira de su balance general un pasivo financiero cuando se haya extinguido la obligación contraída con los terceros, esto es, cuando la obligación específica en el correspondiente contrato haya sido pagada o cancelada.

\subsection{Presentación y Revelaciones}

La presentación en los estados financieros y las revelaciones en notas relacionados con los pasivos financieros se efectuará considerando lo siguiente:

- Se deben presentar por separado los pasivos financieros en términos corrientes y no corrientes. Se presenta como corriente los saldos o cuotas de obligaciones que se deben pagar en los 12 meses siguientes a la fecha de cierre. Se presenta como no corriente las obligaciones cuyos plazos o fechas de pago, exceden de un (1) año, después de la fecha de cierre. 
- Revelar las condiciones o requisitos comprometidos a cumplir en virtud de acuerdos con los terceros.

- Revelar las políticas contables para el reconocimiento y medición de los intereses y costos financieros sobre los pasivos financieros.

- Revelar compromisos adquiridos para recibir nuevos pasivos financieros. 


\section{Política contable de deterioro del valor de los activos}

\subsection{Objetivo}

Establecer las bases contables para el reconocimiento, medición, presentación y revelación del deterioro de valor de las cuentas por cobrar y otros activos financieros medidos al costo menos deterioro y costo amortizado en COMERCIALIZADORA ALLCOMPUTER S.A.S

\subsection{Alcance}

Esta política contable aplica para los siguientes grupos de activos financieros o cuentas por cobrar que posee COMERCIALIZADORA ALLCOMPUTER S.A.S
a. Cuentas por cobrar a clientes
b. Cuentas por cobrar a socios
c. Cuentas por cobrar a empleados
d. Cuentas por cobrar deudores varios
e. Inversiones medidas al costo y costo amortizado, tales como:

- Certificados de depósitos a término CDT

- Encargos fiduciarios o carteras colectivas que no cumplan con la definición de equivalentes de efectivo, citada en la política contable NIIF de efectivo

- Acciones 
- Instrumento de deuda: Bonos ordinarios

- Otras inversiones aprobadas que no estén dentro del alcance de otra política contable NIIF

No es del alcance de esta política las cuentas por cobrar por concepto de impuestos y contribuciones por pagar al Estado (o cruzar con cuentas por pagar) debido a que no presentarían retraso en su pago, adicionalmente los anticipos por concepto de impuestos no se consideran cuentas por cobrar bajos las NIIF, debido a que no generan el derecho a recibir efectivo u otro instrumento financiero.

\subsection{Normativa Aplicable}

La elaboración de esta política contable para el deterioro del valor de los activos de COMERCIALIZADORA ALLCOMPUTER S.A.S, se sustenta en las siguientes normas:

Sección 3, Presentación de Estados Financieros

Sección 10, Políticas Contables, Estimaciones y Errores

Sección 27, Deterioro del Valor de los Activos

\subsection{Definiciones}

Deterioro del valor de un activo: se da cuando el valor en libros de un activo es mayor a su valor recuperable (precio de venta menos los costos de terminación y venta). 
Valor en libros: es el valor por el que se reconoce un activo, una vez deducidas la depreciación o amortización acumuladas y las pérdidas por deterioro del valor acumuladas, que se refieran al mismo.

Valor razonable menos los costos de venta: es el valor que se puede obtener por la venta de un activo, en una transacción realizada en condiciones de independencia mutua, entre partes interesadas y debidamente informadas, menos los costos de disposición.

Pérdida por deterioro del valor: es el monto en que excede el valor en libros de un activo a su valor recuperable.

Valor recuperable de un activo: es el mayor entre su valor razonable menos los costos de venta y su valor en uso.

Valor en uso: es el valor presente de los flujos futuros de efectivo estimados que se pueden obtener de un activo a lo largo de su vida útil.

Para calcular el valor presente es necesario proyectar las entradas y salidas de efectivo originadas en la utilización del activo y aplicar una tasa de descuento adecuada según los flujos futuros que se esperan obtener con el tiempo.

Deterioro del valor de los inventarios: el deterioro de los inventarios se produce cuando al cierre del periodo que se va a informar, el valor en libros de cada partida del inventario es mayor a su valor recuperable (precio de venta menos los costos de terminación y venta). Este deterioro se registra en las cuentas de resultados como un gasto y se disminuye el valor del inventario.

La Compañía, en el siguiente periodo que se va a informar, hará una nueva evaluación del valor recuperable de los inventarios y si las condiciones económicas que habían originado el ajuste por deterioro hacen que este valor mejore en relación con el valor en libros, se reversará el deterioro registrado hasta el límite contabilizado. 
Deterioro del valor de otros activos distintos de los inventarios: el deterioro de otros activos, distintos de los inventarios, se produce cuando al cierre del periodo que se va a informar, el valor en libros del activo es mayor a su valor recuperable. El valor recuperable es el mayor entre el valor razonable menos los costos de venta y el valor en uso. Este deterioro se registra en las cuentas de resultados como un gasto y se disminuye el valor del activo.

\subsection{Identificación de Indicadores de Deterioro del Valor de los Activos}

Al final de cada periodo contable COMERCIALIZADORA ALLCOMPUTER S.A.S, deberá verificar la existencia de indicadores de deterioro en el valor de los activos.

Si existiera evidencia objetiva de este indicio, la Compañía estimará el valor recuperable del activo, y contabilizará en resultados una perdida por deterioro. Si no existen indicios de deterioro del valor, no será necesario estimar el valor recuperable.

\subsubsection{Fuentes Externas, Indicadoras de Deterioro}

1. Si durante el periodo, el valor de mercado de un activo ha disminuido significativamente más de lo que cabría esperar como consecuencia del paso del tiempo o de su uso normal:

- Una nueva tecnología está disponible

- Las frecuentes reparaciones han disminuido el valor del activo

2. Si han tenido lugar o van a tener en un futuro cambios adversos en el ambiente económico, del mercado, o legales en los cuales la entidad opera:

- Inestabilidad política en la región donde la Compañía opera 
- La entrada de competencia en el mercado

Imposición de nuevas obligaciones a la venta o prestación de servicios de la Compañía

1. Ante una venta potencial, el valor en libros de los activos es superior al valor razonable estimado por la Compañía

2. Incremento de las tasas de mercado u otras tasas de rendimiento y esos incrementos afectan significativamente la tasa de descuento utilizada para calcular el valor en uso de un activo y, que disminuyan su valor razonable menos los costos de venta.

\subsubsection{Fuentes Internas, Indicadoras de Deterioro}

1. Evidencia de obsolescencia o deterioro físico del activo

- El reemplazo de los activos se realizará en un futuro cercano (ejemplo doce meses).

- Hay un activo con tecnología más avanzada disponible para reemplazar los existentes.

2. Evidencia de daños físicos en los activos, que afecte su capacidad esperada, afecte la vida útil esperada o se tenga planes de venta.

- El reemplazo de los activos se hará en un futuro cercano (doce meses).

3. Sí han tenido lugar o van a tener en un futuro cambios significativos en la forma en que se usa o se espera usar el activo, que afectarán desfavorablemente a la Compañía:

- El activo no está (o no estará) en funcionamiento.

- La Compañía planea trasladarse y dejar los activos.

- Planes de discontinuar el activo o deshacerse de él.

- Planes de reestructuración de la operación a la que pertenece el activo.

- Planes de reevaluación de la vida útil del activo. 
4. Evidencia disponible en informes internos de la Compañía que indican que el desempeño económico del activo es inferior al esperado:

- Los gastos o el mantenimiento de operación del activo son significativamente más altos que lo que fue presupuestado inicialmente

- Las ganancias operativas (o flujos de efectivo) del activo son significativamente inferiores a lo que fue presupuestado, o a lo que fue en periodos anteriores

\subsection{Medición del Valor Recuperable}

El valor recuperable de un activo es el mayor entre su valor razonable menos los costos de venta y, su valor en uso.

Si no es posible medir el valor razonable, por la inexistencia de bases para realizar una estimación fiable del precio que se podría obtener por la venta del activo, la Compañía puede utilizar el valor en uso del activo como su valor recuperable.

\section{Valor Razonable menos Costos de Venta}

Es el valor que se puede obtener por la venta de un activo, en una transacción realizada en condiciones de independencia mutua entre partes interesadas y debidamente informadas, menos los costos de disposición (venta). La mejor evidencia del valor razonable del activo menos los costos de venta es la existencia de un precio, dentro de un acuerdo vinculante de venta, en una transacción realizada en condiciones de independencia mutua, o el precio de mercado en un mercado activo. Si no existiera esta evidencia, el valor razonable del activo menos los costos de venta, se calculará a partir de la mejor información disponible para reflejar el valor que la 
Compañía podría obtener, en la fecha sobre la que se informa, sobre una transacción de estas características, una vez deducidos los costos de disposición del activo.

\section{Valor en Uso}

Es el valor presente de los flujos futuros de efectivo que se espera obtener de un activo. Este cálculo contempla las siguientes fases:

- Estimar las entradas y salidas futuras de efectivo derivadas de la utilización continuada del activo y de su disposición final

- Aplicar la tasa de descuento adecuada a estos flujos de efectivo futuros

\subsection{Reconocimiento y Medición de la Perdida por Deterioro}

COMERCIALIZADORA ALLCOMPUTER S.A.S, deberá evaluar al final de cada periodo contable, la existencia de evidencia objetiva que indique deterioro sobre el valor de los activos. En caso de existir indicios de pérdida de valor, se estimará el monto recuperable del activo respectivo.

Si el valor recuperable del activo es menor que su valor en libros, este valor deberá ser reducido por la diferencia entre el valor recuperable y el saldo en libros del activo.

La reducción deberá ser reconocida de inmediato en resultados.

Dado que el valor en libros del activo se reduce, los cargos por depreciación del activo se ajustarán en los periodos futuros 


\subsection{Reversión de la Perdida por Deterioro}

COMERCIALIZADORA ALLCOMPUTER S.A.S, en cada periodo posterior al que se informa, evaluará si existe algún indicio de que la perdida por deterioro del valor de los activos reconocida, en periodos anteriores, ya no existe o ha disminuido. Si existiera tal indicio, la Compañía estimará de nuevo el monto recuperable del activo y revertirá la perdida por deterioro del valor de los activos deteriorados.

En caso que sea necesario revertir las pérdidas por deterioro del valor de los activos reconocidos con anterioridad, se aumentará el valor en libros del activo hasta que alcance su valor recuperable. De igual forma, se reajustará el cargo por depreciación (amortización) para los periodos futuros.

Algunos Indicadores de reversión del deterioro, podrían ser:

- Un incremento significativo del valor del activo, en el mercado

- Cambios significativos durante el periodo o esperados en un futuro cercano en el entorno tecnológico, económico, del mercado o legal teniendo un efecto favorable

- Disminuciones significativas en las tasas de interés del mercado que puedan afectar la tasa de descuento utilizada para calcular el valor en uso del activo e incrementar materialmente el valor recuperable del activo

- Cambios significativos que afectaran en la medida en la cual el activo es utilizado

- Evidencias de un informe interno de que el desempeño económico del activo es, o será mayor de lo esperado. 


\subsection{Presentación y Revelaciones}

COMERCIALIZADORA ALLCOMPUTER S.A.S, revelará en las notas a sus estados financieros, respecto al deterioro del valor de los activos, la siguiente información:

1. El valor de las pérdidas por deterioro del valor de los activos reconocidas en resultados durante el periodo; para cada clase de activo deteriorado, y la partida o partidas del estado del resultado integral, en las que esas pérdidas por deterioro del valor estén incluidas.

2. El valor de las reversiones de pérdidas por deterioro del valor de los activos reconocidas en resultados durante el periodo; para cada clase de activo que se reverso el deterioro, y la partida o partidas del estado del resultado integral, en que tales pérdidas por deterioro del valor revirtieron.

3. Para cada pérdida por deterioro del valor o su reversión, que ha sido reconocida durante el ejercicio, la Compañía revelará, los sucesos y circunstancias que llevaron a tal procedimiento.

Si la pérdida de valor reconocida es significativa se debe revelar:

- Sucesos que llevaron a ello, valor

- Para cada activo su naturaleza y el segmento

- Para cada unidad: descripción de la unidad, valor de la perdida, cambios en la forma de agrupar los activos

- El valor recuperable del activo y la forma en que se determino

- Si es el precio de venta, los criterios para ello

- Si es el valor en uso, la tasa de descuento usada 


\section{Política beneficios a empleados}

\subsection{Objetivo}

Definir los criterios que COMERCIALIZADORA ALLCOMPUTER S.A.S, en adelante la Compañía, aplicará para el reconocimiento, medición, presentación e información a revelar de los beneficios o retribuciones que la Compañía les otorga a sus empleados.

\subsection{Alcance}

Los empleados pueden prestar servicios a la Compañía a tiempo completo o tiempo parcial, de forma permanente, ocasional o temporal. Para los propósitos de esta política, el término “empleado” incluye también a los administradores y al personal gerencial.

Esta política contable ha sido elaborada con base en todas las retribuciones, salariales, prestacionales y otras, que COMERCIALIZADORA ALLCOMPUTER S.A.S, otorga a sus empleados, a la fecha de emisión de la misma, y aplicará a la contabilización de:

- Beneficios corrientes o a corto plazo: comprende sueldos, salarios, horas extras, recargos, incapacidades, auxilios, prestaciones sociales, vacaciones, indemnizaciones, aportes a la seguridad social y parafiscales, dotaciones, ausencias y otros, propios de la relación contractual, pagaderos en el plazo de un año. 
Esta política no se aplicará a los servicios recibidos de terceros cuya relación contractual obedece a un acuerdo de prestación de servicios.

\subsection{Normativa Aplicable}

La elaboración de esta política contable para los beneficios a los empleados de COMERCIALIZADORA ALLCOMPUTER S.A.S, se sustenta en las siguientes normas:

Sección 3. Presentación de Estados Financieros

Sección 28. Beneficios a los Empleados

\subsection{Definiciones}

Beneficios a empleados: es todo tipo de contraprestaciones que la Compañía proporciona a los trabajadores a cambio de los servicios prestados.

Ausencias remuneradas acumulables: son ausencias remuneradas cuyo disfrute se difiere, de manera que pueden ser usadas en periodos posteriores, si en el periodo corriente no se han usado en su totalidad (vacaciones).

Valor presente: es una estimación actual del valor descontado presente de las futuras entradas netas de flujos de efectivo en el curso normal de la operación. Convierte valores futuros en un valor presente único.

Valor razonable: es el valor por el que puede intercambiarse un activo, cancelarse un pasivo, o intercambiarse un instrumento de patrimonio concedido, entre partes interesadas y debidamente informadas, que realizan una transacción en condiciones de independencia mutua. 


\subsection{Reconocimiento y Medición de los Beneficios a Empleados}

COMERCIALIZADORA ALLCOMPUTER S.A.S reconoce el costo de todos los beneficios a empleados a los que éstos tengan derecho como resultado de servicios prestados a la COMERCIALIZADORA ALLCOMPUTER S.A.S, durante el ejercicio contable y se miden por el valor total adeudado, que se define como la cantidad a pagar establecida entre las partes, en el momento de reconocer el pasivo, de acuerdo con la normatividad laboral vigente en Colombia y demás normas o políticas internas de COMERCIALIZADORA ALLCOMPUTER S.A.S

Como principio de reconocimiento general, COMERCIALIZADORA ALLCOMPUTER S.A.S, da el siguiente tratamiento contable a todos los beneficios de sus empleados; COMERCIALIZADORA ALLCOMPUTER S.A.S reconoce:

- Un pasivo cuando el empleado ha prestado los servicios a cambio de los cuales se le genera el derecho de recibir una contraprestación en el futuro; y

- Un gasto a menos que otra sección de esta NIIF requiera que el costo se reconozca como parte de un activo, como inventarios o propiedades, planta y equipo.

\subsubsection{Beneficios a los Empleados a Corto Plazo}

Los beneficios que COMERCIALIZADORA ALLCOMPUTER S.A.S, entrega a sus empleados son del tipo de beneficios a corto plazo, los cuales comprenden todos los beneficios establecidos en la legislación laboral, y otros a mera liberalidad del empleador, originados de la relación contractual pactada entre la Compañía y sus empleados, sobre los cuales se cumplen todas las regulaciones vigentes en el momento de su reconocimiento. 
Los beneficios a corto plazo se reconocerán a medida que el servicio relacionado sea prestado a la Compañía por parte del empleado, durante el período contable, reconociendo el valor que ha de pagar por tales servicios:

- Como un costo o gasto, a menos que se requiera o permita la inclusión de esos beneficios en el costo de un activo, como por ejemplo inventarios.

- Como un pasivo, beneficios a los empleados por pagar, después de deducir cualquier monto ya abonado

Los beneficios a los empleados de corto plazo no requieren hipótesis actuariales para medir la obligación o el costo y, por lo tanto, no hay ganancias o pérdidas actuariales.

\section{Ausencias Remuneradas a Corto Plazo}

COMERCIALIZADORA ALLCOMPUTER S.A.S, reconocerá el costo esperado de los beneficios a los empleados a corto plazo en forma de ausencias remuneradas (por ejemplo: vacaciones y ausencias remuneradas por enfermedad), aplicando lo descrito en el párrafo anterior, según se trate de beneficios acumulativos o no acumulativos:

- En el caso de ausencias remuneradas cuyos derechos se van acumulando; se reconocen a medida que los empleados prestan los servicios que les permiten disfrutar de futuras ausencias retribuidas (ejemplo vacaciones acumuladas), y

- En el caso de ausencias remuneradas no acumulativas; cuando las mismas se hayan producido y reconocido por la entidad prestadora de salud o de riesgos profesionales (ejemplo incapacidades y licencias) la empresa realizará el debido tramite de cobro ante estas entidades. 


\section{Contribuciones y Aportes}

El valor de las obligaciones laborales por concepto de contribuciones y aportes se determinará con base en la legislación laboral, de acuerdo con la prestación del servicio por parte del trabajador y a su remuneración cuando hubiere lugar a ello.

Incluyen principalmente incapacidades por accidentes de trabajo o ausencias por enfermedad, licencias de maternidad, aportes a los fondos de seguridad social (salud y riesgos laborales), pagos a las compañías de seguros y otras entidades responsables de la administración y gestión de los sistemas de seguridad social, pagos a las cajas de compensación familiar, Instituto Colombiano de Bienestar Familiar y Sena.

\section{Pago de las Obligaciones Laborales}

Los pagos de obligaciones laborales y conceptos asociados a ellas deben ser reconocidos en la fecha en que se efectúa el desembolso para el giro respectivo.

\section{Pago de Auxilios Laborales}

Los pagos de auxilios de alimentación, rodamiento, etc., serán sujetos a autorización de la gerencia.

\subsection{Medición}

Los costos y gastos, pasivos laborales deben valorarse por el valor total adeudado, que se define como la cantidad a pagar en el momento de reconocer el pasivo.

COMERCIALIZADORA ALLCOMPUTER S.A.S, actualizará los pasivos laborales periódicamente, observando las disposiciones vigentes, reconociendo en los resultados del periodo el mayor o menor valor causado por efectos del ajuste. 


\section{Medición Posterior}

Los pasivos laborales se actualizarán periódicamente observando las disposiciones vigentes, reconociendo en los resultados del periodo el mayor o menor valor causado por efectos del ajuste.

\subsection{Presentación y Revelaciones}

La presentación en los estados financieros y las revelaciones en notas relacionados con las obligaciones laborales se efectuará considerando lo siguiente:

1. Las políticas y métodos contables utilizados, incluyendo los que corresponden al reconocimiento y las bases de medición aplicados para las obligaciones laborales.

2. Total, de las obligaciones laborales indicando su clase y valor.

3. El total de costos y gastos por cada uno de los conceptos relacionados con beneficios a los empleados, revelando por separado:

- Los valores reconocidos en resultados como costo o gastos, y

- Los valores incluidos en el costo de un activo (inventarios)

4. Efectuar y revelar la conciliación de los movimientos producidos durante el período en los pasivos por obligaciones laborales. 


\section{Política contable de impuesto a las ganancias}

\subsection{Objetivo}

Establecer las bases para el reconocimiento, medición, presentación e información a revelar, que COMERCIALIZADORA ALLCOMPUTER S.A.S, en adelante la Compañía, aplicará para sus impuestos corrientes y diferidos.

\subsection{Alcance}

Esta política contable ha de ser aplicada por COMERCIALIZADORA ALLCOMPUTER S.A.S, para la contabilización de los impuestos basados en las ganancias físcales, considerando los tributos sobre los cuales la Compañía es responsable.

COMERCIALIZADORA ALLCOMPUTER S.A.S, deberá reconocer las consecuencias fiscales actuales y futuras del conjunto de operaciones comerciales reconocidas en los estados financieros. Estos valores fiscales incluyen el impuesto corriente y el impuesto diferido.

El impuesto corriente es el tributo por pagar por las ganancias fiscales del periodo corriente, o en su defecto el impuesto recuperable por las pérdidas de periodos anteriores.

El impuesto diferido es el tributo por pagar o por recuperar en periodos futuros, como resultado de que la Compañía recupera o liquida sus activos y pasivos por su valor en libros actual, 
y el efecto fiscal de la compensación de pérdidas o créditos fiscales no utilizados hasta el momento procedentes de periodos anteriores.

\subsection{Normativa Aplicable}

La elaboración de esta política contable para los impuestos corrientes y diferidos de COMERCIALIZADORA ALLCOMPUTER S.A.S, se encuentra sustentada en las siguientes normas:

Sección 3, Presentación de Estados Financieros

Sección 29, Impuesto a las Ganancias

\subsection{Definiciones}

Resultado contable: es la ganancia neta o la pérdida neta del ejercicio antes de deducir el gasto por el impuesto sobre las ganancias.

Ganancia o Pérdida fiscal: es la ganancia o pérdida de un ejercicio, calculada de acuerdo con la normativa vigente establecida por la autoridad fiscal, sobre la que se calculan los impuestos a pagar o recuperar.

Gasto (ingreso) por el impuesto a las ganancias: es el valor que, por este concepto, se incluye en el estado de resultado integral al determinar la ganancia o pérdida neta fiscal del ejercicio, incluyendo tanto el impuesto corriente como el diferido.

Impuesto a las ganancias: comprende todos los tributos basados en ganancias fiscales 
Impuesto corriente: es el valor a pagar (recuperar) por el impuesto sobre las ganancias, relativa a la ganancia (pérdida) fiscal del ejercicio.

Impuesto diferido: es el valor a pagar (recuperar) por el impuesto sobre las ganancias, relativa a la ganancia (pérdida) fiscal de periodos futuros.

Pasivos por impuestos diferidos: es el valor de los impuestos sobre las ganancias a pagar en ejercicios futuros, relacionadas con las diferencias temporarias imponibles.

Activos por impuestos diferidos: es el valor de los impuestos sobre las ganancias a recuperar en ejercicios futuros, relacionadas con:

- Las diferencias temporarias deducibles

- La compensación de pérdidas obtenidas en ejercicios anteriores, que todavía no hayan sido objeto de deducción fiscal

- La compensación de créditos fiscales no utilizados procedentes de ejercicios anteriores.

Diferencias temporarias: son las diferencias que existen entre el valor en libros de un activo o un pasivo y el valor que constituye la base fiscal de los mismos.

Las diferencias temporarias pueden ser:

- Diferencias temporarias imponibles, que son aquellas diferencias temporarias que dan lugar a valores imponibles al determinar la ganancia (pérdida) fiscal correspondiente a ejercicios futuros, cuando el valor en libros del activo sea recuperado o el del pasivo sea liquidado

- Diferencias temporarias deducibles, que son aquellas diferencias temporarias que dan lugar a valores que son deducibles al determinar la ganancia (pérdida) fiscal correspondiente a ejercicios futuros, cuando el valor en libros del activo sea recuperado o el del pasivo sea liquidado. 
La base fiscal de un activo o pasivo: es el valor atribuido, para fines fiscales, ha dicho activo o pasivo.

Tarifa de impuesto: es la tasa definida por la autoridad fiscal a ser aplicada sobre las ganancias fiscales

\subsection{Reconocimiento de Activos y Pasivos por Impuestos Corrientes}

El impuesto corriente, correspondiente al ejercicio presente y a los anteriores, será reconocido por COMERCIALIZADORA ALLCOMPUTER S.A.S, como una obligación de pago (pasivo). Si el valor ya pagado (retenciones a favor), que corresponde al ejercicio presente y a los anteriores, excede el valor a pagar por esos ejercicios, el exceso debe ser reconocido como un activo.

El valor a cobrar que corresponda a una pérdida fiscal, si ésta puede ser aplicada para recuperar las cuotas corrientes pagadas en ejercicios anteriores, debe ser reconocido como un activo.

Cuando una pérdida fiscal se utilice para recuperar el impuesto corriente pagado en ejercicios anteriores, la Compañía reconocerá tal derecho como un activo en el mismo ejercicio en el que se produce la citada pérdida fiscal, puesto que es probable que la Compañía obtenga el beneficio económico derivado de tal derecho, y además este beneficio puede ser valorado de forma fiable.

\subsection{Reconocimiento Activos y Pasivos por Impuestos Diferidos}

COMERCIALIZADORA ALLCOMPUTER S.A.S, reconocerá un activo o pasivo por impuestos diferidos, por el valor del tributo por recuperar o por pagar en periodos futuros como resultado de transacciones o sucesos pasados. 
Este impuesto surge de la diferencia entre los valores reconocidos de los activos y pasivos de la Compañía en el estado de situación financiera y el reconocimiento de los mismos por parte de las autoridades fiscales, y la compensación de pérdidas o créditos fiscales no utilizados.

\subsubsection{Diferencias Temporarias}

Las diferencias temporarias surgen cuando:

- Existe una diferencia entre los valores en libros y las bases fiscales en el reconocimiento inicial de los activos y pasivos, o en el momento en que se crea una base fiscal pero que no se reconocen como activos y pasivos.

- Existe una diferencia entre el valor en libros y la base fiscal que surge tras el reconocimiento inicial, porque el ingreso o gasto se reconoce en el resultado integral o en el patrimonio de un periodo sobre el que se informa, pero se reconoce en ganancias fiscales en otro periodo diferente.

- La base fiscal de un activo o pasivo cambia y el cambio no se reconocerá en el valor en libros del activo o pasivo de ningún periodo.

\section{Diferencias Temporarias Imponibles}

COMERCIALIZADORA ALLCOMPUTER S.A.S, reconocerá un pasivo por impuestos diferidos por causa de cualquier diferencia temporaria imponible.

Todo reconocimiento de un activo lleva inherente la suposición de que su valor en libros se recuperará en forma de beneficios económicos, que la Compañía recibirá en ejercicios futuros. Cuando el valor en libros del activo exceda a su base fiscal, el valor de los beneficios económicos imponibles excederá al valor fiscalmente deducible de ese activo. 
Esta diferencia será una diferencia temporaria imponible, y la obligación de pagar los correspondientes impuestos en futuros ejercicios será un pasivo por impuestos diferidos. A medida que la Compañía recupere el valor en libros del activo, la diferencia temporaria deducible irá revirtiendo y, por tanto, la Compañía tendrá una ganancia imponible. Esto hace probable que los beneficios económicos salgan de la Compañía en forma de pagos de impuestos.

\section{Diferencias Temporarias Deducibles}

COMERCIALIZADORA ALLCOMPUTER S.A.S, reconocerá un activo por impuestos diferidos, por causa de todas las diferencias temporarias deducibles, en la medida que sea probable que la Compañía disponga de ganancias fiscales futuras, contra las cuales cargará esas diferencias temporarias deducibles.

Detrás del reconocimiento de cualquier pasivo está inherente la expectativa de que la cantidad correspondiente será liquidada, en ejercicios futuros, por medio de una salida de recursos que incorporen beneficios económicos. Cuando tales recursos salgan efectivamente de la Compañía, una parte o la totalidad de sus valores pueden ser deducibles para la determinación de la ganancia fiscal en ejercicios posteriores al del reconocimiento del pasivo. En esos casos se producirá una diferencia temporaria entre el valor en libros del citado pasivo y su base fiscal. De acuerdo con ello, aparecerá un activo por impuestos diferidos, respecto a los impuestos sobre las ganancias que se recuperarán en ejercicios posteriores, cuando sea posible la deducción del pasivo para determinar la ganancia fiscal. De forma similar, si el valor en libros de un activo es menor que su base fiscal, la diferencia entre ambos valores dará lugar a un activo por impuestos diferidos respecto a los impuestos sobre las ganancias que se recuperarán en ejercicios posteriores. 
INFORME FINAL

En conclusión, los impuestos diferidos generados por las diferencias temporarias entre la base fiscal y la base contable, serán imponibles o deducibles de acuerdo a las siguientes circunstancias:

\begin{tabular}{lll}
\hline ELEMENTO & CONDICIÓN & TIPO DE DIFERENCIA \\
\hline Activos o Patrimonio & Valor Contable $>$ Valor Fiscal & Imponible \\
& Valor Contable $<$ Valor Fiscal & Deducible \\
Pasivos & Valor Contable $>$ Valor Fiscal & Deducible \\
& Valor Contable $<$ Valor Fiscal & Imponible \\
\hline
\end{tabular}

\subsubsection{Pérdidas y Créditos Fiscales No Utilizados}

COMERCIALIZADORA ALLCOMPUTER S.A.S, reconocerá un activo por impuestos diferidos, siempre que se puedan compensar, con ganancias fiscales de ejercicios posteriores, las pérdidas o créditos fiscales no utilizados hasta el momento, pero sólo en la medida en que sea probable la disponibilidad de ganancias fiscales futuras, contra los cuales cargar esas pérdidas o créditos fiscales no utilizados.

\subsubsection{Pasivos y Activos por Impuestos Diferidos}

COMERCIALIZADORA ALLCOMPUTER S.A.S, reconocerá un activo o pasivo por impuesto diferido en los siguientes casos:

- Pasivo por Impuesto Diferido, por todas las diferencias temporarias que se espere incrementen la ganancia fiscal en el futuro 
- Activo por Impuesto Diferido, por todas las diferencias temporarias que se espere reduzcan la ganancia fiscal en el futuro

- Activo por Impuesto Diferido, por la compensación de pérdidas fiscales y créditos fiscales, procedentes de ejercicios anteriores y no utilizados hasta el momento

Cuando COMERCIALIZADORA ALLCOMPUTER S.A.S, espere recuperar el valor en libros de un activo, o liquidar el valor en libros de un pasivo, sin afectar las ganancias fiscales, no surgirá ningún impuesto diferido con respecto al activo o pasivo.

\subsubsection{Base Fiscal y Tasas Impositivas en Activos y Pasivos por Impuestos Diferidos}

COMERCIALIZADORA ALLCOMPUTER S.A.S, determinará la base fiscal de un activo, pasivo u otra partida de acuerdo con la legislación tributaria vigente. La base fiscal determina los valores que se incluirán en ganancias fiscales en la recuperación o liquidación del valor en libros de un activo o pasivo.

La Compañía medirá un activo o pasivo por impuestos diferidos, usando las tasas impositivas según la legislación tributaria vigente, en la fecha sobre la que se informa.

Cuando se apliquen diferentes tasas impositivas a distintos niveles de ganancia fiscal, la Compañía medirá los gastos (ingresos) y los pasivos (activos) por impuestos diferidos, utilizando las tasas medias aprobadas, que se espera sean aplicables a la ganancia (o perdida) fiscal de los periodos en los que se espere que el activo o el pasivo por impuestos diferidos, se realice o se liquide, respectivamente. 


\subsection{Medición de Impuestos Corrientes y Diferidos}

Los pasivos y activos corrientes de tipo fiscal, ya procedan del ejercicio presente o de ejercicios anteriores, serán valorados por la Compañía por los montos que se espere pagar o recuperar de la autoridad fiscal, utilizando la normativa y tipos impositivos vigentes en la fecha del balance.

Los activos y pasivos de tipo fiscal, diferidos a largo plazo deben valorarse según los tipos que vayan a ser de aplicación en los ejercicios en los que se espere realizar los activos o pagar los pasivos, a partir de la normativa y tipos impositivos vigentes en la fecha del balance.

La valoración de los activos y los pasivos por impuestos diferidos debe reflejar las consecuencias fiscales que se derivarían de la forma en que la Compañía espera, a la fecha del balance, recuperar el valor en libros de sus activos o liquidar el valor en libros de sus pasivos.

El valor en libros de un activo por impuestos diferidos debe someterse a revisión al final de cada fecha sobre la que se informa, con el objetivo de proceder a hacer los ajustes a que haya lugar.

\subsection{Reconocimiento de Impuestos Corrientes y Diferidos}

Los impuestos, tanto si son del ejercicio corriente como si son diferidos, deben ser reconocidos como gasto o ingreso, e incluidos en la determinación de la ganancia o pérdida neta del ejercicio en que se generen.

Los impuestos sobre las ganancias, ya sean del ejercicio corriente o diferidos, deben ser cargados o abonados directamente al patrimonio neto si se relacionan con partidas que se llevan directamente a las cuentas del patrimonio neto, ya sea en el mismo ejercicio o en otro diferente. 


\subsection{Presentación}

Cuando COMERCIALIZADORA ALLCOMPUTER S.A.S, presente activos corrientes o no corrientes y pasivos corrientes o no corrientes, como clasificaciones separadas en su estado de situación financiera, no clasificara ningún activo o pasivo por impuestos diferidos como activos o pasivos corrientes.

\subsubsection{Compensación}

COMERCIALIZADORA ALLCOMPUTER S.A.S, compensará los activos por impuestos y los pasivos por impuestos, solo si la Compañía:

- Tiene reconocido legalmente un derecho para compensar frente a la autoridad fiscal los valores reconocidos en esas partidas

- Tiene la intención de liquidar las deudas netas que resulten, o bien de realizar los activos y liquidar simultáneamente las deudas que ha compensado con ellos.

\subsection{Información a Revelar}

El área contable y financiera de COMERCIALIZADORA ALLCOMPUTER S.A.S, serán las encargadas y responsables de construir las revelaciones relacionadas con impuestos.

COMERCIALIZADORA ALLCOMPUTER S.A.S, revelará información respecto a los impuestos corrientes y diferidos, que permita a los usuarios de sus estados financieros evaluar la naturaleza y el efecto financiero de estos tributos. 
Los principales componentes del gasto (ingreso) por el impuesto sobre las ganancias deben ser revelados por separado en los estados financieros de COMERCIALIZADORA

\section{ALLCOMPUTER S.A.S}

Los componentes del gasto (ingreso) por el impuesto sobre las ganancias pueden incluir:

1. El gasto (ingreso) correspondiente al impuesto corriente del presente ejercicio

2. Ajustes reconocidos en el periodo por impuestos corrientes de ejercicios anteriores

3. Valor del gasto (ingreso) por impuestos diferidos relacionado con el origen y reversión de diferencias temporarias

4. Valor del gasto (ingreso) por impuestos diferidos relacionado con cambios en las tasas impositivas o con la aparición de nuevos impuestos

5. Valor de los beneficios de carácter fiscal, procedentes de pérdidas fiscales, créditos fiscales o diferencias temporarias, no reconocidos en ejercicios anteriores, que se han utilizado para reducir el gasto por impuestos del presente ejercicio o impuestos diferidos

6. Efecto sobre el gasto por impuestos que surja de un cambio efecto de una revisión por parte de las autoridades fiscales

7. Valor del gasto por impuestos relacionado con cambios en las políticas contables y errores.

La siguiente información deberá ser revelada, por separado, dentro de la información financiera de COMERCIALIZADORA ALLCOMPUTER S.A.S:

1. Valor total de los impuestos, corrientes o diferidos, relativos a partidas cargadas o abonadas directamente a las cuentas del patrimonio neto en el ejercicio

2. Una explicación de las diferencias significativas en los valores presentados en el estado de resultado integral y los valores presentados a las autoridades fiscales. 
3. Una explicación de los cambios en las tasas impositivas, en comparación con las del periodo anterior

4. Para cada tipo de diferencia temporaria y para cada tipo de pérdidas y créditos fiscales no utilizados:

- El valor de los activos y pasivos por impuestos diferidos y las correcciones de valor al final del periodo

- Análisis de los cambios en los activos y pasivos por impuestos diferidos y en las correcciones de valor durante el periodo

5. Fecha de caducidad de las diferencias temporarias y de las perdidas y los créditos fiscales no utilizados 


\section{Política contable de hechos posteriores}

\subsection{Objetivo}

Establecer los principios que COMERCIALIZADORA ALLCOMPUTER S.A.S, en adelante la Compañía, aplicará para el reconocimiento, medición, presentación e información a revelar, de los hechos ocurridos entre el final del periodo sobre el que se informa y, la fecha de autorización de los estados financieros para su publicación.

\subsection{Alcance}

Esta política contable ha de ser aplicada por COMERCIALIZADORA ALLCOMPUTER S.A.S, en el procedimiento contable a seguir, correspondiente a los hechos posteriores.

Definir los hechos ocurridos después del periodo sobre el que se informa y establecer los principios para el reconocimiento, medición y revelación de esos hechos. Son los hechos, favorables o desfavorables, ocurridos entre el final del periodo sobre el que se informa y la fecha de autorización para la publicación de los estados financieros. Incluirán todos los hechos hasta la fecha en que los estados financieros queden autorizados para su publicación, incluso si esos hechos tienen lugar después del anuncio público de los resultados u otra información financiera especifica. 


\subsection{Normativa Aplicable}

La construcción de esta política para hechos posteriores a la fecha del estado de situación financiera de COMERCIALIZADORA ALLCOMPUTER S.A.S, se encuentra sustentada bajo las siguientes normas:

Sección 3, Presentación de Estados Financieros

Sección 10, Políticas Contables, Estimaciones y Errores

Sección 32, Hechos Ocurridos Después del Periodo Sobre el que Informa

\subsection{Definiciones}

Hechos posteriores a la fecha de estado de situación financiera: son todos aquellos eventos, ya sean favorables o desfavorables, que se hayan producido entre la fecha del balance y la fecha de formulación o de autorización de los estados financieros para su divulgación.

Se identifican dos tipos de hechos posteriores:

- Eventos que proporcionan evidencia de las condiciones que ya existían en la fecha de estado de situación financiera, hechos posteriores que implican ajuste; y

- Los que indican condiciones que surgieron después de la fecha del estado de situación financiera, hechos posteriores que no implican ajuste. 


\subsection{Reconocimiento y Medición}

\subsubsection{Hechos Posteriores que Implican Ajustes}

COMERCIALIZADORA ALLCOMPUTER S.A.S, ajustará los saldos reconocidos en sus estados financieros, para reflejar la incidencia de los hechos posteriores a la fecha del estado de situación financiera que impliquen ajustes.

Algunos ejemplos de hechos posteriores a la fecha del estado de situación financiera, que obligan a COMERCIALIZADORA ALLCOMPUTER S.A.S, a ajustar los saldos reconocidos en sus estados financieros o bien, a reconocer partidas no reconocidas con anterioridad, son:

- La resolución de litigios judiciales, posterior a la fecha del estado de situación financiera, que confirma que la Compañía tenía una obligación presente en la fecha del balance.

- La recepción de información, después de la fecha del estado de situación financiera, que indique el deterioro del valor de un activo a esa fecha o bien, la necesidad de ajustar la pérdida por deterioro del valor reconocido previamente para este activo.

- La determinación, con posterioridad a la fecha del estado de situación financiera, del costo de los activos adquiridos o del valor de ingresos por activos vendidos antes de dicha fecha.

- El descubrimiento de fraudes o errores que demuestren que los estados financieros eran incorrectos.

- Ver estimación de hechos ocurridos después del periodo sobre el que informa, que implican ajuste, en memorando técnico de estimaciones 


\subsection{Hechos Posteriores que no Implican Ajustes}

La Compañía no ajustará los valores reconocidos en sus estados financieros, para reflejar la incidencia de los hechos posteriores a la fecha del estado de situación financiera, si éstos no implican ajustes.

Son ejemplos de algunos hechos posteriores a la fecha del estado de situación financiera, que no implican ajustes, ni reconocimiento de partidas no reconocidas con anterioridad, en los estados financieros de COMERCIALIZADORA ALLCOMPUTER S.A.S, los siguientes:

- La caída en el mercado del valor de las inversiones

- Un valor que pase a ser exigible a favor de la Compañía, como resultado de una sentencia o por resolución de un litigio judicial

\subsection{Presentación y Revelaciones}

COMERCIALIZADORA ALLCOMPUTER S.A.S, revelará la siguiente información relacionada con los hechos ocurridos después del periodo sobre el que se informa, (después de la fecha del estado de situación financiera):

1. La fecha en que los estados financieros han sido autorizados para ser publicados, y quien ha dado dicha autorización. En el caso de que los accionistas de la Compañía u otros, tengan poder para modificar los estados financieros tras la publicación, COMERCIALIZADORA ALLCOMPUTER S.A.S, revelará ese hecho. 
2. Si después de la fecha del estado de situación financiera, la Compañía recibe información acerca de condiciones que existían ya en dicha fecha, actualizará en las notas, en función de la información recibida, las revelaciones relacionadas con tales condiciones.

3. Cuando los hechos posteriores a la fecha del estado de situación financiera, que no implican ajustes, sean de tal importancia que si no se revelan podría afectar a la capacidad de los usuarios de los estados financieros para realizar las evaluaciones pertinentes y tomar decisiones económicas, COMERCIALIZADORA ALLCOMPUTER S.A.S, revelará la siguiente información, para cada una de las categorías importantes de estos hechos:

- La naturaleza del evento; y

- Una estimación de sus efectos financieros, o un pronunciamiento sobre la imposibilidad de realizar tal estimación.

- Ejemplos característicos de esta situación podría ser:

○ Una combinación de negocios importante

- El anuncio de un plan para discontinuar definitivamente una operación

○ Las compras o disposiciones de activos muy importantes

○ La destrucción por incendio de una planta de producción importante

○ El anuncio, o el comienzo de la ejecución, de una reestructuración importante

- Los cambios significativos en los precios de los activos o en las tasas de cambio de la moneda extranjera

- Los cambios significativos en las tasas impositivas, que tengan efecto significativo en los impuestos

- El inicio de litigios importantes, surgidos solo como consecuencia de hechos ocurridos después del periodo sobre el que se informa. 


\section{Política contable de adopción por primera vez de la niif para pymes}

\subsection{Objetivo}

Definir los criterios que COMERCIALIZADORA ALLCOMPUTER S.A.S, en adelante la Compañía, aplicará para la emisión de sus estados financieros con arreglo a las Normas Internacionales de Información Financiera para Pequeñas y Medianas Entidades, NIIF para las PYMES, asegurándose de que estos estados financieros, contienen información de alta calidad que:

- Sea transparente para los usuarios y comparable para todos los ejercicios que se presenten

- Suministre un punto de partida adecuado para la contabilización según las NIIF para PYMES

- Pueda ser obtenida a un costo que no exceda a los beneficios proporcionados a los usuarios.

\subsection{Alcance}

Esta política contable ha sido elaborada con base a los primeros estados financieros de COMERCIALIZADORA ALLCOMPUTER S.A.S, bajo NIIF para las PYMES; en los cuales la Compañía presenta una declaración, explícita y sin reservas, del cumplimiento de las Secciones NIIF para las PYMES. 
La Compañía, solo puede adoptar por primera vez la NIIF para las PYMES en una única ocasión. Por tanto, las exenciones especiales, simplificaciones y otros requerimientos, no serán aplicables a una nueva adopción, en caso de que esta normativa se haya dejado de usar durante uno o más periodos.

\subsection{Normativa Aplicable}

La elaboración de esta política contable para el procedimiento de adopción por primera vez de las NIIF para las PYMES, COMERCIALIZADORA ALLCOMPUTER S.A.S, se sustenta en la Sección 35 Transición a la NIIF para PYMES.

\subsection{Definiciones}

Fecha de transición a las NIIF: es el comienzo del primer periodo para el que la Compañía presenta información comparativa completa de conformidad con las NIIF para PYMES, en sus primeros estados financieros que cumplen con la normativa.

Costo atribuido: es un valor que se puede utilizar como una exención voluntariamente elegida por parte de la Compañía en la adopción por primera vez en partidas pertenecientes a propiedades, planta y equipo, propiedades de inversión, si se escoge la aplicación del modelo del costo; y activos intangibles, si cumplen los criterios de reconocimiento. El costo atribuido no se puede usar en la medición de otros activos o pasivos. Costo atribuido se define como el valor usado sustituto del costo o del costo depreciado en una fecha determinada. 
Valor razonable: es el valor por el que puede ser intercambiado un activo o cancelado un pasivo, entre partes interesadas y debidamente informadas, en una transacción realizada en condiciones de independencia mutua.

Primeros estados financieros con arreglo a las NIIF: son los primeros estados financieros anuales en los cuales la Compañía adopta las Normas Internacionales de Información Financiera NIIF, mediante una declaración, explícita y sin reservas, de cumplimiento con la normativa.

Primer ejercicio sobre el que se informa con arreglo a las NIIF: es el ejercicio sobre el que se informa más reciente cubierto por los primeros estados financieros de la Compañía con arreglo a las NIIF.

Normas Internacionales de Información Financiera (NIIF): son el conjunto de normas legalmente exigibles y globalmente aceptadas, comprensibles y de alta calidad basados en principios claramente articulados, que requieren que los estados financieros contengan información comparable, transparente y de alta calidad, que ayude a los inversionistas y a otros usuarios, a tomar decisiones económicas.

Estas Normas comprenden:

- Las Normas Internacionales de Información Financiera (NIIF)

- Las Normas Internacionales de Contabilidad (NIC)

- Las Interpretaciones desarrolladas por el Comité de Interpretaciones de las NIIF (CINIIF), o el antiguo Comité de Interpretaciones (SIC)

- Las Secciones NIIF para las PYMES

NIIF para las PYMES: corresponde a la versión simplificada de las NIIF. Las cinco características de esta simplificación son: 
- Algunos temas en las NIIF Plenas son omitidos ya que no son relevantes para las PYMES típicas.

- Algunas alternativas a políticas contables en las NIIF Plenas no son permitidas ya que una metodología simple está disponible para las PYMES.

- Simplificación de muchos principios de reconocimiento y medición de aquellos que están en las NIIF Plenas.

- Sustancialmente se requieren menos revelaciones

- Simplificación de Exposición de motivos

Estado de situación financiera de apertura con arreglo a las NIIF: es el estado de situación financiera de la Compañía en la fecha de transición a las NIIF.

PCGA anteriores: son los principios de contabilidad generalmente aceptados que la Compañía, que adopta por primera vez las NIIF, utilizaba antes de la adopción.

Excepciones: se refieren a la aplicación retrospectiva del cambio en algunas políticas contables. Evitan que la información para el proceso de adopción por primera vez tenga que ser retroactiva.

Exenciones: tienen relación con algunas prácticas que no es necesario aplicar en la adopción por primera vez. Opciones o alternativas que señala la normativa para simplificar el proceso de adopción por primera vez. 


\subsection{Reconocimiento y Valoración}

\subsubsection{Estado de Situación Financiera de Apertura con Arreglo a las NIIF para PYMES}

El estado de situación financiera de apertura según las NIIF para Pequeñas y Medianas Entidades, es el punto de partida para la contabilidad posterior en la aplicación de las NIIF para las Pymes. COMERCIALIZADORA ALLCOMPUTER S.A.S, preparará un estado de situación financiera de apertura ESFA) según las NIIF para Pymes en la fecha de transición a las NIIF. Este se refiere al balance inicial del primer período para el cual se presenta información comparativa completa de acuerdo con las NIIF para Pymes.

La fecha de transición de COMERCIALIZADORA ALLCOMPUTER S.A.S, es el $1^{\circ}$ de enero de 2015, lo cual quiere decir que la Compañía preparará su estado de situación financiera de apertura (ESFA) según las NIIF para Pymes en dicha fecha. Por lo tanto, la Compañía preparará sus primeros estados financieros bajo NIIF para Pymes para el año que finaliza el 31 de diciembre de 2016 comparado con el periodo a 31 de diciembre de 2015.

La Compañía deberá, en su estado de situación financiera de apertura con arreglo a las NIIF para Pymes:

- Reconocer todos los activos y pasivos cuyo reconocimiento sea requerido por las NIIF

- No reconocer partidas como activos o pasivos si las NIIF no lo permiten

- Reclasificar partidas reconocidas como activos, pasivos o componentes del patrimonio neto de acuerdo con PCGA anteriores, con arreglo a las categorías de activo, pasivo o componente del patrimonio neto según las NIIF, y

- Aplicar las NIIF al valorar todos los activos y pasivos reconocidos. 


\subsubsection{Políticas Contables}

COMERCIALIZADORA ALLCOMPUTER S.A.S, usará las mismas políticas contables en su estado de situación financiera de apertura con arreglo a las NIIF para Pymes, y a lo largo de todos los ejercicios que se presenten estados financieros con arreglo a las NIIF para Pymes.

Estas políticas contables cumplirán con cada NIIF vigente al final del primer ejercicio sobre el que informe según las Secciones NIIF para Pymes, contenidas en cada una de las políticas contables de la Compañía.

COMERCIALIZADORA ALLCOMPUTER S.A.S, no aplicará versiones diferentes de las Secciones NIIF para Pymes que estuvieran vigentes en fechas anteriores. La Compañía podrá aplicar una nueva NIIF que todavía no sea obligatoria, siempre que en la misma se permita la aplicación anticipada.

Las políticas contables que COMERCIALIZADORA ALLCOMPUTER S.A.S, utilice en su estado de situación financiera de apertura con arreglo a las NIIF para Pymes, pueden diferir de las que aplicaba en la misma fecha con arreglo a sus PCGA anteriores. Los ajustes resultantes surgen de sucesos y transacciones anteriores a la fecha de transición a las NIIF. Por tanto, COMERCIALIZADORA ALLCOMPUTER S.A.S, reconocerá tales ajustes, en la fecha de transición a las NIIF para Pymes, directamente en su patrimonio, en las ganancias acumuladas o retenidas. 


\subsubsection{Exenciones y Excepciones a la Aplicación Retroactiva de las NIIF para Pymes}

El principio general que debe seguir COMERCIALIZADORA ALLCOMPUTER S.A.S, en su proceso de adopción por primera vez de las NIIF para Pymes, para efectos de la medición de las partidas de activos y pasivos reconocidos en el balance de apertura, es usar las bases establecidas en cada una de las NIIF aplicables a cada hecho económico. Por lo tanto, tiene efectos retroactivos.

Sin embargo, la NIIF para Pymes, Sección 35 Transición a las NIIF para las Pymes, establece una serie de exenciones y excepciones al principio general indicado anteriormente que solo son aplicables para conformar el estado de situación financiera de apertura.

En la preparación de los estados financieros posteriores, se deberán usar las NIIF para Pymes correspondientes para cada hecho económico y no será aplicable esta posibilidad.

\section{Exenciones Opcionales}

Las exenciones permiten apartarse de los criterios de medición y reconocimiento indicados en las NIIF para Pymes. Su uso es optativo, es decir, serán aplicadas en la medida en que no se disponga de la información confiable con arreglo a la NIIF para Pymes respectiva. Por lo tanto, COMERCIALIZADORA ALLCOMPUTER S.A.S, podrá usar una o varias de estas exenciones, que son interdependientes y solo podrán ser aplicadas para los hechos económicos allí indicados. No podrán ser usadas por analogía a otros hechos diferentes de los indicados expresamente.

Las NIIF para Pymes, establece como exención que en la fecha de transición a las NIIF la Compañía podrá medir sus propiedades, planta y equipo, propiedades de inversión, o activos intangibles, a su valor razonable; o, una revaluación según los PCGA anteriores; como costo 
atribuido en dicha fecha; es decir, ese será el costo a partir del cual se inicia la aplicación de las NIIF en periodos posteriores.

COMERCIALIZADORA ALLCOMPUTER S.A.S, decidió tomarse la exención del Valor Razonable como Costo Atribuido de las propiedades, planta y equipo, y activos intangibles.

Adicionalmente, COMERCIALIZADORA ALLCOMPUTER S.A.S, se tomará la exención del Impuesto Diferido, la cual indica que no se requiere que una entidad que adopta por primera vez las NIIF reconozca, en la fecha de transición a las NIIF para las PYMES (ESFA), activos por impuestos diferidos ni pasivos por impuestos diferidos relacionados con diferencias entre la base fiscal y el valor en libros de los activos y pasivos.

\section{Excepciones Obligatorias}

En la adopción por primera vez de esta NIIF, Transición a las NIIF para Pymes, la Compañía no cambiará retroactivamente la contabilidad llevada a cabo según su marco de información financiera bajo PCGA para ninguna de las siguientes transacciones:

\section{- Baja de Activos Financieros y Pasivos Financieros}

Los activos financieros y pasivos financieros que, según el marco de contabilidad anterior de la Compañía, se hayan dado de baja antes de la fecha de transición, no deben reconocerse tras la adopción de la NIIF para las PYMES. Por el contrario, para los activos financieros y pasivos financieros que hubieran sido dados de baja conforme a las NIIF para las PYMES en una transacción anterior a la fecha de transición, pero que no fueron dados de baja según los PCGA, la Compañía tendrá la opción de elegir entre darlos de baja en el momento de la adopción de la NIIF para las PYMES; o seguir reconociéndolos hasta que se proceda a su disposición o hasta que se liquiden. 


\section{- Estimaciones Contables}

El motivo de contar con esta exención en la Sección 35 es evitar que la Compañía utilice el beneficio de los ajustes retroactivos para ajustar las estimaciones contables sobre la base de información que no estaba disponible al momento en que se estimaron los valores por primera vez, de acuerdo con el marco de información financiera anterior.

\subsection{Presentación y Revelaciones}

COMERCIALIZADORA ALLCOMPUTER S.A.S, explicará cómo ha afectado la adopción desde el marco de información financiera anterior a esta NIIF a su situación financiera, al rendimiento financiero y a los flujos de efectivo presentados con anterioridad, en su estado de revelaciones de apertura, preparado en la fecha de la transición a las NIIF para las PYMES.

\section{Conciliaciones en los Primeros Estados Financieros según las NIIF}

Los primeros estados financieros según las NIIF para Pymes deben incluir una conciliación de:

- El patrimonio de los PCGA anteriores a las NIIF para Pymes en la fecha de transición, y al final del último período en el que la Compañía presentó los estados financieros según los PCGA anteriores; y

- El resultado neto de los PCGA anteriores a las NIIF para Pymes para el último período en el que la Compañía presentó los estados financieros según los PCGA anteriores.

Las onciliaciones deberán contener suficiente detalle para permitir que los usuarios entiendan los ajustes significativos en el estado de situación financiera y el estado de ganancias y pérdidas, 
así como para distinguir los cambios en las políticas contables debido a la corrección de los errores identificados durante la transición.

\section{Otras Revelaciones de los Primeros Estados Financieros según las NIIF}

COMERCIALIZADORA ALLCOMPUTER S.A.S, revelará los juicios profesionales tenidos en cuenta en el proceso de aplicación de las políticas contables de la Compañía, que tengan el efecto más significativo sobre los valores reconocidos en los estados financieros.

Además, la Compañía deberá revelar información sobre los supuestos clave acerca del futuro y otras fuentes clave de incertidumbre en la estimación en la fecha sobre la que se informa, que tengan un riesgo significativo de ocasionar ajustes importantes en el valor en libros de los activos y pasivos dentro del ejercicio contable siguiente.

\section{Información Comparativa y Resúmenes Históricos}

Los primeros estados financieros según las NIIF para las PYMES deberán incluir al menos un año de información comparativa preparada según las NIIF para Pymes, dependiendo de las exenciones y excepciones que permiten o exigen no volver a presentar información comparativa reestructurada.

Para COMERCIALIZADORA ALLCOMPUTER S.A.S, esta información comparativa será al cierre de 31 de diciembre de 2016 comparativa con el 2015.

Cuando se presenten resúmenes históricos o información comparativa según un PCGA anterior, debe señalarse claramente que la información no cumple con las NIIF para Pymes, y debe describirse la naturaleza de los ajustes principales necesarios para cumplir con las NIIF. 


\section{Apéndice B. Manual de}

\section{estimaciones contables}




\title{
MEMORANDO TÉCNICO DE ESTIMACIONES CONTABLES
}

\author{
NORMAS \\ INTERNACIONALES DE \\ INFORMACIÓN FINANCIERA \\ PARA PYMES \\ 01 DE ENERO DE 2015
}




\section{Autorizaciones}

\begin{tabular}{llll}
\hline \multicolumn{1}{c}{ ELABORÓ } & \multicolumn{1}{c}{ REVISÓ } & APROBÓ \\
\hline Equipo NIIF asignado por & $\bullet$ & Claudia Patricia Murillo & GERENCIA \\
la Compañía para el & $\bullet$ & Kelly Johana Ayala & \\
proceso de convergencia & & & \\
\hline
\end{tabular}

Origen de cambios de versiones

\begin{tabular}{cc}
\hline VERSIÓN & ORIGEN DE LOS CAMBIOS \\
\hline 01 & Versión Inicial \\
\hline
\end{tabular}

Las estimaciones no harán parte del Manual de Políticas Contables, se llevarán a un Memorando Técnico el cual deberá ser actualizado anualmente según la revisión de estas por parte de COMERCIALIZADORA ALLCOMPUTER SAS.

Los cambios en estimaciones o el mantenimiento de las adoptadas inicialmente, deberán ser reportadas en un nuevo Memorando Técnico y este será parte integral del grupo de estados financieros de adopción por primera vez y de estados financieros posteriores, es decir tiene vigencia de un año. 


\section{Contenido}

\section{Pág.}

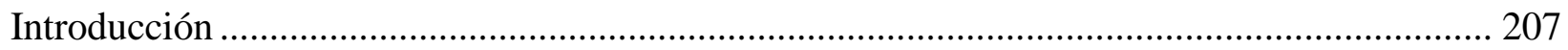

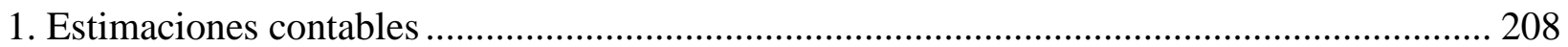

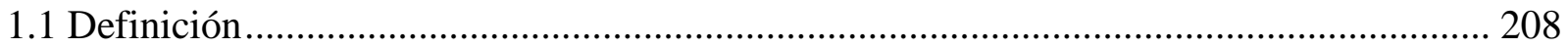

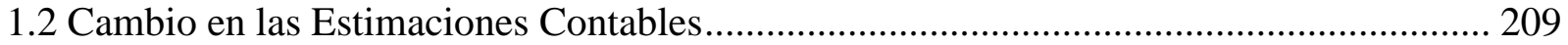

2. Estimaciones contables para instrumentos financieros ...................................................... 210

2.1 Reconocimiento y Medición del Deterioro ………………………………………....... 210

3. Estimaciones contables para propiedades, planta y equipo ………………………................ 212

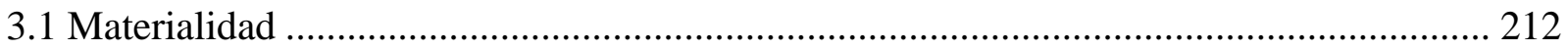

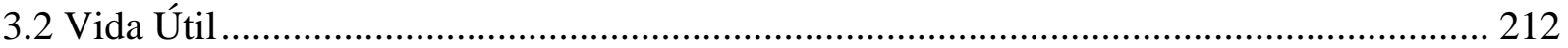

3.3 Método de Depreciación ................................................................................................. 213

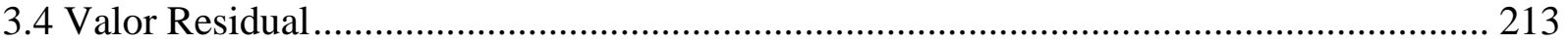

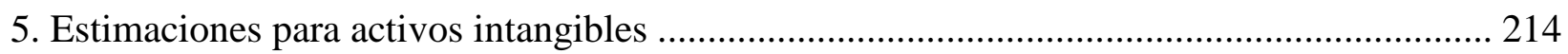

5.1 Vida Útil, Método de Amortización y Valor Residual........................................................ 214

6. Hechos ocurridos después del periodo sobre el que se informa ………………..................... 215 


\section{Introducción}

Una estimación contable tiene que ver con información disponible utilizada por parte de la Compañía al momento de considerar un criterio de medición inicial o medición posterior de un elemento de los estados financieros. Es una aproximación al valor de una partida en ausencia de un medio preciso de medición.

Un cambio en una estimación contable se refiere a nueva información obtenida por la Compañía como consecuencia de un cambio en las condiciones, en el patrón de consumo de un activo o en la obtención de nuevos datos estadísticos.

El efecto de un cambio de una estimación contable, solo tiene que ver con impactos en los resultados del periodo actual, y en algunos casos en periodos futuros, a este cambio se le conoce como "aplicación prospectiva" es decir, el cambio aplica a partir de la fecha de la modificación.

Cuando existe un cambio en los periodos futuros, generado por un cambio en una estimación contable, es necesario que la Compañía revele los efectos que espere vaya a producir sobre los resultados futuros de la entidad. 


\section{Estimaciones contables}

\subsection{Definición}

Las estimaciones son partidas de los estados financieros que no pueden ser cuantificadas con precisión; corresponde a la valoración de activos y pasivos que se produce tras la evaluación de la situación actual del elemento, así como de los beneficios futuros esperados y de las obligaciones asociadas con los activos y pasivos correspondientes.

Son consideradas estimaciones contables, las siguientes:

- Calculo del deterioro de cuentas por cobrar por dudosa recuperación

- Obsolescencia de los inventarios

- Valor neto de realización de los inventarios

- Valor razonable de los instrumentos financieros

- Valor del pasivo por provisiones de garantías concedidas

- Valor del pasivo por provisiones de un litigio o demanda en contra de la compañía

- Vida útil de los elementos de PP\&E e intangibles de la entidad

- Valor residual de un elemento de PP\&E o de intangibles

- Método de depreciación o amortización de un elemento de propiedad, planta y equipo, o de un intangible

- Valor del pasivo por la obligación de desmantelar un activo, o de retirarlo o de rehabilitar el terreno sobre el cual se asienta 


\subsection{Cambio en las Estimaciones Contables}

Un cambio en una estimación contable, es un ajuste que procede de la evaluación de la situación actual de los activos y pasivos, así como de los beneficios y las obligaciones que se prevén a futuro en relación con dichos activos y pasivos. El ajuste puede realizarse, en el valor en libros de un activo o un pasivo, o en el gasto que refleja el consumo del activo.

Los cambios en las estimaciones contables son el resultado de nueva información o nuevos acontecimientos y, en consecuencia, no son correcciones de errores.

El efecto de un cambio en una estimación contable será reconocido prospectivamente incluyéndolo en el resultado del ejercicio:

- Del periodo en que tiene el lugar el cambio si este afecta solo ese periodo; o

- Del periodo del cambio y periodos futuros, si el cambio afecta a todos ellos.

Cuando existe un cambio en los periodos futuros, generado por un cambio en una estimación contable, es necesario que la Compañía revele los efectos que espere vaya a producir sobre los resultados futuros de la entidad. 


\section{Estimaciones contables para instrumentos financieros}

Un Instrumento Financiero es toda acción contractual (un contrato) que da lugar a un activo financiero (derecho a recibir) para la Compañía y a un pasivo financiero o a un instrumento de patrimonio (obligación de pagar) en otra Compañía.

\subsection{Reconocimiento y Medición del Deterioro}

COMERCIALIZADORA ALLCOMPUTER SAS., reconocerá deterioro a los instrumentos financieros activos generados a clientes, así:

Se evaluará el deterioro a este rubro agrupándolas de acuerdo con las características de riesgo similares que son indicativas de la capacidad de los deudores para cumplir con sus obligaciones en los términos pactados. Utilizando la metodología de deterioro por rangos según el tiempo de morosidad de la deuda se define de la siguiente forma:

- De 0 hasta 90 días de mora, posteriores al vencimiento pactado el $0 \%$

- De 91 hasta 120 días de mora, posteriores al vencimiento pactado el $1 \%$

- De 121 hasta 150 días de mora, posteriores al vencimiento pactado el $1 \%$

- De 151 hasta 180 días de mora, posteriores al vencimiento pactado el $1 \%$

- De 181 hasta 210 días de mora, posteriores al vencimiento pactado el 15\%

- De 211 hasta 240 días de mora, posteriores al vencimiento pactado el $15 \%$

- De 241 hasta 270 días de mora, posteriores al vencimiento pactado el $15 \%$ 
- De 271 hasta 300 días de mora, posteriores al vencimiento pactado el 15\%

- De 301 hasta 330 días de mora, posteriores al vencimiento Pactado el $15 \%$

- Más de 331 días de mora, posteriores al vencimiento pactado el $22 \%$

Los demás deudores y anticipos entregados, se entenderán deteriorados a los 360 días posteriores al vencimiento pactado, y se aplicará una tasa el $100 \%$ del saldo deudor. 


\section{Estimaciones contables para propiedades, planta y equipo}

Propiedad, planta y equipo son activos tangibles mantenidos por la Compañía, para su uso en la producción o suministro de bienes y servicios, para arrendarlos a terceros o con propósitos administrativos y se esperan usar más de un periodo.

\subsection{Materialidad}

Para el reconocimiento de propiedades, planta y equipo de menor cuantía COMERCIALIZADORA ALLCOMPUTER SAS. optará como política, la capitalización de estos elementos cuando superen el monto de dos (2 salarios mínimos mensuales legales vigentes SMMLV); al momento del reconocimiento, salvo cuando considere que dicho artículo adquirido puede usarse en más de un periodo y necesario ejercer un control sobre él, en dicho caso pueden contabilizarse como activos fijos sin tener en cuenta la base.

\subsection{Vida Útil}

La vida útil estimada para cada categoría de los elementos de propiedades, planta y equipo, para COMERCIALIZADORA ALLCOMPUTER SAS. Son las que se indican a continuación: 


\begin{tabular}{ll}
\hline \multicolumn{1}{c}{ CLASE DE ACTIVO } & \multicolumn{1}{c}{ VIDA UTIL EN AÑOS } \\
\hline Terrenos & No se deprecia \\
Construcciones y Edificaciones & 60 Años \\
Maquinaria y Equipo & 10-30 Años \\
Muebles y Enseres y Equipos Electrónicos & 5-10 Años \\
Equipo de Computación y Comunicación & 3-5 Años \\
Vehículos & 5-20 Años \\
\hline
\end{tabular}

\subsection{Método de Depreciación}

El método de depreciación utilizado por COMERCILIZADORA ALLCOMPUTER SAS., para todas las categorías de propiedades, planta y equipo será Línea Recta.

\subsection{Valor Residual}

COMERCIALIZADORA ALLCOMPUTER SAS., No aplicará valor residual para los elementos de propiedades, planta y equipo. 


\section{Estimaciones para activos intangibles}

Intangibles son aquellos activos sin apariencia física, de carácter no monetario, pero identificables.

\subsection{Vida Útil, Método de Amortización y Valor Residual}

COMERCIALIZADORA ALLCOMPUTER SAS., realizara la amortización de los intangibles

durante la vida útil del activo, la cual corresponde a la duración de los derechos legales que se tengan sobre el intangible.

Cuando no esté claro la duración de los derechos legales se estima la vida útil del software adquiridos en diez (10) años.

El método de amortización que la Compañía aplicará para sus activos intangibles es el Método de Línea Recta.

COMERCIALIZADORA ALLCOMPUTER SAS., no estima que el valor residual para sus intangibles. 


\section{Hechos ocurridos después del periodo sobre el que se informa}

Corresponden a aquellos eventos surgidos entre la fecha de corte de los estados financieros y la fecha de autorización para su divulgación.

COMERCIALIZADORA ALLCOMPUTER SAS., ajustará los saldos de los estados financieros, por hechos que impliquen ajustes, cuando no se hayan reconocido ingresos, costos o gastos en el periodo, a causa de éstos, que su materialidad supere la cuantía del 5\% del monto de sus ingresos anuales. 